\title{
APPLICATION OF DESIGN OF EXPERIMENTS FOR WELL PATTERN OPTIMIZATION IN UMIAT OIL FIELD: \\ A NATURAL PETROLEUM RESERVE OF ALASKA CASE STUDY
}

\section{By}

Yojana Shivaji Gurav, B. E.

A Dissertation Submitted in Partial Fulfillment of the Requirements

for the Degree of

Master of Science

in

Petroleum Engineering

University of Alaska Fairbanks

May 2020

APPROVED:

Abhijit Dandekar, Committee Chair

Shirish Patil, Committee Co-Chair

Santanu Khataniar, Committee Member

James Clough, Committee Member

Samarth Patwardhan, Committee Member

Abhijit Dandekar, Chair

Department of Petroleum Engineering

William Schnabel, Dean

College of Engineering and Mines

Michael Castellini,

Dean of the Graduate School 


\section{Abstract}

Umiat field, located in Alaska North Slope poses unique development challenges because of its remote location and permafrost within the reservoir. This hinders the field development, and further leads to a potential low expected oil recovery despite latest estimates of oil in-place volume of 1550 million barrels. The objective of this work is to assess various possible well patterns of the Umiat field development and perform a detailed parametric study to maximize oil recovery and minimize well costs using statistical methods.

Design of Experiments (DoE) is implemented to design simulation runs for characterizing system behavior using the effect of certain critical parameters, such as well type, horizontal well length, well pattern geometry, and injection/production constraints on oil recovery. After carrying out simulation runs using a commercially available simulation software, well cost is estimated for each simulation case. Response Surface methodology (RSM) is used for optimization of well pattern parameters. The parameters, their interactions and response are modeled into a mathematical equation to maximize oil recovery and minimize well cost.

Economics plays a key role in deciding the best well pattern for any field during the field development phase. Hence, while solving the optimization problem, well costs have been incorporated in the analysis. Thus, based on the results of the study performed on selected parameters, using interdependence of the above mentioned methodologies, optimum combinations of variables for maximizing oil recovery and minimizing well cost will be obtained. Additionally, reservoir level optimization assists in providing a much needed platform for solving the integrated production optimization problem involving parameters relevant at different levels, such as reservoir, wells and field. As a result, this optimum well pattern methodology will help ensure optimum oil recovery in the otherwise economically unattractive field and can provide significant insights into developing the field more efficiently.

Computational algorithms are gaining popularity for solving optimization problems, as opposed to manual simulations. DoE is effective, simple to use and saves computational time, when compared to algorithms. Although, DoE has been used widely in the oil industry, its 
application in domains like well pattern optimization is novel. This research presents a case study for the application of DoE and RSM to well optimization in a real existing field, considering all possible scenarios and variables. As a result, increase in estimated oil recovery is achieved within economical constraints through well pattern optimization. 


\section{Table of Contents}

Page

Abstract

i

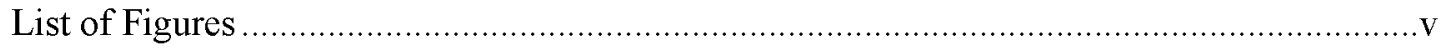

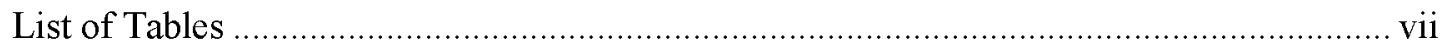

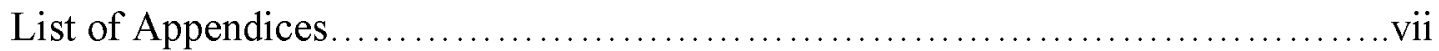

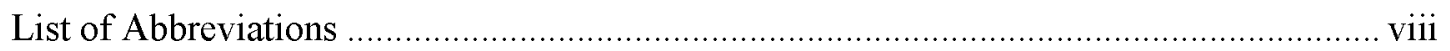

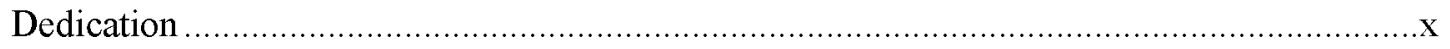

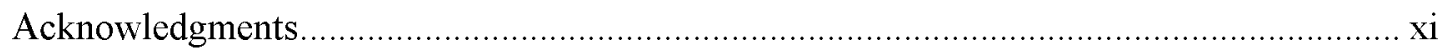

Chapter 1: Introduction ............................................................................................1

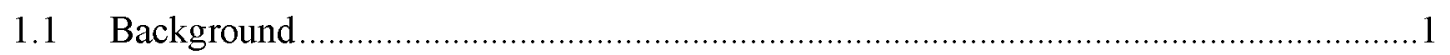

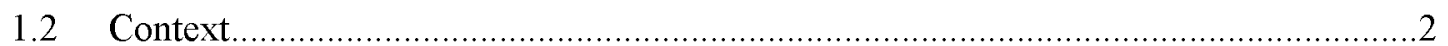

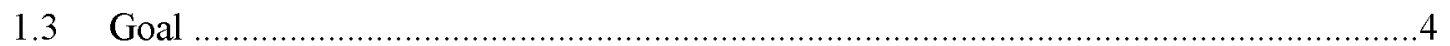

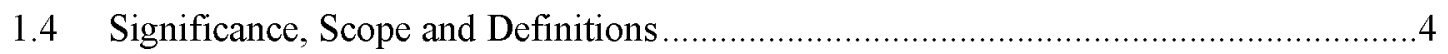

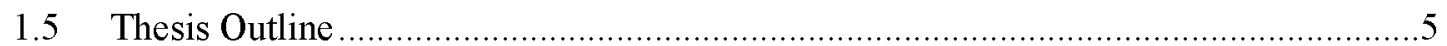

Chapter 2: $\quad$ Literature Review..................................................................7

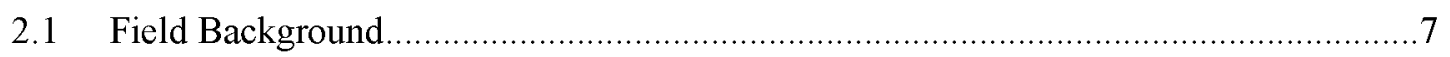

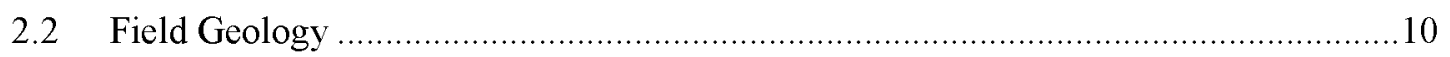

2.3 Previous Work Done on Umiat Field …................................................................. 17

2.4 Application of Design of Experiments/RSM in Reservoir Simulation.......................21

Chapter 3: $\quad$ Research Design..................................................................................25

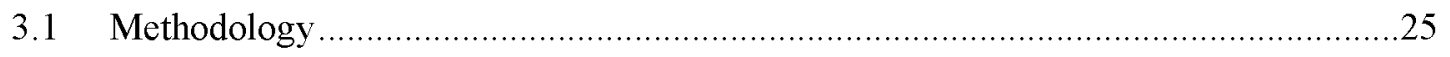

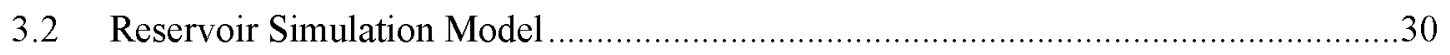

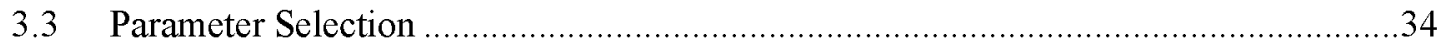

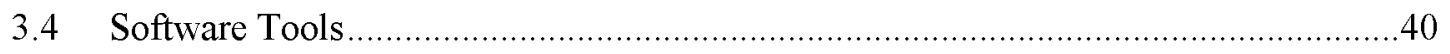

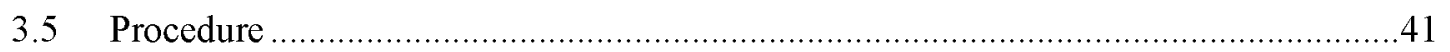

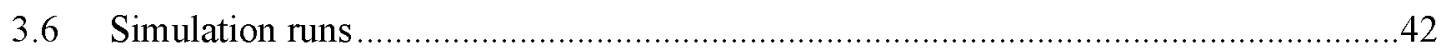

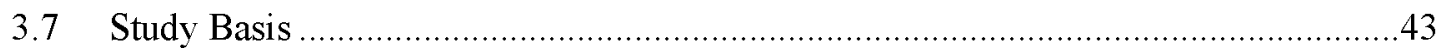

Chapter 4: Result and Discussion .................................................................45

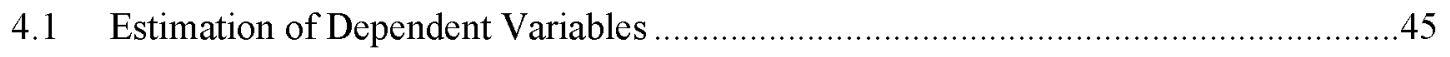

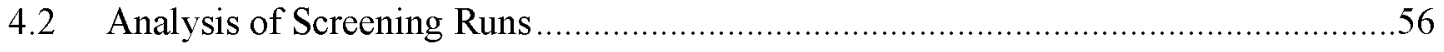

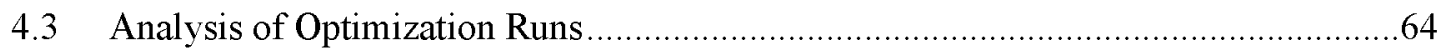




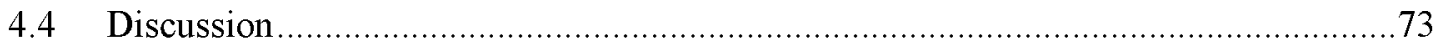

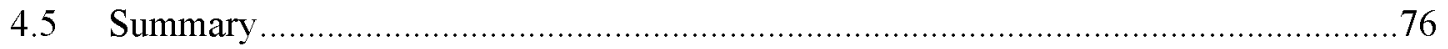

Chapter 5: Conclusion and Recommendation .............................................79

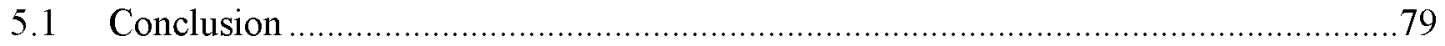

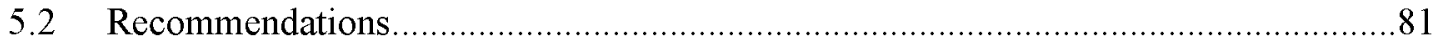

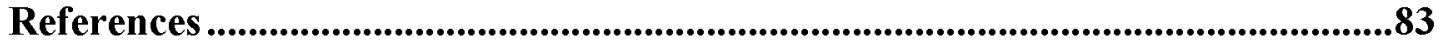




\section{List of Figures}

Page

Figure 1: Recovery optimization process.

Figure 2: Umiat field location on North Slope of Alaska (Modified from (Kumar et el., 2002))

Figure 3: Location of Umiat Test Wells (Adapted from Gates et al., 1960).

Figure 4: Alaska Permafrost Map showing continuous permafrost and discontinuous permafrost regions (Modified from (Romanovsky et al., 2002))

Figure 5: Geologic map of Northern Alaska showing the Brooks Range fold-and-thrust belt and Colville Basin (Hanks et al., 2012).

Figure 6: Map of North Slope of Alaska, Chukchi Sea and Beaufort Sea showing main geologic elements, seismic facies and paleocurrent data from Lower Cretaceous first-order depositional sequence(Houseknecht et al., 2009).

Figure 7: Nanushuk shelf margin seen in a west-east seismic line showing Torok-Nanushuk and Seabee-Tuluvak sequences; A: uninterpretated image, B: interpretated image showing different formations(Houseknecht andSchenk, 2005).

Figure 8: False-color infrared aerial photomosaic of Umiat area, with superimposed structure-contour map of the Grandstand sand with Umiat well locations (Houseknecht and Schenk, 2005).

Figure 9: A) A regional stratigraphy of the Brookian sequence, showing the relevant stratigraphic units of the Colville Basin B) Informal reservoir stratigraphic nomenclature for the Umiat field. From Shimer et al. (2014).

Figure 10: Production capacity of Umiat test wells related to drilling mud (Gates et al., 1960)

Figure 11: Comparison of Dead oil molar compositions with recreated oil sample (Shukla, 2011)

Figure 12: Recovery efficiency for average permeability case of $10 \mathrm{mD}$ (Modified from

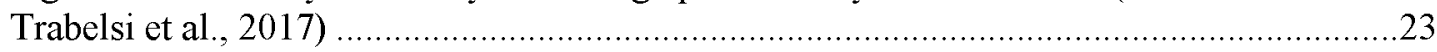

Figure 13: Research Methodology for Umiat Field Well Pattern Optimization .....................26

Figure 14: No of Experiments for three factors a. Two Factorial Design, b. Three Factorial Design c. Box Behnken Design

Figure 15: Representation of the Workflow followed for optimization of well pattern in

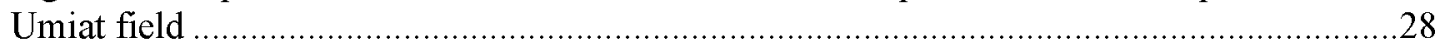

Figure 16: Objective of the optimization process in current research.

Figure 17: Reservoir simulation model for Umiat field showing permeability distribution in topmost layer of LGS

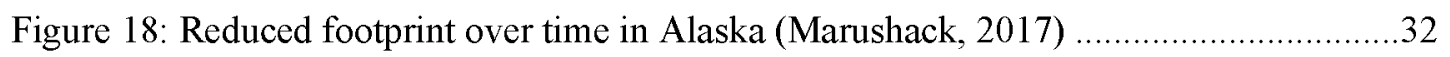

Figure 19: Schematic representation of location of producers and injectors in a pad..............33 
Figure 20: Location of Umiat, East Umiat and Gubik (Modified from Houseknecht and Bird, 2006)

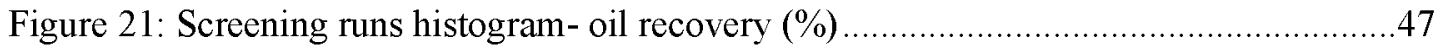

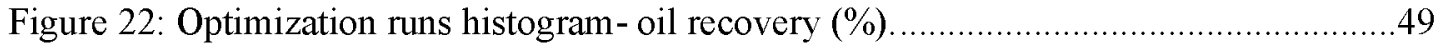

Figure 23: Optimization runs histogram- development cost (MM USD) ............................50

Figure 24: Development cost break-up: Optimization run-4 .........................................54

Figure 25: Development cost break-up: Optimization run-5 ........................................55

Figure 26: Normal probability plot of residuals- Oil recovery (Screening)..........................58

Figure 27: Residuals vs predicted- Oil recovery (Screening) ............................................5

Figure 28: Predicted vs Simulated- Oil recovery (Screening) ............................................6

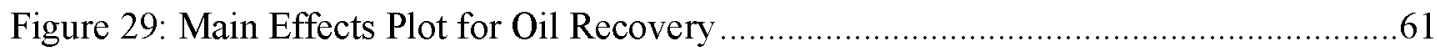

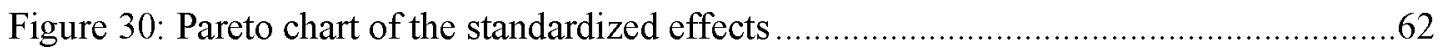

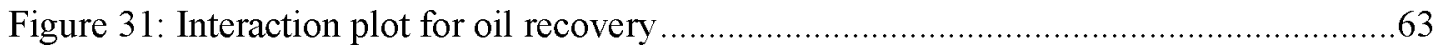

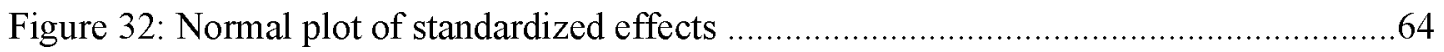

Figure 33: Normal probability plot of residuals- Oil recovery (Optimization) .....................66

Figure 34: Residuals vs predicted- Oil recovery (Optimization) ......................................67

Figure 35: Predicted vs Simulated- Oil recovery (Optimization) ......................................68

Figure 36: Normal probability plot of residuals- Development cost (Optimization) .............69

Figure 37: Residuals vs predicted- Development cost (Optimization) ................................... 70

Figure 38: Predicted vs actual- Development Cost (Optimization) ........................................ 71

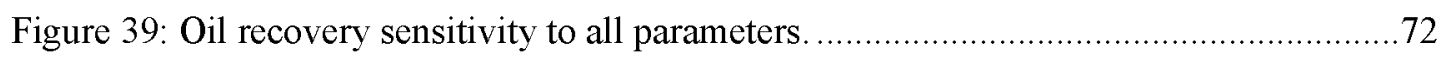

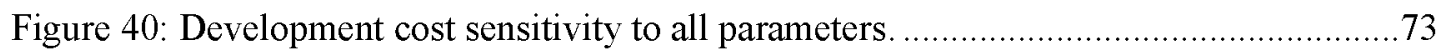

Figure 41: Liquid supply cost curve showing production costs versus recoverable quantities (Modified from Aguilera, 2014) 76

Figure 42: Desirability contour for well length and Prod/Inj ratio with injection pressure at levell and number of injectors/pad at level 0 


\section{List of Tables}

Page

Table 1: Simulation model properties for Umiat field reservoir simulation ...........................30

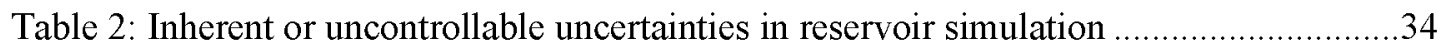

Table 3: Decision or controllable parameters in reservoir simulation (Bevillon and

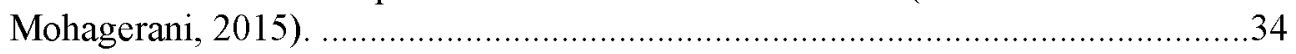

Table 4: Controllable Parameters range for Screening Analysis ...........................................39

Table 5: Controllable Parameters range for Optimization Analysis ....................................40

Table 6: Design matrix for $2 \mathrm{k}$ factorial analysis showing coded levels of parameters...........41

Table 7: Design matrix for Box Behnken analysis showing coded levels of parameters .......42

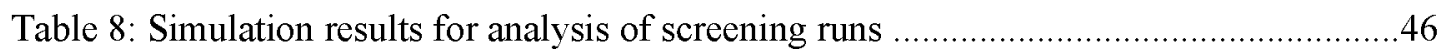

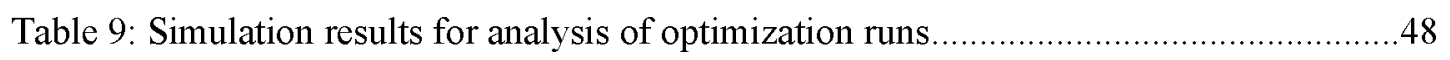

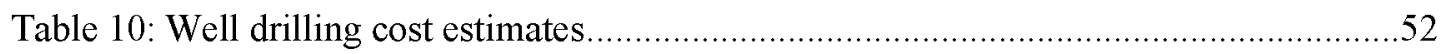

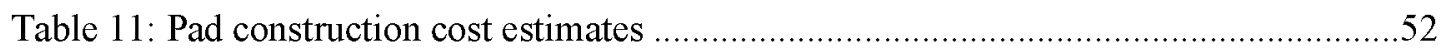

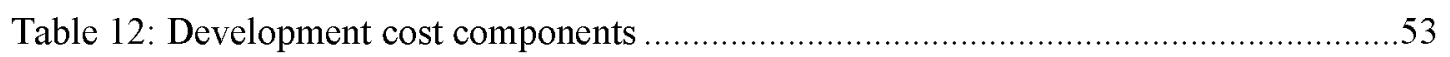

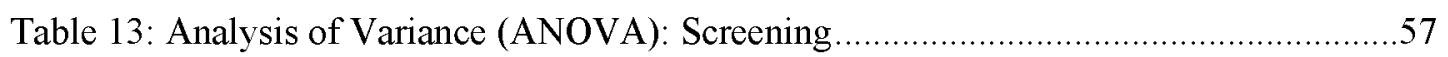

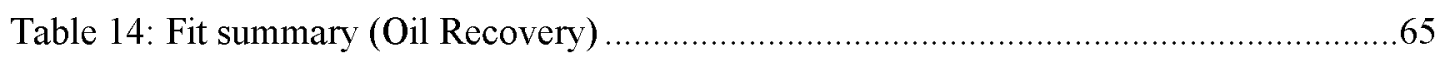

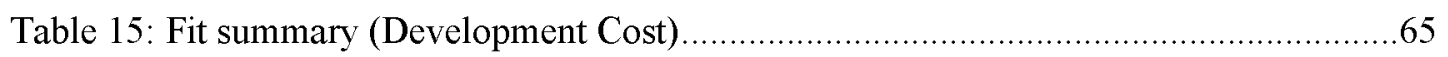

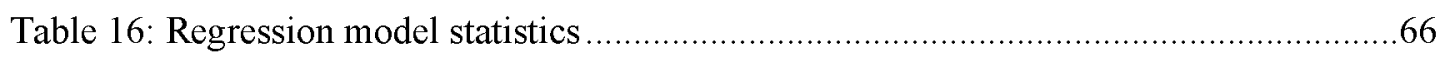

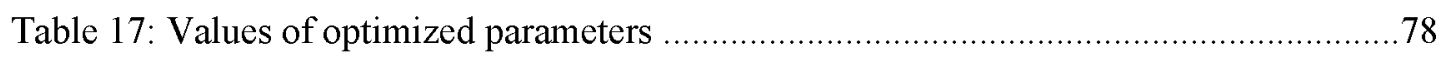

\section{List of Appendices}

Page

Appendix A: DOE DESIGN GENERATION USING DESIGN-EXPERT SOFTWARE ....91

Appendix B: WELL PAD LOCATIONS FOR DIFFERENT WELL LENGTHS ............93 


\section{List of Abbreviations}

ANS- Alaska North Slope

API- American Petroleum Institute

BBL/D- barrels per day

BHP- Bottomhole Pressure

DLS- Dog-Leg Severity

DoE- Design of Experiments

EOR- Enhanced Oil Recovery

EOS- Equation of State

FBHP- Flowing Bottomhole Pressure

GOR- Gas Oil Ratio

IRR- Internal Rate of Return

LGS- Lower Grandstand

LLGS- Lower Grandstand

$\mathrm{Kv} / \mathrm{Kh}$ - Ratio of vertical permeability to horizontal permeability

MM- Million

NOA- Nearly-Orthogonal Arrays

NPRA- National Petroleum Reserve Alaska

NPV- Net Present Value

OA- Orthogonal Arrays

OOIP- Original Oil in Place

PIR- Profit to Investment Ratio

PVT-Pressure Volume Temperature 
RSM- Response Surface Methodology

TAPS- Trans-Alaska Pipeline System

TD- Total Depth

UGS- Upper Grandstand

ULGS- Upper Lower Grandstand

USD- United States Dollar

WAG- Water Alternating Gas 


\section{Dedication}

To the dearest Krishna, Dr Harishchandra Joshi and my beloved parents, for their unconditional love, support, and constant encouragement. 


\section{Acknowledgments}

With boundless love and gratitude, I would like to acknowledge and thank the following people who have been a source of support and strength throughout the timeline of this thesis completion.

To my advisor Dr. Abhijit Dandekar whose constant support and consistent feedback helped me to successfully complete the study;

To my co-chair Dr. Shirish Patil for his encouragement and valuable suggestions throughout my research;

To Dr. Santanu Khataniar- committee member, for his thoughtful suggestions and brainstorming sessions;

To James Clough- committee member, for sharing his expert knowledge in Geology and his constant support;

To Dr. Samarth Patwardhan- committee member, for his insights into my research and neverending support;

To Iman Oraki Kohshour, former graduate student and Dr. Mohabbat Ahmadi- faculty from Petroleum Engineering department for providing me with the reservoir simulation model for the research;

To Leanne Isaacson and Nicole Dufour, office managers, for administrative support and for always being there to help me;

To all the faculty members, staff and fellow graduate students of Petroleum Engineering department of University of Alaska Fairbanks for their invaluable cooperation; 
Kelly Gitter- my former manager and Video Conferencing Services Manager, Carol HolzAssociate Director, Immigration Compliance, Reija Shnoro- International Student Program Coordinator, Shelly Baumann- Assistant Director, Graduate School and Interdisciplinary Programs for their guidance and moral support;

My friends at Fairbanks for being part of my extended family in Alaska;

To my beloved friends Vatsala, Shrikant, Unmesh, Niraj, Kunal, Nilesh, Shivani, Vrushabh, Akanksha, Hema, Sandeep, Hemanth, Rushi, Amit, Sachin, Rahul, Mitali, and Shireen, who helped me in various ways, listened to me and offered me advice in critical phases of this research and in my life;

To Debu uncle and Lily aunty for being there for me during my tough times;

To my caring family including my brother, sister, brother-in-law, niece and grandmother and everybody else for being the pillar of strength;

To my loving parents for their unconditional love, inspiration and encouragement.

Finally, To God Almighty, for giving me the strength and perseverance to undertake this research and complete it to the best of my abilities and meet the expectations set on me. 


\section{Chapter 1: Introduction}

This chapter gives an overview of the research objectives, defines key concepts and gives a brief outline of the background and research approach.

This chapter outlines the background (section 1.1) and context (section 1.2) of the research, and its goal (section 1.3). Section 1.4 describes the significance and scope of this research and provides definitions of the terms used. Finally, section 1.5 includes an outline of the remaining chapters of the thesis.

\subsection{BACKGROUND}

Oil and gas operators are constantly trying to maximize hydrocarbon recovery by different means while keeping costs to a minimum. Recovery optimization is a process of employing different actions to increase recovery from a reservoir within economical constraints. It is an important aspect in field development planning and reservoir management.

The latest oil and gas discoveries are being made in significantly challenging environments since there is a limited supply of easy-to-reach oil as against the rapidly growing demand. Also, the number of new discoveries is gradually decreasing. Challenging environments such as deepwater, Arctic setting, heavy oil, shale reservoirs and oil sands, present unique challenges in developing the resources efficiently. Different methods of secondary and tertiary recovery are being employed in order to extract the hydrocarbons effectively. This highlights the everincreasing importance of economics and production optimization in petroleum exploration and production. Thus, optimizing the recovery has become an inevitable aspect of today's and future oil and gas development projects. Figure 1 shows that oil recovery is dependent on several factors such as reservoir conditions including geology, fluid properties, rock properties, as well as operating conditions. It is a complex problem where the type of trap, geological heterogeneity, presence of faults, stratigraphy, facies variations, reservoir thickness variation, drilling schedule and production strategy affect the drainage. For optimal drainage from the reservoir, multiple 
factors such as the total number and length of wells, productivity, well path, and drilling schedule of producers and injectors, geometric configuration of wells along with injection parameters need to be optimized (Onwunalu and Durlofsky, 2011). Generally, cost as well as cumulative hydrocarbon production are considered while defining objective functions for recovery optimization. The aim is to maximize the recovery while minimizing the associated costs (Figure $1)$.

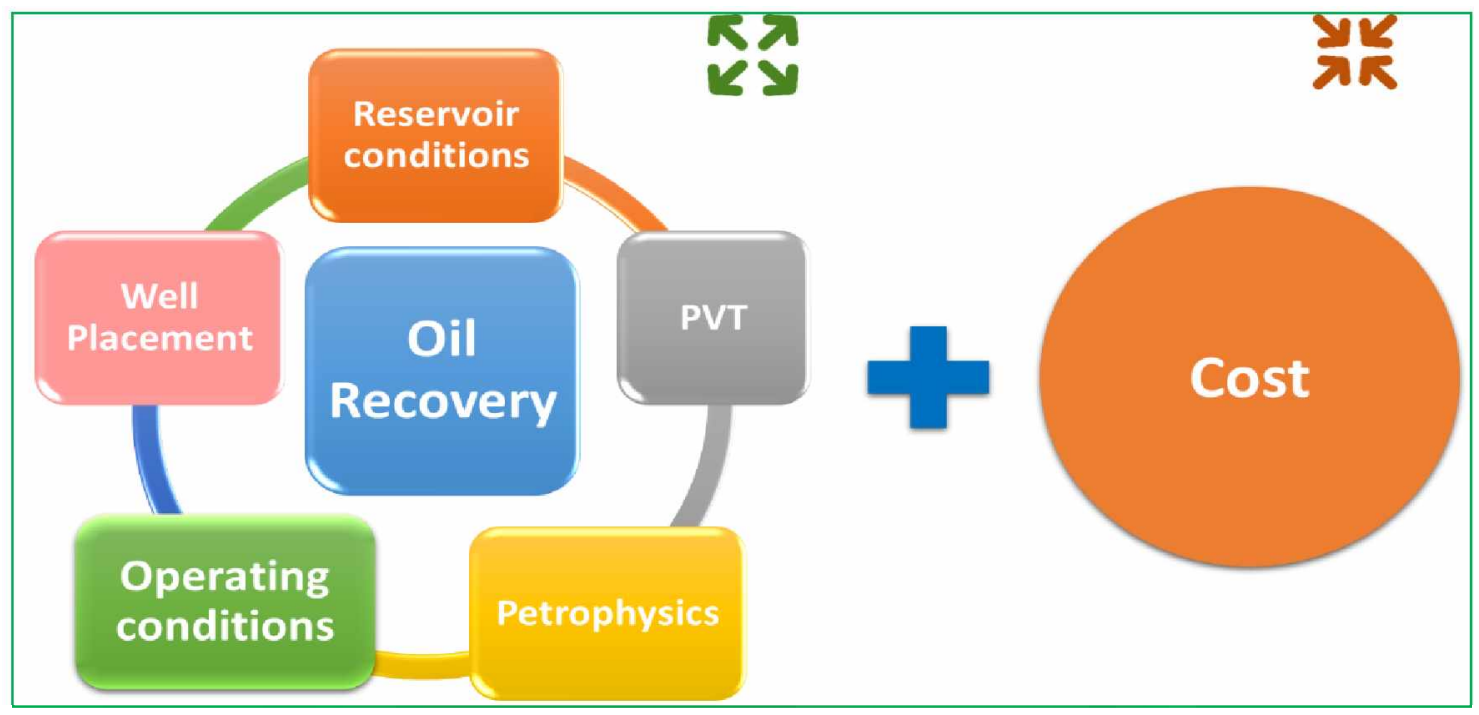

Figure 1: Recovery optimization process

\subsection{CONTEXT}

Umiat field was discovered in the late 1940s by the U.S. Navy post World War II. This oil field is located in the National Petroleum Reserve Alaska (NPRA) on the North Slope of Alaska (Figure2). Permafrost in this field is reported to be from the surface down to 770 to $1055 \mathrm{ft}$ deep. Oil depth varies from 275 to $1100 \mathrm{ft}$ whereas oil pressure ranges from 50 to $350 \mathrm{psi}$ (Baptist, 1960). This implies that most of the oil in NPRA is located within permafrost, making it an unconventional reservoir. Oil at Umiat has a pour point below $5^{\circ} \mathrm{F}$ (Collins et al., 1958), which indicates that oil can remain in the liquid state and flow at the aforementioned temperature from the shallow Upper Grandstand formation at 500 feet through permafrost. API of $37^{\circ}$ (Collins et al., 1958) makes it a crude of very high quality. Six out of 11 tested wells in the Nanushuk Formation at Umiat between 1945 and 1952, have produced oil (Collins et al., 1958). In the past decade, industry exploration resumed at Umiat with new wells being drilled in 2013 and 2014 (Lidji, 
2016)after the acquisition of a three-dimensional seismic survey on the site in 2008 (Bailey, 2009). The field is located 92 miles from Trans-Alaska Pipeline (TAPS) (Oil and Gas Journal, 2011) which makes development of the field economically challenging. Along with remoteness, permafrost and lower reservoir energy make it a necessity to consider all aspects to field development thoughtfully.

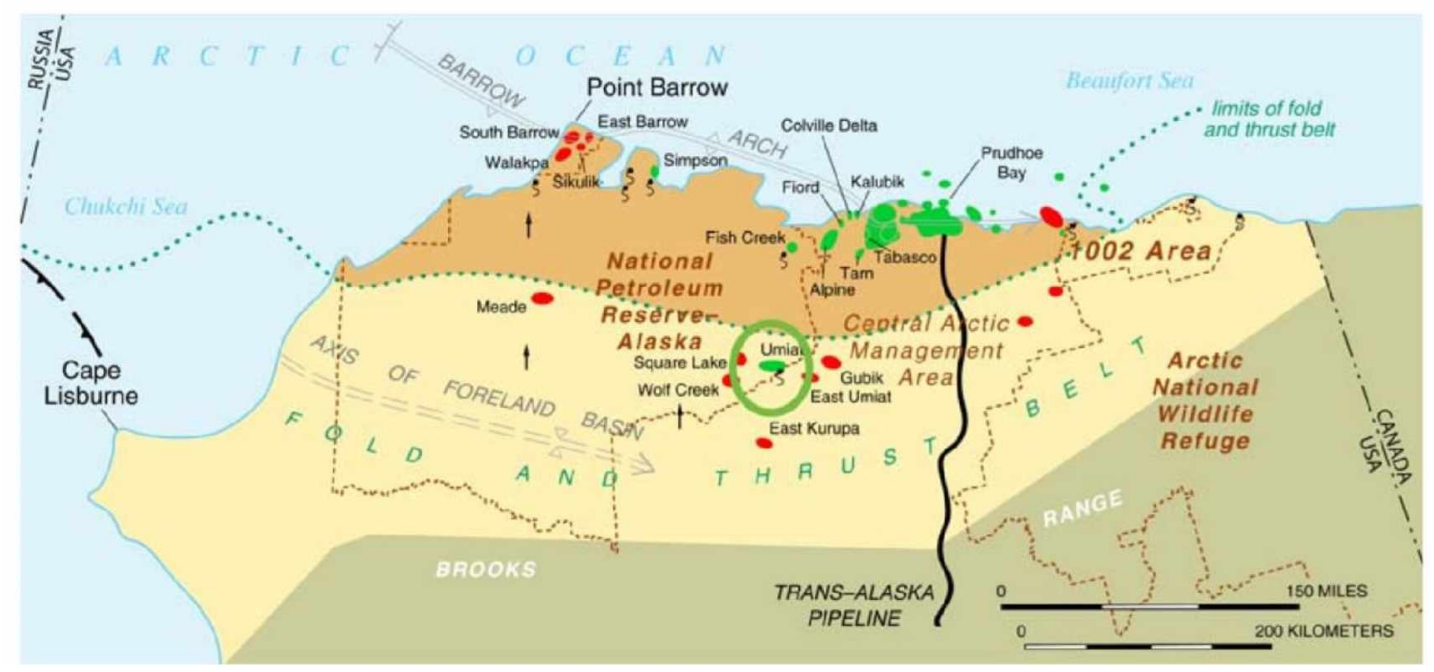

Figure 2: Umiat field location on North Slope of Alaska (Modified from (Kumar et el., 2002))

Extremely low reservoir pressure affects primary oil recovery in Umiat. Thermal injection would cause thawing of permafrost and subsequent subsidence of production facilities (Gubaidullin and Makarsky, 2013) while waterflooding might block the pores because of low reservoir temperature, resulting in poor injectivity. Thus, the field is a poor candidate for the most secondary and tertiary recovery methods due to its unique characteristics. Nonetheless, excellent oil quality and huge reserves in Umiat demand attention especially with constant advances in technology.

In any field, there are multiple factors such as porosity which cannot be modified. Hence, the well pattern becomes an important parameter to be adjusted for recovery optimization problem because of its direct impact on the hydrocarbon recovery and associated high drilling costs. At the same time, it is a difficult problem to solve because of multiple parameters involved, size of search space and its non-linear and discrete nature (Minton, 2012). 
Consequently, one of the limited options to optimize the oil recovery in Umiat field, is to modify the well pattern. The current research deals with increasing oil recovery in the field through well pattern optimization.

\subsection{GOAL}

The objectives of the study are as follows:

1. To determine effect of various controllable factors associated with well pattern and operating conditions on oil recovery in Umiat field

2. To propose a combination of parameters of well patterns that provide optimum oil recovery in Umiat.

The Umiat field has long been considered for development by a number of operators. With current technological advances, it would be interesting to see if using different values of the parameters than those considered by previous operators can lead to higher oil recovery in the field within economic constraints. This study also helps in understanding the role of well pattern optimization in achieving higher recovery within the Umiat field.

\subsection{SIGNIFICANCE, SCOPE AND DEFINITIONS}

The proposed research uses a reservoir simulation tool to investigate various scenarios of well patterns. The number of simulations required to generate the information is generally very high in such analysis utilizing a one-factor-at-a-time approach. It is exhausting and takes considerable amount of time. On the other hand, DoE can be used to increase the efficiency of simulations by attaining more information with a lesser number of runs. DoE is a design of any task that is intended at describing the relationship between independent variables and dependent variables.

DoE is used quite often in the Oil and Gas industry. There have been several attempts to use it in reservoir simulation applications for minimizing simulation runs while increasing the value. However, its application in domains such as well pattern optimization is unique.

Using this technique in reservoir simulation of Umiat will save computational time as opposed to one-factor-at-a-time approach. It will determine important factors out of all factors 
affecting the output. RSM will also be applied to reservoir simulation to carry out optimization. It will determine optimum values of well pattern parameters affecting oil recovery and costs.

This research presents a case study for the application of DoE and RSM to well pattern optimization in a real existing field, considering all possible scenarios and variables.

\subsection{THESIS OUTLINE}

Chapter 2 discusses Umiat field summary including field background, its geology, previous research conducted on the Umiat field as well as a literature review of DoE. Research design is explained in detail in Chapter 3. It covers research methodology, the approach followed to conduct the research and research tools. Chapter 4 deals with analysis of the results obtained from DoE application to simulation runs and presents detailed discussion and results. Chapter 5 provides recommendation for future work on the field and presents conclusions from the study. 


\section{Chapter 2: Literature Review}

\subsection{FIELD BACKGROUND}

\subsubsection{Field Discovery and Location}

The Umiat field was discovered in the late 1940s by the U.S. Navy following World War II The oil field is located near the southeastern boundary of the NPRA in the North Slope of Alaska. It is an anticlinal structure, situated at the northern edge of the Brooks Range thrust-fault belt.

During the exploration phase, the U.S. Navy drilled 11 test wells in the 1940s and 1950s Out of 11 , six wells produced oil and along with unique reservoir conditions posed serious questions about the productivity of the Nanushuk formation and possible recovery of the oil despite excellent crude quality. Location of test wells are shown in Figure 3.

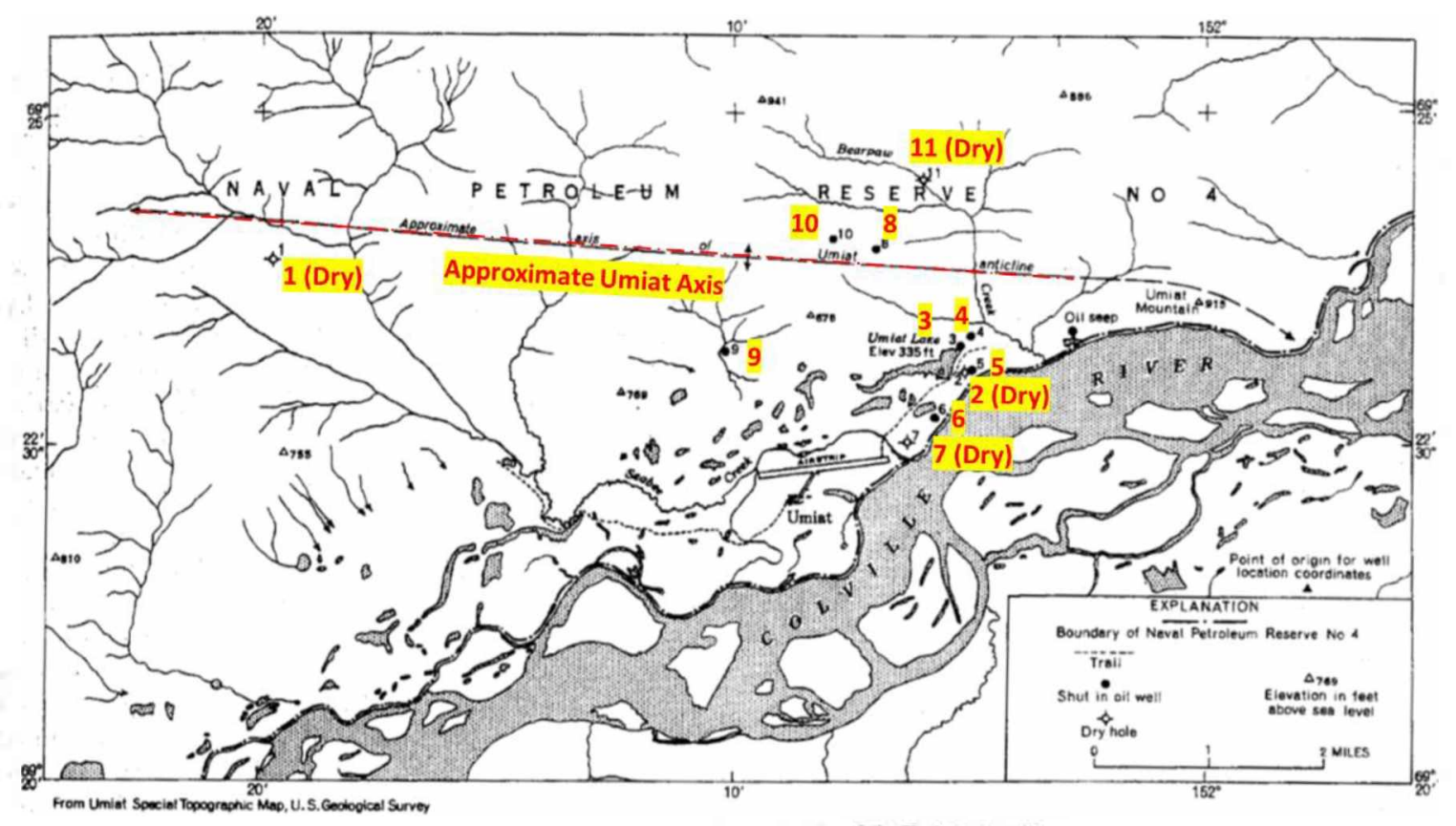

Figure 3: Location of Umiat Test Wells (Adapted from Gates et al., 1960) 
As shown in Figure 4, the Umiat field lies within the continuous permafrost region of Alaska. Permafrost in the Umiat region extends down to a depth of 770 to $1055 \mathrm{ft}$. Oil was discovered at depths 275 to $1000 \mathrm{ft}$ (Baptist, 1960). Thus, most of the oil is in permafrost and the reservoir becomes unconventional for production.

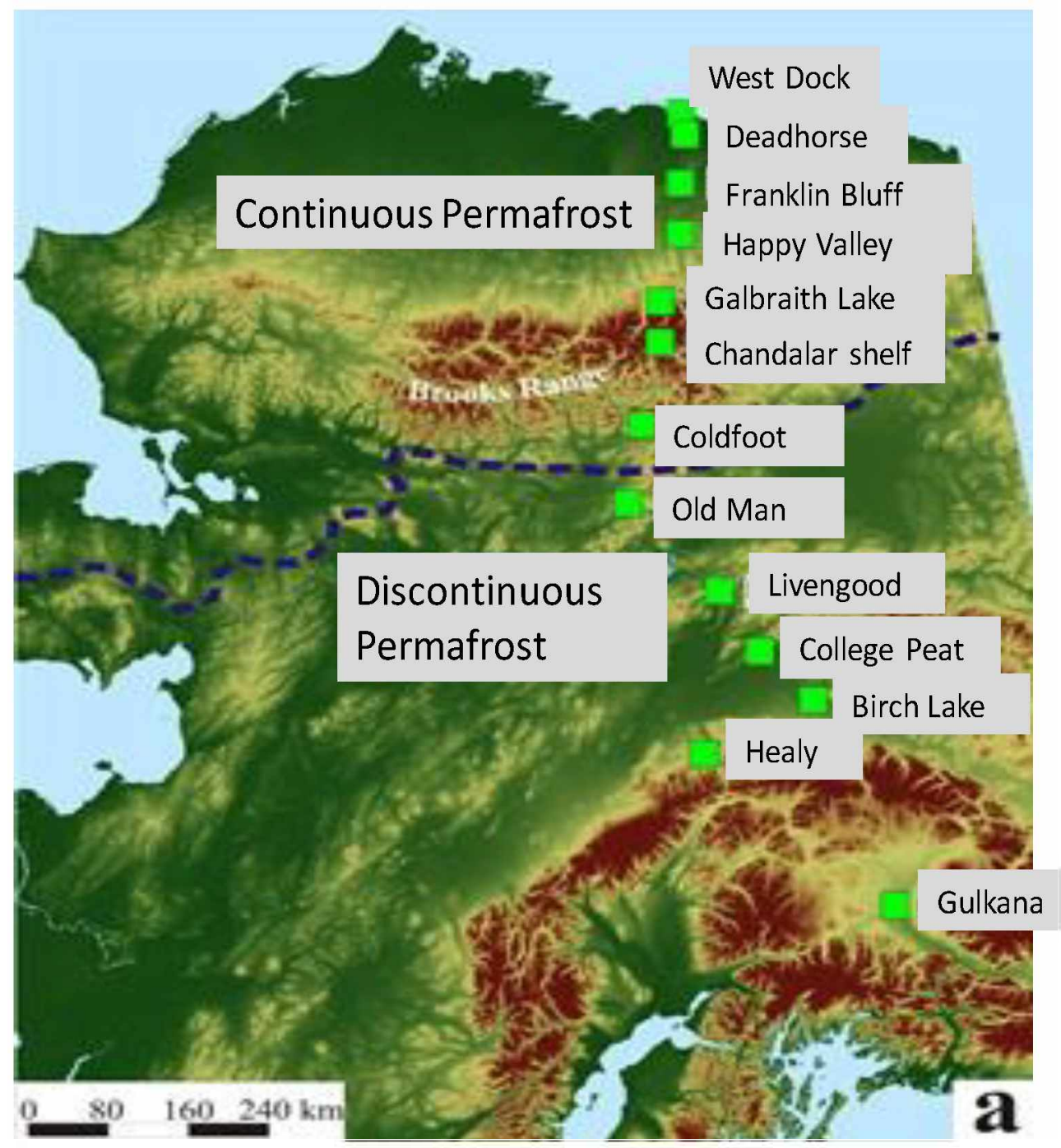

Figure 4: Alaska Permafrost Map showing continuous permafrost and discontinuous permafrost regions (Modified from (Romanovsky et al., 2002))

\subsubsection{Rock and Fluid Characteristics}

The average reservoir pressure in the reservoir interval of our interest is 350 psi. A very small quantity of gas observed during initial testing indicated absence of a gas cap(Baptist, 1960). 
Thus, primary recovery of oil can be attributed to solution gas drive which indicates low recoveries of around $5-30 \%$ as compared to other drive mechanisms such as gas cap drive or water drive (Drive mechanisms and recovery - AAPG Wiki).

Umiat crude oil is excellent quality with $37^{\circ} \mathrm{API}$ and pour point of $5^{\circ}$ Fahrenheit $\left(-15^{\circ} \mathrm{C}\right)$ (Gates et al., 1960). This shows Umiat oil can flow at reservoir conditions within the permafrost zone.

\subsubsection{Changing Lease Ownership}

The Umiat field covers 19,358 gross acres over three leases, out of which, two are managed by United States Department of Interior, Bureau of Land Management (BLM) and the remaining is managed by the State of Alaska (NS Energy, 2011; Malamute Energy -Alaska Oil Exploration).

- The Umiat acreage was offered for lease for the first time in 1999 lease sale. Renaissance Alaska acquired entire acreage from initial lease owners, R3 Exploration and Arctic Falcon Exploration during 2004 to 2007(Anchorage Daily News, 2009).

In 2011, Linc Energy (Alaska) Inc. acquired a controlling interest in the Umiat oil field. According to NS Energy, 2011- "Acquisition occurred through the purchase of an $84.5 \%$ interest in Renaissance Umiat LLC (which owns a 100\% working interest and $80 \%$ net revenue interest in the Umiat project)".

However, in 2016, Linc Energy Ltd. filed for bankruptcy protection citing the expensive drilling activities in Alaska and U. S. Gulf Coast and decline in oil prices as reasons (Australasian Mine Safety Journal, 2016).

In November 2016, Malamute Energy purchased a controlling interest in the project.

\subsubsection{Past Activities}

Renaissance Alaska conducted an 86 mile $^{2}$ 3D seismic survey in 2008 to get more information about the reservoir (Hart Energy, 2008).

When Linc took over, it announced an aggressive drilling program of 4-5 wells in 2012, consisting of horizontal and vertical wells in shallow formation as well as a deeper vertical well. After some delay, Linc drilled Umiat no. 18 in 2013(Alaska Journal, 2013), which collected 
around $300 \mathrm{ft}$ of core. However, the flow test failed in the well due to mechanical problems. In 2014, it drilled one more horizontal well Umiat no. $23 \mathrm{H}$ and tested it successfully at a TD of 4100 $\mathrm{ft}$ (measured depth). The well produced oil at 250 BBL/D. They used open-hole completion with slotted liner.

\subsubsection{Road to Umiat}

The Umiat field is located 92 miles from TAPS (Oil and Gas Journal, 2011), which makes development of the field economically challenging. State declared a plan to build an all-weather road from TAPS to Umiat in 2009. This would have reduced Umiat field development risk and made it economically more feasible (Petroleum News, 2014). However, the plan could not be executed due to the opposition from local communities and budget shortfalls.

\subsubsection{Difficulties in Development}

The field has not yet developed due to several reasons. Reservoir pressure is low and apparently does not have a gas cap which could have increased the recovery from the field. Presence of permafrost can bring challenges during drilling and production phases due to ice bridging and collapse in boreholes (Collins et al., 1958) and pore-clogging ice (Baptist, 1960; Hanks et al., 2014). Harsh weather conditions such as Arctic cold, high winds in North Slope of Alaska (ANS) affect the drilling operations window and transportation of the equipments. It also makes the operations in ANS expensive. Location of the field is such that it would require standalone production facility in case of production since there are no producing fields in the nearby area. In addition, the field is far away from TAPS which poses a question regarding transportation of the produced oil.

\subsection{FIELD GEOLOGY}

\subsubsection{Structural Settings}

The North Slope of Alaska in conjunction with Chukchi and Beaufort continental shelves contains more than thirty billion barrels of oil and two hundred trillion cubic feet of natural gas (Bird, 1999). The North Slope consists of sequences of continental platform as well as successor 
basin, which are folded and thrusted at south and undeformed toward a passive margin in the north (Bird, 1985)

The North Slope consists of three major provinces- the Brooks Range, the Arctic Foothills, and the Arctic Coastal Plain. The Brooks Range contains east-west trending mountain range with elevation greater than $3000 \mathrm{~m}$ in the east and decreasing toward the west (Figure 5) (Moore et al., 1994).It is an orogenic belt with $1000 \mathrm{~km}$ length and $300 \mathrm{~km}$ width( Bird and Molenaar, 1992). During the evolution of the Brooks Range, collision of an island arc and continental margin of Arctic Alaska took place. The south facing margin collapsed and caused seven regionally extensive allochthons to be positioned (Moore et al., 1994). Toward the north of the Brooks Range, Colville Basin lies beneath the North Slope. This basin is an east-west trending foreland basin of Cretaceous-Tertiary age which was formed by loading of lithosphere due to allochthons and crust thickening as a result of continuous growth of the range (Moore et al., 1994) (Figure 5). Toward the northern boundary, the basin is demarcated by Barrow Arch (Coakley and Watts, 1991; Moore et al., 1994).

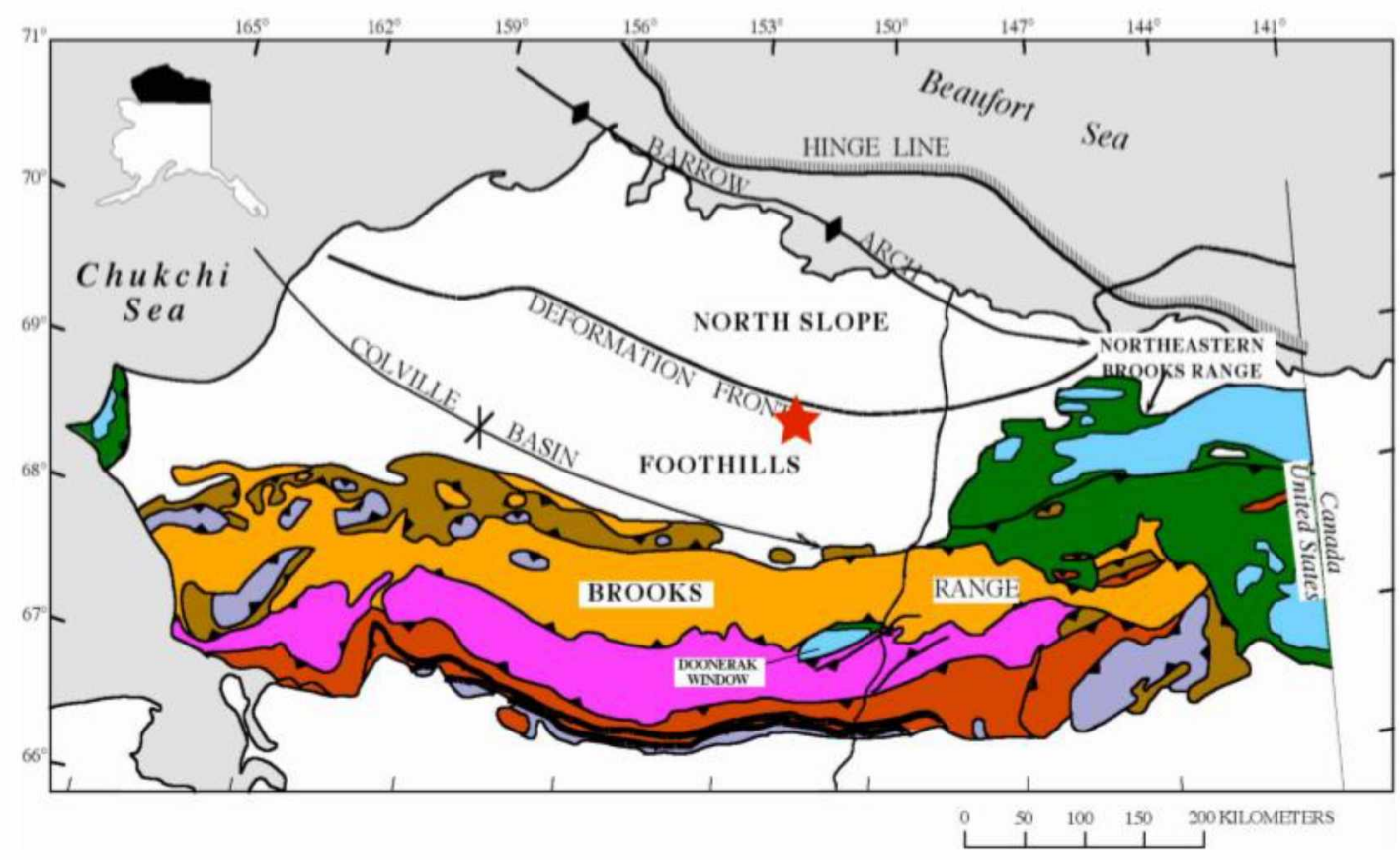

Figure 5: Geologic map of Northern Alaska showing the Brooks Range fold-and-thrust belt and Colville Basin (Hanks et al., 2012). 


\subsubsection{Stratigraphy}

\subsubsection{Regional Stratigraphy}

The North Slope of Alaska is mainly comprised of sedimentary rock with a few igneous rock bodies (Moore et al., 1994). There are four main sequences in the regional stratigraphy of the North Slope of Alaska. These sequences belong to the Paleozoic to Cenozoic Era and are as follows (Moore et al., 1994):

- Franklinian or Pre-Mississippian sequence (pre-Middle Devonian)

- Ellesmerian sequence (Mississippian to Jurassic)

- Beaufortian sequence (Jurassic and Lower Cretaceous)

- Brookian sequence (Cretaceous to Tertiary)

The Brookian sequence resulted from the formation of the Brooks Range in the south, downlapping northward onto the older underlying Ellesmerian and Beaufortian sequences. It filled the Colville Basin from a west to east-northeast direction and onlapped the Beaufort rift shoulder. Figure 6 indicates the paleocurrent direction in the depositional sequence (Houseknecht et al., 2009). 


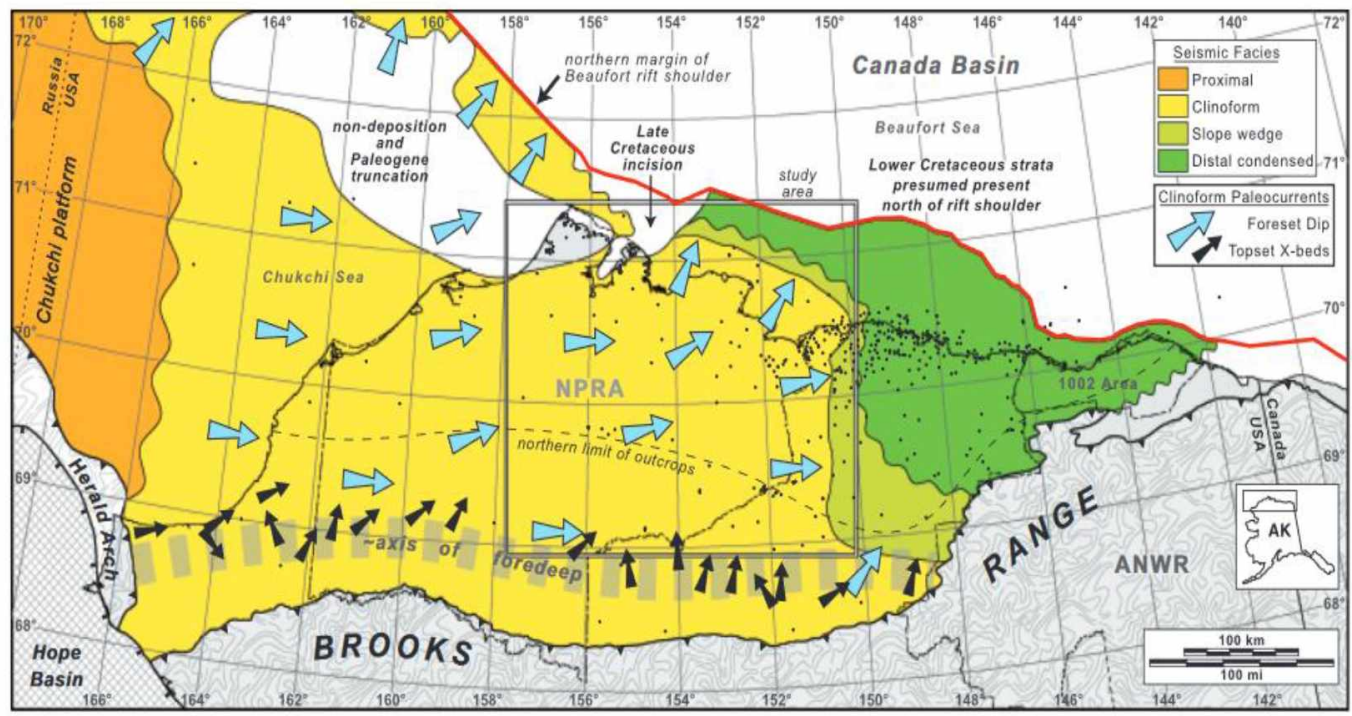

Figure 6: Map of North Slope of Alaska, Chukchi Sea and Beaufort Sea showing main geologic elements, seismic facies and paleocurrent data from Lower Cretaceous first-order depositional sequence(Houseknecht et al., 2009).

\subsubsection{Colville Basin}

Colville Basin is a foreland basin with Mesozoic and Cenozoic sequences (Bird and Molenaar, 1992). The basin was filled due to tectonic sedimentation from the Herald arch and the Brooks Range (Bird and Molenaar, 1992; Moore et al., 1994).

In the Umiat area, two key depositional sequences are observed- the Torok-Nanushuk (Aptian to Cenomanian age) sequence and the Seabee-Tuluvuk sequence (Turonian to Santonian age) (Figure 7). Nanushuk and Torok represent clastic deposits of same age from eastward and north-eastward progradation (Mull et al., 2003). A clinoform depositional sequence in the Lower Cretaceous filled the western Colville Basin with prograding sediments of the Brooks Range into the foredeep (Houseknecht et al., 2009). 


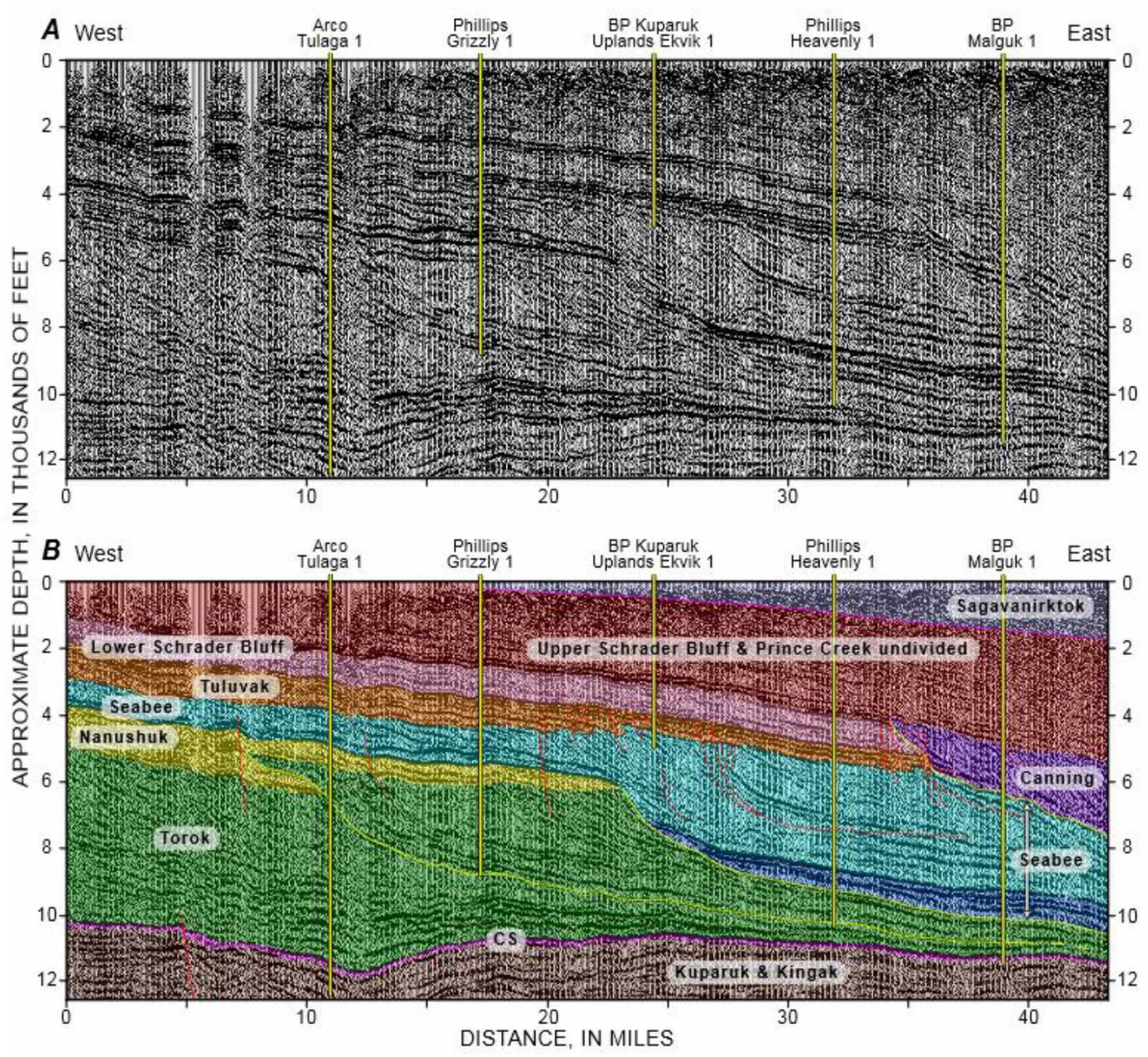

Figure 7: Nanushuk shelf margin seen in a west-east seismic line showing Torok-Nanushuk and Seabee-Tuluvak sequences; A: uninterpretated image, B: interpretated image showing different formations(Houseknecht andSchenk, 2005).

\subsubsection{Umiat Oil Field}

Umiat field is an anticlinal structure in the Cretaceous rocks in the foothills of the Brooks Range (Figure 5). The anticline is a broad, low-amplitude detachment fold with reverse faults in the axis (Figure 8). 


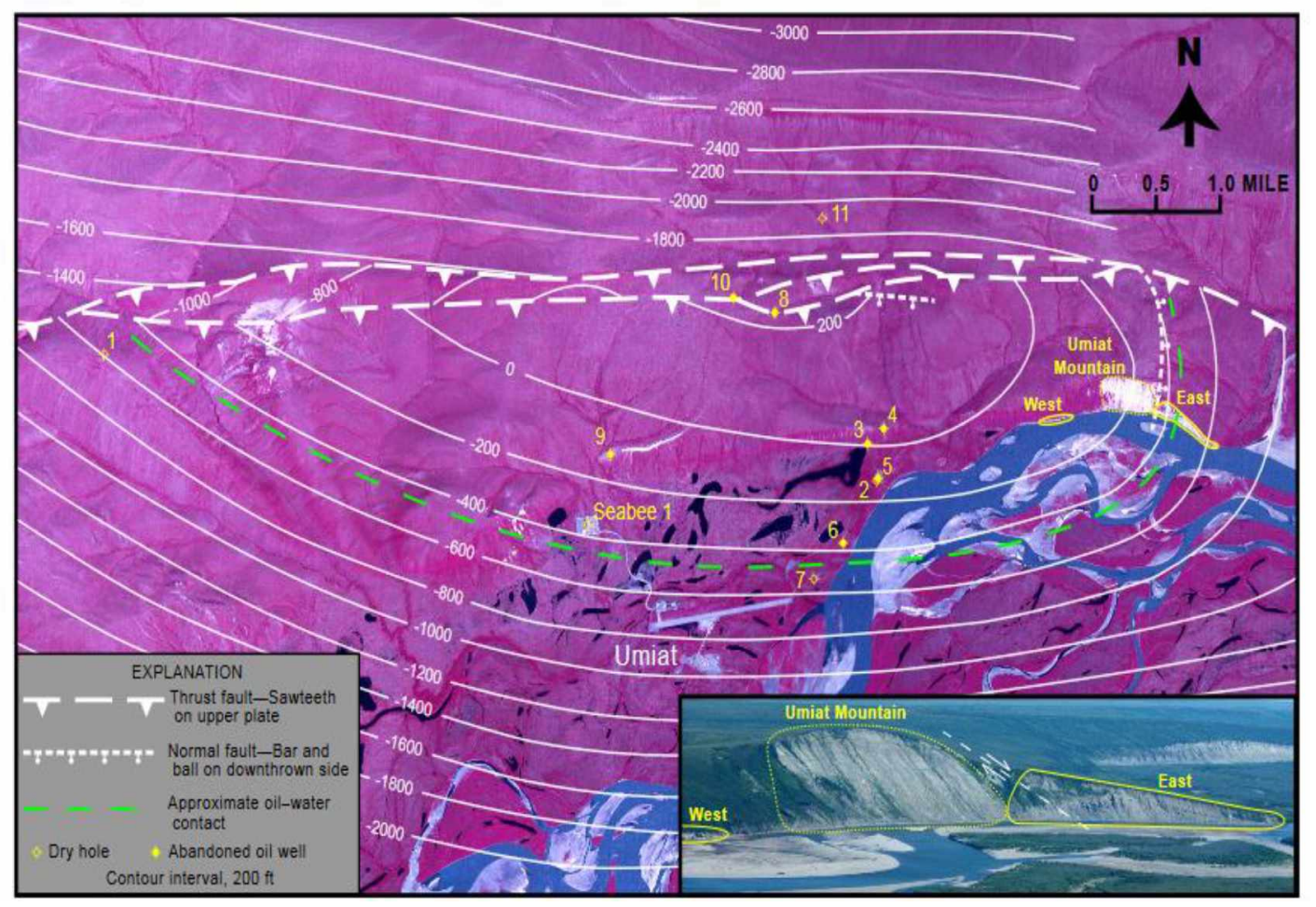

Figure 8: False-color infrared aerial photomosaic of Umiat area, with superimposed structurecontour map of the Grandstand sand with Umiat well locations (Houseknecht and Schenk, 2005).

Interest in the Nanushuk Formation increased after multiple wells were drilled in the Brookian sequence in NPRA during the federal exploration campaign in the 1940s. The Nanushuk Formation was initially defined as a group, however, later it was lowered to a formation category by Mull et al. (2003). The Albian to Cenomanian Nanushuk Formation characterizes a thick deltaic unit with a great variation in thickness, having 4,600 ft thickness in the west with both marine and nonmarine deposits and thins to $775 \mathrm{ft}$ thick in the northeast with primarily marine and marginal deposits(Mull et al., 2003).

The informal units from the Nanushuk Formation are Tuktu/shale barrier (marine mudstone), Lower and Upper Grandstand (shallow marine to deltaic sandstone), Chandler also known as Killik (nonmarine to marginal marine sandstone) and Ninuluk (shallow marine sandstone) (Figure 9) (Hanks et al., 2012; Shimer et al., 2014). These informal units can be further categorized into two deltaic systems. Tuktu and Lower Grandstand belong to the progradational wave-dominated deltaic system while the shale barrier, Upper Grandstand, and Killik belong to the progradational river-dominated deltaic system. Shimer et al., (2014) observed that the Lower Grandstand is 
comprised of two sandstone intervals separated by a large flooding surface. This identifies two different reservoir intervals within the Lower Grandstand (Upper Lower Grandstand and Lower Lower Grandstand). Upper Grandstand is a regionally extensive sandstone and does not contain an internal flooding surface, hence it can be considered as a single reservoir unit (Shimer et al., 2014). Ninuluk, which is a backstepping transgressive system, overlays the above two upwardcoarsening regressive systems (Shimer et al., 2014). Erosion has caused the Ninuluk to be mostly absent from most parts of the Umiat field and especially in the southern limb (Shimer et al., 2014). Tuktu is a marine mudstone and it intertongues with both Grandstand sands (Shimer et al., 2014)

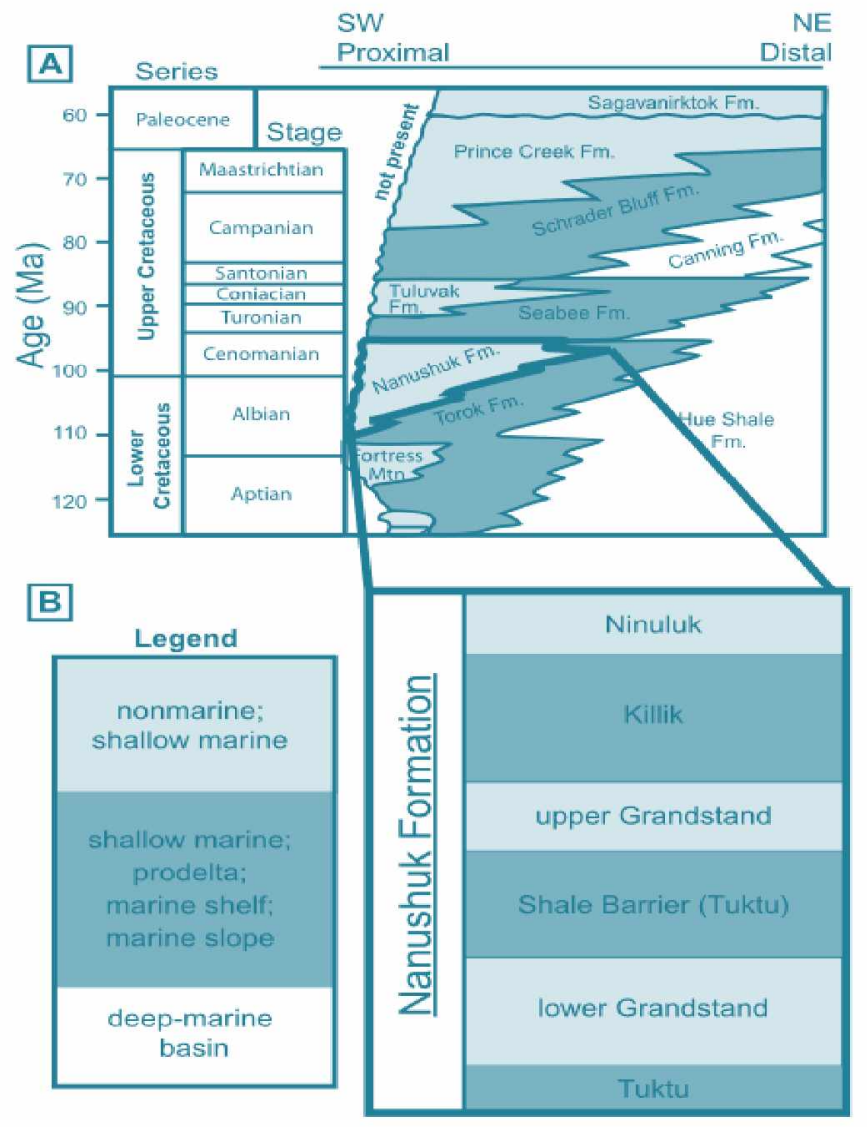

Figure 9: A) A regional stratigraphy of the Brookian sequence, showing the relevant stratigraphic units of the Colville Basin. B) Informal reservoir stratigraphic nomenclature for the Umiat field. From Shimer et al. (2014).

\subsubsection{Source rock}

Three mudstone units rich in organic matter from the Lower Cretaceous are interpreted to be the source rocks for the Umiat oil field (Magoon et al., 2003): the pebble shale unit, gamma-ray 
zone (GRZ), and the lower Torok formation. Petroleum from these source units migrated from the foreset deposits of the Torok formation or through faults to the updip Nanushuk Formation during early Cretaceous (Magoon et al., 2003). Both source rocks and reservoir rocks of the Umiat field were deposited in the Colville foreland basin (Huckabay andHanks, 2009).

Burns et al. (2002) studied the timing of hydrocarbon generation in the Ellesmerian, Beaufortian, and Brookian sequences in the NPRA using thermal and burial history modeling. According to the models, hydrocarbon generation was heavily influenced by progradational deposition of the sediments. It started in the southwest during the Albian and further advanced toward northeast across NPRA during Albian and Cenomanian time. The oil generation and migration from lower Brookian source rocks happened at 100-90 Ma, along with rapid Brookian sedimentation and burial. However, the structural traps were formed during $60 \mathrm{Ma}$. Thus, it is inferred that Umiat oil field was formed as a stratigraphic trap at $100 \mathrm{Ma}$ and due to successive folding, a combination of structural and stratigraphic trap was formed (Potter and Moore, 2003).

\subsection{PREVIOUS WORK DONE ON UMIAT FIELD}

During the 1940s, the U.S. Navy started a drilling campaign in NPRA and drilled 11 test wells in the Umiat structure to determine its production potential. The operator could not comprehend the behavior of the wells as only 6 out of 11 wells produced oil. Gates et al. (1960) observed that out of different drilling fluids used, those wells drilled with oil-based mud produced maximum oil rates. Figure 10 provides a summary of type of mud used for drilling different wells and the oil rates from corresponding wells. 


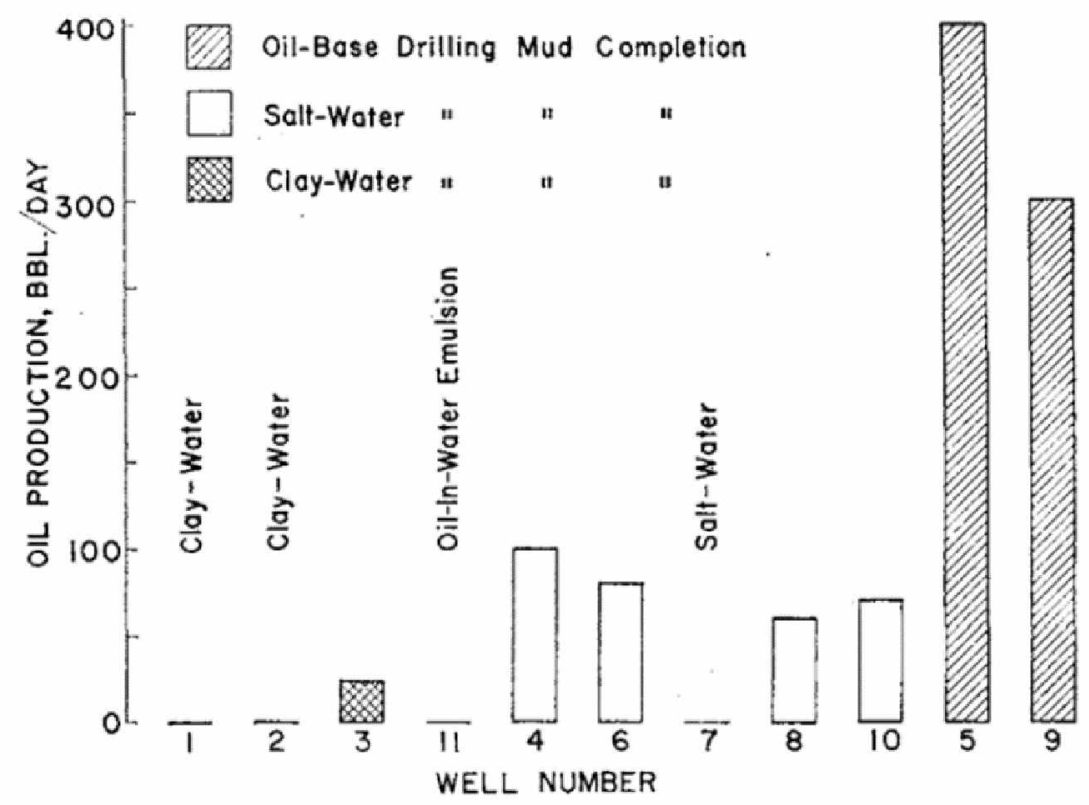

Figure 10: Production capacity of Umiat test wells related to drilling mud (Gates et al., 1960)

A detailed study was carried out by U.S. Bureau of Mines on the core samples of Umiat. The study aimed at determining the cause of well plugging and estimating oil recovery from the field by simulating field conditions. It was observed that the severe damage experienced in wells was due to blocking of the pore space caused by the freezing of invaded drilling mud filtrate(Baptist, 1960).It was also seen that the freezing of interstitial water reduced oil permeability due to an increase in water volume. Baptist reports $27 \%$ reduction in permeability due to freezing of interstitial water. Also noticed was an increase in immobile water saturation in $41-45 \%$ of pore space due to freezing, which could be further affecting oil permeability and oil recovery. Additionally, average oil recovery for four tested samples at $75^{\circ} \mathrm{F}$ was $40 \%$ while the average reduced to $29 \%$ at $26^{\circ} \mathrm{F}$ implying around $27 \%$ reduction in oil recovery due to low temperature. However, high recoveries were obtained (upto $36 \%$ in case of solution gas drive) even at $26^{\circ} \mathrm{F}$.

To understand two-phase fluid flow behavior in the Umiat field, routine core analysis was performed on six representative Umiat core plugs by (Godabrelidze, 2010). Godabrelidze (Godabrelidze, 2010) used a wider range of temperatures for testing $\left(23^{\circ} \mathrm{C}\right.$ to $-10^{\circ} \mathrm{C}$ ) as compared to previous experiments. Oil relative permeability was found to decrease by an average of $61 \%$ at 
$-10^{\circ} \mathrm{C}$ because of irreducible water freezing. Saturation-height function for each rock type was also prepared using air-kerosene capillary pressures in absence of resistivity logs.

Further insight into the relative permeability reduction of oil due to formation freezing was provided by Venepalli (2011). Venepalli performed core flood experiments on two Berea sandstones under permafrost conditions at different temperatures and different water salinities. It was found that cores showed maximum reduction in the oil relative permeability in the presence of deionized water ( $43.2 \%$ in both cores) while minimum reduction was observed in presence of $6467 \mathrm{ppm}$ of water. Anti-freezing agent with $60 \%$ ethylene glycol (or propylene glycol) and $40 \%$ water was found to be the best flooding agent as compared to other tested fluids such as deionized water and saline water.

Ideally, a fluid characterization study requires a fluid sample from the bottomhole. However, the Umiat oil sample available was weathered due to being very old. Shukla (2011) created a pseudo-live sample of Umiat oil by comparing fluid composition obtained by Pederson method with the available sample and adding the missing components. Comparison of recreated oil sample with dead oil molar compositions can be seen in Figure 11.

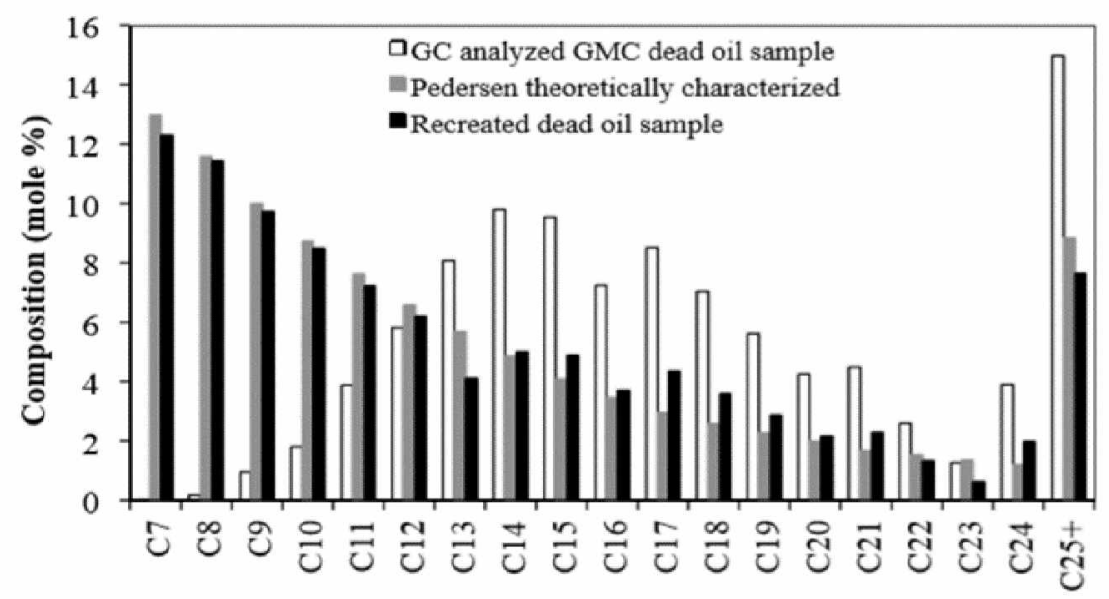

Figure 11: Comparison of Dead oil molar compositions with recreated oil sample (Shukla, 2011)

The measured experimental data was then used to tune the EOS model in order to simulate differential liberation tests. The fluid composition data was then used as an input to reservoir simulation. 
From examination of older Umiat well cores and analog outcrop observations, Wentz (2014) observed three fracture sets in Umiat field- 1. calcite filled or open pre-folding regional extension fractures in the north-south direction 2. Unfilled hinge-parallel extension fractures in east-west direction 3. Unfilled vertical conjugate shear fractures perpendicular to fold hinges. This could result in productivity variation with wellbore azimuth.

Shimer et al. (2014) noted that the two reservoir intervals within Lower Grandstand and the Upper Grandstand are laterally extensive across the field, however, Upper Grandstand is heterolithic. All three reservoir intervals indicate coarsening upward sequences, resulting in higher permeability in the topmost part of the interval. Also, Upper Grandstand has more micaceous and carbonaceous laminae, thus vertical permeability is poorer in Upper Grandstand is poor than that in Lower Grandstand (Shimer et al., 2014). Thus, Lower Grandstand is considered the best reservoir interval because it is the deepest and hence least affected by the permafrost.

The petrophysical model was created by Levi-Johnson (2010) for both upper and lower Grandstand sands, with large grid dimensions. Kohshour (2013) refined the grids for higher resolution and the model was constructed of only lower Grandstand sand. Sub-units Upper, Middle and Lower Grandstand were modeled. Kohshour also performed reservoir simulation on the reconstructed reservoir model with a total 105 wells in a wagon-wheel pattern with five well pads, as per then operator Linc Energy's guidance. Kohshour (2013) performed an extensive uncertainty analysis based on the uncertainties related to geology such as oil-water contact, porosity and permeability variogram, water saturation, porosity and net-to-gross ratio. Oil-water contact was found to be the highest rank parameter among the uncertain parameters. Various sensitivities on permeability anisotropy, relative permeability end curves as well as producing GOR was conducted. Monte Carlo simulation for uncertainty in in-place volume was also performed and the range of OOIP for Lower Grandstand was found out to be 790 MMSTB to 2474 MMSTB with a P50 value of 1550 MMSTB. Kohshour (2013) obtained a recovery of $12 \%$ with cold gas injection as a base case of the simulation study. 


\subsection{Application of Design of Experiments/RSM in Reservoir Simulation}

One of the various techniques used in reservoir engineering is numerical modeling. Numerical models are mathematical models that use timesteps to determine model response over time. High performance computers are utilized to perform these activities due to increasingly inexpensive computational resources. Subsequently, dependency on numerical modeling has increased and engineers have started using numerical modeling for more and more complex problems. Almost invariably, the inputs as well as outputs are multivariate. Also, the nature of the relationship between the input and output is complicated due to involvement of multiple variables. A run of a numerical model wherein a set of combinations of input variables is used, is called a numerical experiment. The design problem is the conscious effort to choose a set of inputs combination and running multiple realizations for effective analysis of the output. Experimental design can be used to design the problem in clever way to pick the combinations to minimize the runs.

Experimental design is different than one-factor-at-a-time method as it can see the effect of changing multiple factors in the same run. It provides additional information of interaction effects as compared to one-factor-at-a-time approach with the benefit of reduced experimental runs.

Application of DoE in reservoir simulation dates back to mid-1990s (Faidi et al., 1996). Given that the measurements in the subsurface are susceptible to errors, the simulation input is always associated with a degree of uncertainty. As a result, this translates to uncertainty in the simulation output. Effective understanding of the subsurface behavior needs quantification of the effects of the uncertainty. DoE is a widely used methodology/approach in uncertainty analysis using reservoir simulation models and acts as a simple and time saving tool. Uncertainty in subsurface properties can affect the recovery forecasts and there are several papers discussing the use of experimental design and proxy models to determine effect of various parameters on factors such as cumulative production, in-place volumes or NPV. Friedmann et al. (2003) applied experimental design to channelized sandstone system and prepared recovery type curves from the results. Cyril and Peacock (2010) used Placket Burman design to D1000 reservoir from Epu field in Niger Delta to quantify the uncertainty in in-place and recoverable volumes. There has been an attempt to determine the number of optimum wells in a gas field in North Africa by using experimental design (Vicente et al., 2010). 
Various authors have used DoE approach to study the effect of subsurface uncertainties in different types of fields such as offshore heavy oil field (Vanegas et al., 2005), gas condensate field (Abdul-Latif et al., 2017), onshore light oil field (Kloosterman et al., 2007). Peake et al. (2005) applied DoE for analysis of a producing reservoir. They introduced a new technique combining DoE and history matching to determine the impact of uncertainties on the waterflood oil forecast.

Denney (2007) recommended use of DoE and RSM along with reservoir simulation to obtain knowledge of dynamic uncertainties associated with prediction of production profile and the cumulative volumes. Denney used the methodology only on parameter varying continuously and parameters with discrete values were not used. Application of DoE was seen in scenario planning to study the hydrocarbon in-place volumes in a reservoir by to compensate for the limited data availability during exploration or early appraisal phase. They also mentioned that this approach is better than probabilistic approach since it involves geologic representation of the reservoir.

Determining well count in a reservoir is a complex problem requiring attention to both reservoir characterization and economics. Increasing hydrocarbon recovery needs higher number of wells, however, higher number of wells also result in higher development costs. Thus, optimal well count determination in a field is a vital aspect in the development of oil fields and necessitates extensive numerical modeling. Trabelsi et al. (2017) prepared type curves relating well spacing and heterogeneity to ultimate oil recovery for a $50-\mathrm{ft}$ thick Middle Eastern reservoir. For the average permeability of $10 \mathrm{mD}$ and varying heterogeneity, well spacing has a great impact on oil recovery, which sees a great variation due to well spacing regardless of the degree of heterogeneity (Figure 12). The well spacing determines the well count and thus it is important to study effect of number of wells in a field on recovery. 


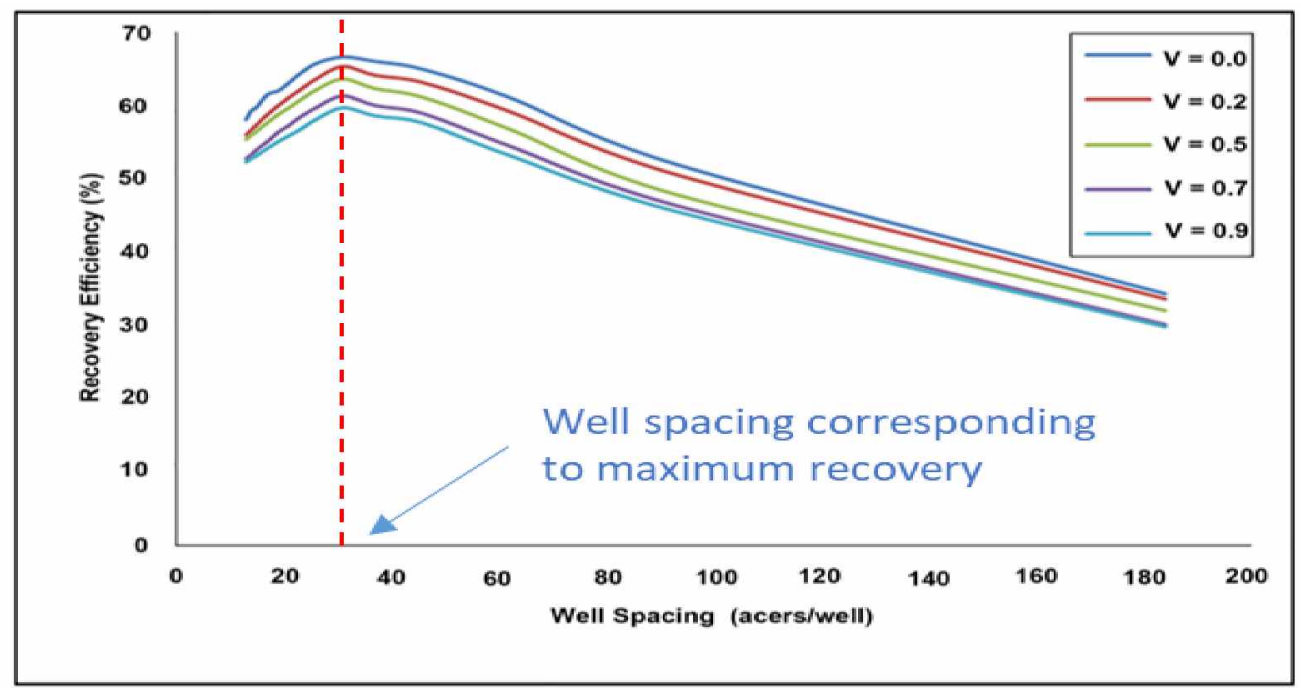

Figure 12: Recovery efficiency for average permeability case of $10 \mathrm{mD}$ (Modified from Trabelsi et al., 2017)

A few researchers have utilized DoE to determine the optimal well spacing or well count for various objectives. Experimental design was used for the optimization of well count in the deepwater field by Narahara et al. (2005). Ghaderi et al. (2012) attempted optimization of WAG process for $\mathrm{CO}_{2} \mathrm{EOR}$-storage in tight formation. The parameters included well spacing, well completion strategy, hydraulic fracture geometry, WAG ratio and $\mathrm{CO}_{2}$ slug size and the timing of the switch from primary or waterflood to WAG scheme and were used to assess $\mathrm{CO}_{2}$ EOR process. Kalla and White (2007) used OAs and NOAs instead of factorial, or partial factorial designs to decrease the number of runs while optimizing large number of parameters such as completion length, tubinghead pressure, and tubing diameter in a gas reservoir. They observed that polynomial regression demonstrated better results than krigging for their study. Box Behnken method was used by Ayokunle and Hashem (2016), to determine ideal operating conditions for multi-lateral wells.

Although, DoE methods are used extensively in reservoir simulation studies, the approach does have some limitations such as non-uniqueness of proxy models and the associated inconsistencies, discrepancy with basic physics principles, inability to provide a correlation between variables that are known to be related, and the challenges faced in application of DoE output in simulation models (Lawal, 2009).

Thus, it can be observed that many authors have successfully applied DoE to reservoir simulation studies to understand the relationship between parameters and the outcome, to screen 
the parameters, and optimize the response within the constrained design space. $2^{\mathrm{k}}$ factorial, fractional factorial, Central Composite, Box Behnken and Plackett-Burman are some of the widely used experimental designs in simulation studies. The application of $\mathrm{DoE}$ is recommended in case of controllable variables or uncertainties with a narrow range to avoid some of the inherent drawbacks of the method. 


\section{Chapter 3: Research Design}

This chapter introduces the methodology adopted to accomplish the objectives of the research. Section 3.1 describes the methodology used and how it was implemented and the research design. Section 3.2 provides the details of the reservoir simulation model used in the study. Section 3.3 explains the basis of selection of parameters while section 3.4 provides information regarding software tools used for the analysis. Information about simulation runs based on the previously described designs is presented in section 3.6.

\subsection{METHODOLOGY}

The current study uses quantitative approach to research. It aims at using DoE and RSM for optimization of the oil production. The study is a case study, where these techniques are applied to reservoir simulation to optimize the well pattern in an undeveloped Umiat field situated in NPRA.

The study is divided in following three stages:

Stage 1: Parameter Selection

Stage 2: Screening of Parameters

Stage 3: Optimization of Parameters

The research methodology used for current study can be described by Figure 13, as shown below. 


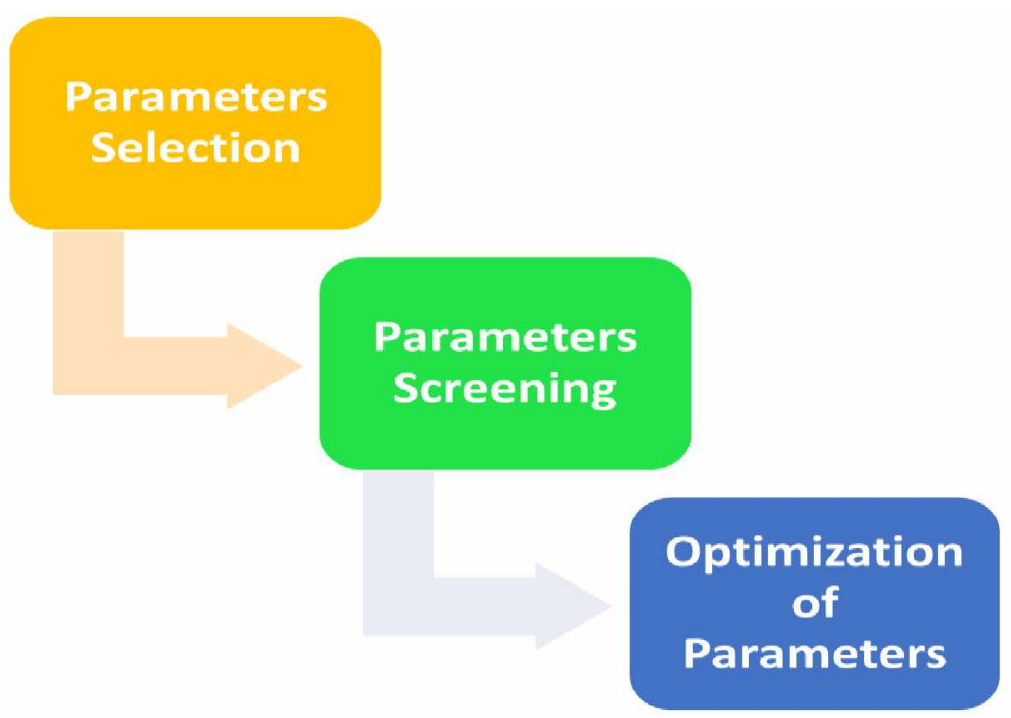

Figure 13: Research Methodology for Umiat Field Well Pattern Optimization

DoE is a systematic approach that aims to explain the relationship between the controllable independent variables affecting a process and dependent variable of the process. Dependent variable is called the response, whereas, independent variables or parameters are called factors Experiments are run at different values of factors, called factor levels. Factor levels can be high, median and low, depending upon the nature of the design. Two types of factor levels, natural and coded, are used in the analysis. Natural level of a parameter is the actual value that a parameter can take. The parameter values are also coded in such a way that high value is +1 , median value is 0 and low value is -1 .

A design is a set of different combinations of the factor levels and response is measured for these set of combinations. Every experimental run contains a certain combination of factor levels. This combination depends upon the objective of design. There are different types of designs, used for different purposes. Each design contains a set of experimental runs with varying factor levels and varying number of experiments. A wide variety of experimental designs can be used, based on the design objective and number of factors involved. For example, if we want to apply a factorial design with two levels, the design will require maximum or minimum value $( \pm 1)$ of each factor in all possible combinations with other factors. The number of experiments in factorial design can be determined by using the formula $2^{\mathrm{K}}$, where $\mathrm{K}$ represents number of factors. For factorial design using three factors, eight experiments will be required as per the formula (Figure 
14a). In the same way, the number of experiments for three factors as well as three levels $(-1,0$, +1 ) with all possible combinations would be 27 (Figure 14b). As the number of factors increase, it would also increase the number of total number of experiments required to run. Such designs take high computational time. With three factors and three levels, Box Behnken design can be applied which requires 15 experiments (Figure 14c). Thus, by using Box Behnken design, we have reduced the number of experiments by avoiding higher order confounding effects. Controlling the number of experiments becomes more and more important as the number of factors.

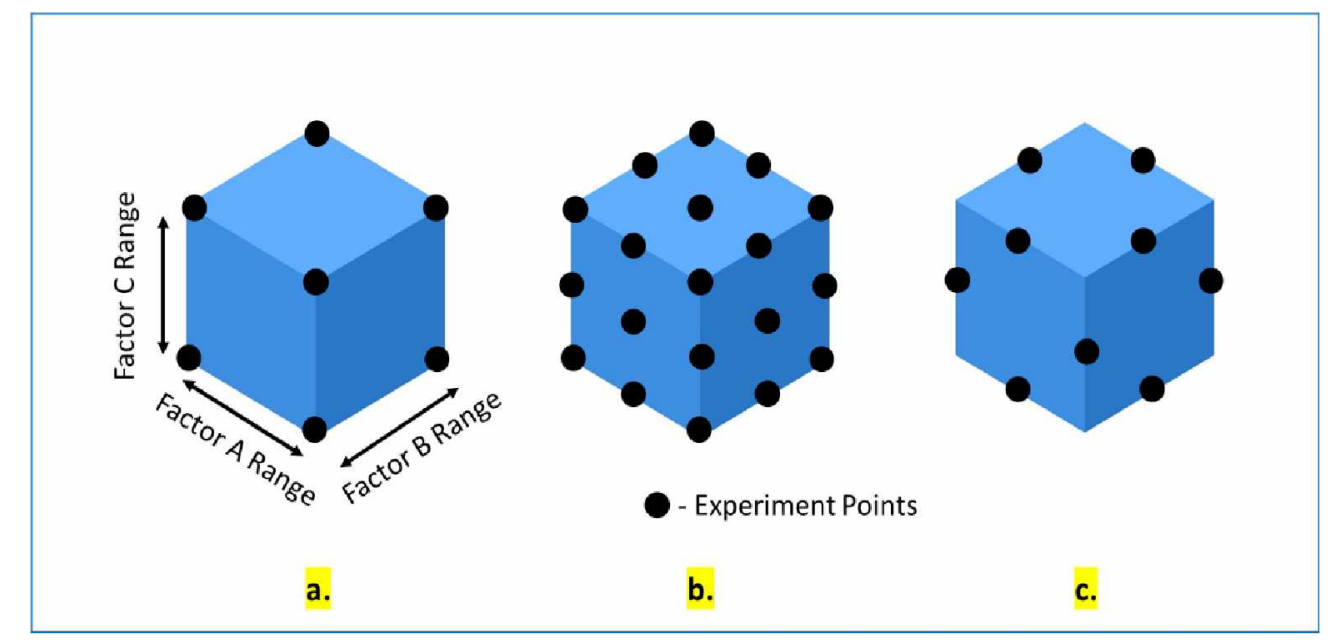

Figure 14: No of Experiments for three factors a. Two Factorial Design, b. Three Factorial Design c. Box Behnken Design

Although, DoE technique was originally developed for experiments, it can also be applied on the simulation models. In the current study, we have used the technique on the reservoir simulation model of Umiat field to run various simulation cases. 
Figure 15 summarizes the workflow followed during the oil recovery optimization study on the Umiat field.

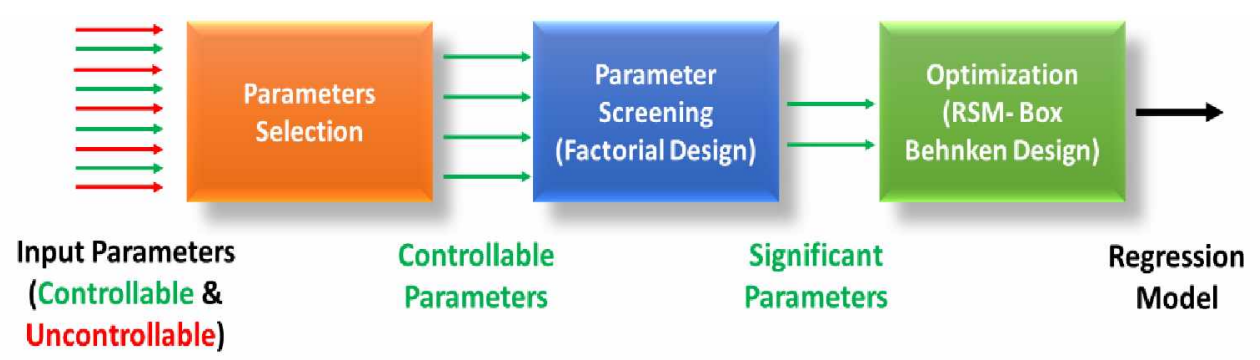

Figure 15: Representation of the Workflow followed for optimization of well pattern in Umiat field

The input factors are selected based on our knowledge about Umiat field and on our ability to change them. Details about the parameters' selection can be found in the subsequent section.

$2^{\mathrm{k}}$ factorial design is the most popular type of experimental design because of its simplicity of execution and effectiveness to determine the effects of individual factors as well as of interaction among the factors. Factors are also called as parameters and the term 'factor' is used with 'parameter' interchangeably, for the current study. For screening purpose, we first applied $2^{\mathrm{k}}$ full factorial design to simulation model to screen the parameters, where $\mathrm{k}$ denotes the number of parameters and 2 denotes the levels of parameters. Then, we perform Analysis of Variance (ANOVA) on the output obtained by applying factorial design on simulation model. Once the significant parameters are identified, next step is to optimize the system behavior. In $2^{\mathrm{k}}$ factorial design, linear relationship between the parameters and the response is assumed as only two levels of the parameters are considered for simplicity. For optimization purpose, it is necessary to determine the nature of the response surface and whether it has any curvature i.e. any deviation from the linear relationship assumption assumed during previously mentioned screening stage. This makes it necessary to choose an experimental design which requires three levels of the factors. RSM uses response surface from the design space and uses it to predict the system behavior. As discussed previously, it also requires fewer number of runs than factorial design with same number of factors (Figure 14). A center-point run is included to make the model more orthogonal, which improves precision of determining the response surface. Center-point run can be designed by 
taking all factors at their median value or at coded value of 0 . Unlike factorial designs, there is no simple formula to determine number of experimental runs and factors' combination in Box Behnken designs. For each experiment point, we conducted reservoir simulation to determine response i.e. oil recovery. We also estimated second response for optimization analysis, which is cost corresponding to each run. To analyze the responses, we have used regression analysis over the response surface with the objective of maximizing the oil recovery and minimizing cost (Figure 16). Polynomial regression is nothing but a form of regression in which relationship between the response and the independent control variables as an $\mathrm{n}^{\text {th }}$ degree polynomial. It can be used to model a non-linear relationship between factors and outcome. Box Behnken design creates a response surface which can be fitted using a second-degree polynomial. The design also reduces estimation error due to inclusion of center-point run. Among response surface designs, Box Behnken designs are independent quadratic designs that are especially used to create higher order response surfaces and need three levels of factors- low, median and high. As compared to central composite design, these require lesser number of levels. Also, they require lesser number of runs than $2^{k}$ factorial designs for generating similar information. Box Behnken contains design points placed on the midpoints of the edges of the cubical design region as the center. Henceforth, we chose Box Behnken method for optimization.

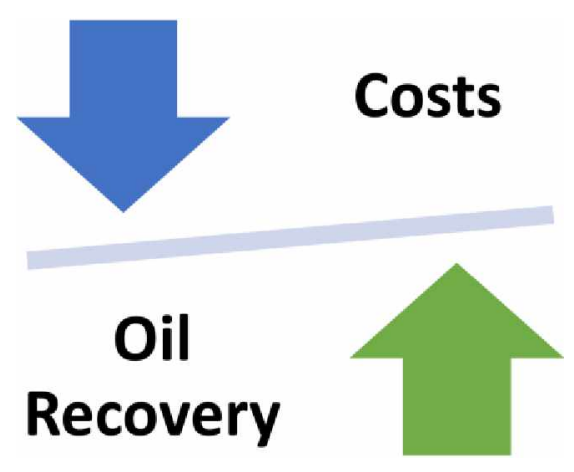

Figure 16: Objective of the optimization process in current research 


\subsection{RESERVOIR SIMULATION MODEL}

Dynamic simulation model used in the current work was prepared during a co-operative study between University of Alaska Fairbanks (UAF), Renaissance Alaska and Linc Energy, and was funded by Department of Energy (Hanks et al., 2012).

The static geologic model was constructed based on the actual logs, core data and seismic data interpretation. High permeability anisotropy ratio (0.45), multiple rock types due to wide variation in permeability (0-500 md) (Ahmadi et al., 2013; Kohshour, 2013), measured PVT data and relative permeability data in the presence of ice were incorporated into a dynamic simulation model. The simulation model is focused on the Lower Grandstand sand (LGS). It is considered as a primary reservoir interval since it is the deepest sand in the reservoir and hence assumed to be the least affected by the permafrost.

LGS is further divided into Upper LGS and Lower LGS separated by a shale barrier. Gross reservoir thickness of LGS is around 90-150 ft which contains upward-coarsening waveinfluenced deltaic successions of sands with an intervening 20-50 ft thick shale. Table 1 summarizes reservoir properties used in the simulation model (Ahmadi et al., 2013; Kohshour, 2013).

Table 1: Simulation model properties for Umiat field reservoir simulation

\begin{tabular}{|l|l|}
\hline \multicolumn{1}{|c|}{ Parameter } & Value \\
\hline Reservoir pressure $(\mathrm{psi})$ at datum depth of $900 \mathrm{ft}$ & 350 \\
\hline Reservoir temperature $\left({ }^{\circ} \mathrm{F}\right)$ & 26 \\
\hline Average permeability $(\mathrm{mD})$ & 43 \\
\hline Permeability anisotropy ratio & 0.45 \\
\hline Average net-to-gross ratio & 0.4 \\
\hline Average porosity $(\%)$ & 12 \\
\hline Oil density at surface conditions $\left(\mathrm{lb} / \mathrm{ft}^{3}\right)$ & 52.2 \\
\hline Gas density at surface conditions $\left(\mathrm{lb} / \mathrm{ft}^{3}\right)$ & 0.045 \\
\hline
\end{tabular}


Figure 17 gives an overview of the simulation model showing reservoir anticlinal structure. It also shows different pads and corresponding wells originating from well pads.

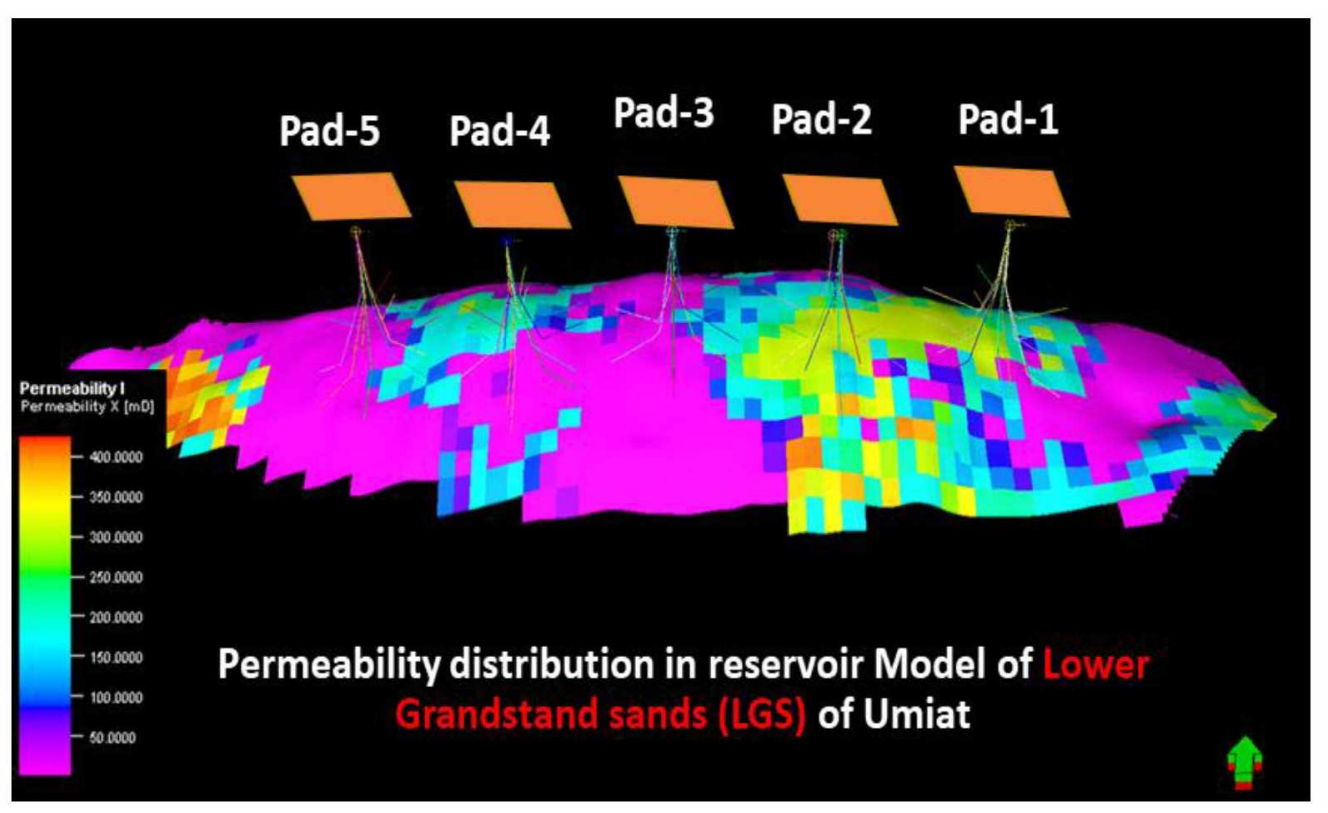

Figure 17: Reservoir simulation model for Umiat field showing permeability distribution in topmost layer of LGS

The simulation model was run for 50 years with gas injection as a pressure maintenance source since the start of production and with flowing bottomhole pressure of 80 psia. Injected gas composition was assumed to be pure methane. Recovery factor of $12 \%$ was obtained for base case with 400 psia injection pressure with wagon-wheel pattern of wells. Uncertainty analysis was performed to understand the impact of uncertainties on the recovery.

Further details of the geologic model and simulation model can be found in (Ahmadi et al., 2013; Hanks et al., 2012; Hanks et al., 2014; Kohshour, 2013).

The current analysis uses the same model to perform parametric study by application of experimental design on the simulation model except the wells. The concept of the wagon-wheel pattern is applied in well design. However, well pattern parameters are changed in the parametric study. The study estimates the impact of the controllable parameters associated with the wagonwheel pattern on the oil recovery and associated development cost.

Following approach was followed to design the well pattern for corresponding to each simulation run. 


\subsubsection{Well Pattern Description}

Pad drilling concept with wagon-wheel pattern of wells was selected for the current study, since it is well known that pad drilling minimizes the surface footprint while maximizing reserves while maximizing reservoir contact. The necessity of reducing the surface footprint arises due to environmental concerns, especially in a much more delicate Arctic environment. This region is a home to vast number of species including terrestrial mammals, marine mammals and a huge number of species (Herlugson et al., 1996). Thus, it is important to minimize damage to wetlands and to minimize the surface area required for developing the surface facilities. While ice pads can be constructed for exploratory wells during winter season, gravel pads are mandatory in case of development wells where operational access is required year around (Renewal of the Federal Grant for the TAPS, Draft Environmental Impact Statement: Renewal of the Federal Grant for the TransAlaska Pipeline System Right-of-way, Volume 3, 2002). It is assumed that in Umiat field, these gravel pads will be created during drilling and will be maintained throughout the production phase to protect permafrost from thawing and provide a stable surface for the surface equipment and buildings (Herlugson et al., 1996). With time, horizontal well drilling using pads, is using less and less surface footprint. The size of the pad has decreased from 64 acres from 1970 s to 12 acre approximately (Figure 18) (Marushack, 2017).

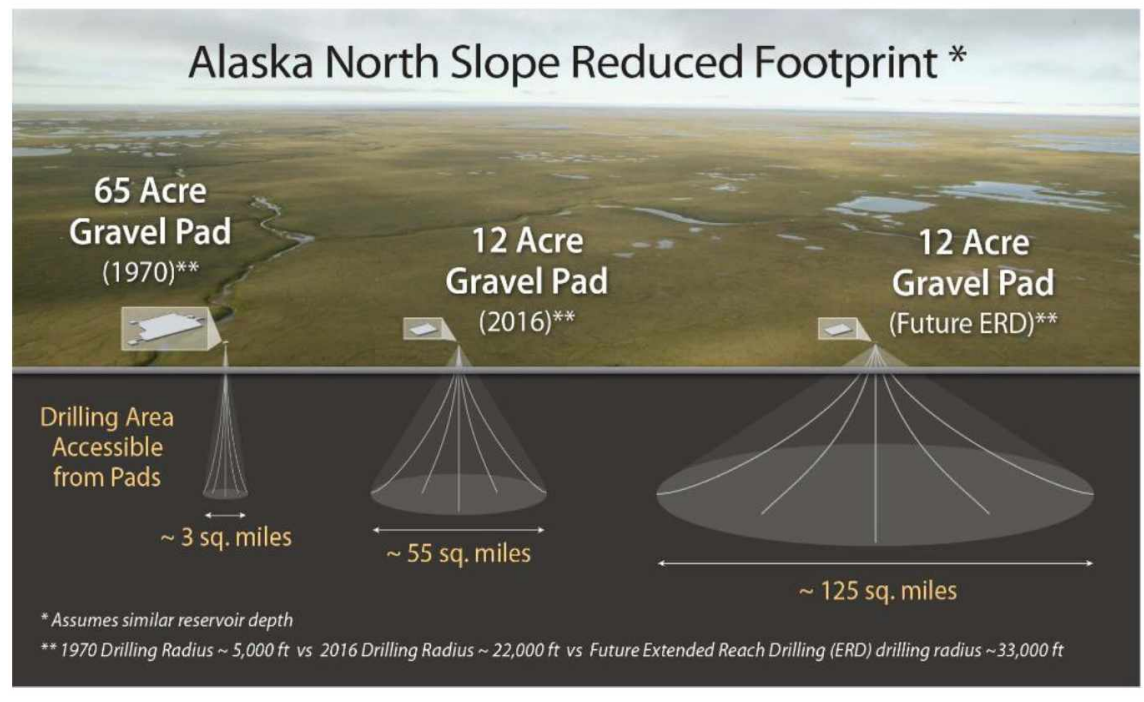

Figure 18: Reduced footprint over time in Alaska (Marushack, 2017)

Each pad in wagon-wheel pattern consists of horizontal wells radiating outwards from the center of the circle in a wagon-wheel pattern with actual number of wells changing run-wise. 
Length and number for both producers as well as cold gas injectors are defined as per the simulation case defined by experimental design (described in the subsequent section). The simulation model consists of two sand zones, namely Upper Lower Grandstand (ULGS) and Lower Lower Grandstand (LLGS) separated by a shale layer. So, the same well pattern is repeated in both ULGS and LLGS. Figure 19a shows a schematic of a typical well pad in ULGS for RSM run 13 (run description in the subsequent section) with wells radiating outwards from the pad. Also, as depicted in Figure 19b, the injectors and producers are placed in the uppermost and lowermost layers, respectively. The same pattern is repeated for LLGS.

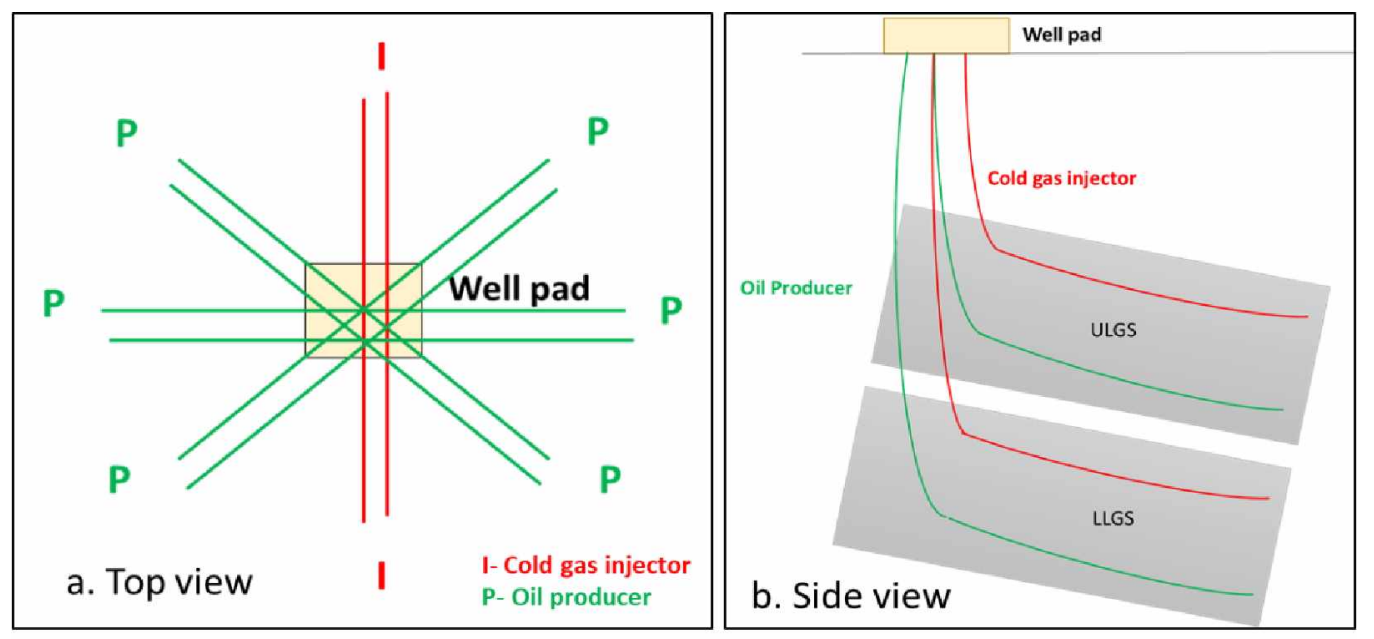

Figure 19: Schematic representation of location of producers and injectors in a pad.

a. Top view of wagon-wheel pattern of wells

b. Side view showing cold gas penetrating the top layers and producer penetrating the bottom layers in the same sand.

More details on the well pad locations can be found in Appendix B.

Umiat $23 \mathrm{H}$, the first horizontal well drilled in Umiat field, in 2014, experienced actual DogLeg Severity (DLS) of about $8 \% 100 \mathrm{ft}$ (Sayers et al., 2015). In current model, we maintained similar DLS constraint while designing the wells. 


\subsection{PARAMETER SELECTION}

\subsubsection{Controllable and Uncontrollable Parameters}

There are two types of parameters in an experimental design context, controllable and uncontrollable. In reservoir simulation framework, subsurface properties are uncontrollable i.e. we cannot change them, although uncertainty is associated with them due to measurement error or correlation inaccuracy (Table 2). These parameters include absolute permeability, $\mathrm{Kv} / \mathrm{Kh}$, reservoir pressure, initial in-place volumes, reservoir thickness.

Table 2: Inherent or uncontrollable uncertainties in reservoir simulation

\begin{tabular}{|lll|}
\hline Rock Properties & Reservoir Fluid Properties & Structural Parameters \\
\hline Absolute Permeability & Reservoir Pressure- $\mathrm{MMP}^{(2)}$ & STOIIP \\
$K_{V} / K_{h}$ & Reservoir Temperature & Fault/ Heterogeneity \\
Relative Permeability $^{(1)}$ & Oil and Water Viscosity & Reservoir Dip/ Thickness \\
\hline
\end{tabular}

(1) Relative permeability includes initial, current and residual oil saturations (to water Sorw, to gas Sorg, and to miscible gas Sorm) as well as trapped gas Sgt. Associated relative permeability and Corey for 3-Phase oil, water and gas.

(2) Reservoir Pressure and Temperature which act on miscibility efficiency through Minimum Miscibility Pressure (MMP) and also on properties such as viscosity

${ }^{(3)}$ Water viscosity affected by Temperature (see point ${ }^{(2)}$ ) and salinity (Sea and Formation water)

Controllable or decision parameters are those parameters that can be controlled during field operation (Table 3). They are decided or optimized by engineers to achieve an objective of maximizing profit or hydrocarbon production.

Table 3: Decision or controllable parameters in reservoir simulation (Bevillon and Mohagerani, 2015).

\begin{tabular}{|lll|}
\hline Well Geometry & Inj./Prod. Design & Injecting Gas Design \\
\hline No. of Wells & Liquid production & WAG Management $^{(6)}$ \\
Length & Injection Rate & \\
Drain Efficiency & $(4)$ & Gas Richness MW \\
\end{tabular}

${ }^{(4)}$ Horizontal well behavior through drain efficiency (pressure losses along lateral)

${ }^{(5)}$ WAG management through: injection rate- gas and water 
${ }^{(6)}$ WAG management through: Slug size (\%HCPV), cycle length, gas injection period, WAG ratio (gas vs. water injection period)

(7) Associated Gas (AG) Molecular Weight (MW): Gas enrichment (blending with Butane) or leaning (blending with methane) which acts on MMP

The aim of the current analysis is to suggest practically feasible values of the controllable parameters in a way that it optimizes the oil recovery within the field (and not to perform uncertainty analysis to account for the uncertainty in the subsurface properties). Based on this objective, relevant parameters need to be chosen for a parametric study. In reality, a variety of parameters including reservoir pressure, fluid properties, rock properties, injection parameters and geology affect the oil recovery. However, not all of them are controllable. We identified following controllable parameters (also known as independent variables or factors) for the current study:

\section{A: Well length, ft}

The well productivity index (J)can be defined as the ratio of total liquid surface flow rate to the pressure drawdown. Productivity Index of a vertical well is expressed in the following equation (Productivity index (J) - PetroWiki, 2016).

Equation 1: Productivity index equation for a vertical well

$$
J=\frac{\mathrm{Q}}{\left(P_{e}-P_{w f}\right)}=\frac{0.0078 \mathrm{kh}}{\left(\mu \beta\left(\ln \left(\frac{\mathrm{r}_{\mathrm{e}}}{\mathrm{r}_{\mathrm{w}}}\right)-0.5-\mathrm{s}\right)\right)}
$$

Where,

$\mathrm{J}=$ productivity index, $\mathrm{STB} /$ day/psi

$\mathrm{Q}=$ Surface flowrate at standard conditions, STB/D

$\mathrm{Pe}=$ External boundary radius pressure, $\mathrm{psi}$

Pwf $=$ Well sand-face mid-perf pressure, psi

$\mathrm{k}=$ permeability, $\mathrm{md}$

$\mathrm{h}=$ net thickness, $\mathrm{ft}$

$\mathrm{u}=$ fluid viscosity, $\mathrm{cp}$

$\mathrm{B}=$ formation volume factor, $\mathrm{rb} / \mathrm{STB}$

$r_{e}=$ external boundary radius, $\mathrm{ft}$

$\mathrm{r}_{\mathrm{W}}=$ wellbore radius, $\mathrm{ft}$

$\mathrm{S}=$ Skin factor 
Horizontal wells started gaining popularity since 1980s for the obvious benefits such as increased productivity. Babu-Odeh model, which has proved to be one of the most useful models for productivity index, is given below (Estimating horizontal well productivity - PetroWiki, 2015).

Equation 2: Productivity index equation for a horizontal well

$$
\begin{aligned}
& \mathrm{J}=\frac{q}{\left(\bar{p}-p_{w f}\right)}=\frac{0.00708 b_{H} \sqrt{k_{\chi} k_{z}}}{\beta \mu\left[\ln \left(\frac{{ }_{\mathrm{H}^{1} \mathrm{~A}^{1 \backslash 2}}}{r_{w}}\right)-0.75+s_{p}+\left(\frac{b_{H}}{L_{w}}\right) s_{d}\right]} \\
& \text { Where, } \\
& J \quad=\text { productivity index, } \mathrm{STB} / \mathrm{D} \text {, psi } \\
& \bar{p} \quad=\text { volumetric average or static drainage-area pressure, } \mathrm{psi} \\
& \text { pwf } \quad=\text { flowing BHP, psi } \\
& \mathrm{bH} \quad=\text { length in direction parallel to wellbore, } \mathrm{ft} \\
& k_{x} \quad=\text { permeability in } x \text {-direction, } \mathrm{md} \\
& k_{z} \quad=\text { permeability in } z \text {-direction, } \mathrm{md} \\
& \beta=\text { turbulence factor } \\
& \mu \quad=\text { viscosity, } \mathrm{cp} \\
& \text { aH } \quad={ }_{\mathrm{ft}}^{\text {to }} \\
& r w \quad=\text { wellbore radius, } \mathrm{ft} \\
& s p \quad \quad=\begin{array}{l}
\text { skin resulting from an incompletely perforated } \\
\text { interval, dimensionless }
\end{array} \\
& \mathrm{Lw} \quad=\text { completed length of horizontal well, } \mathrm{ft} \\
& \text { sd } \quad=\text { skin caused by formation damage, dimensionless }
\end{aligned}
$$

It can be observed from the above equation that the productivity index of a horizontal well is dependent on several factors, one of them being completion length. However, it is to be noted that the relationship is very complex. It is difficult to estimate the optimum length of a horizontal well by just using the above equation.

Also, well length is a parameter that can be changed during well drilling and hence controllable. Shorter well length would require a greater number of pads. As the well length increases from $1500 \mathrm{ft}$ to $7500 \mathrm{ft}$ from low level to high level, it also causes the number of well pads to decrease because of higher well length covering larger reservoir area. Thus, $7500 \mathrm{ft}$ 
simulation case would require only two pads versus three pads for $4500 \mathrm{ft}$ case and five pads for $1500 \mathrm{ft}$. This also has a cost implication, which will be discussed in the subsequent section.

\section{B: Number of injectors/pad}

The number of injectors per pad will govern the distribution of injection gas in the heterogenous reservoir. It is expected that higher number of injectors will help in maintaining the reservoir pressure effectively. However, it would be interesting to find the optimum number of injectors suitable for wagon-wheel pattern.

\section{C: Producer/Injector ratio}

The role of producers is to increase the oil production with higher the number of producers Higher the production until there is no interference between drainage areas of different wells. On the other hand, higher number of injectors is also desired as the injectors help maintain reservoir pressure. It is also important to find the optimum number of producers per injectors to design the well pattern efficiently. However, every reservoir is unique, thus producer/injector ratio is considered in the current study as it can prove to be important in maximizing the production in our case study. This parameter along with number of injectors/pad will determine the total number of wells in the field.

\section{D: Injection pressure, psi}

Injection pressure can be defined as the surface pump pressure of the injected fluid. In our study, the injected fluid is the cold methane gas at the temperature of $26^{\circ} \mathrm{F}$. Generally, higher injection pressure is desirable as long as it is below fracture pressure. It is included in the study, as it is a controllable parameter and also affects the ultimate oil recovery.

Corresponding response variables (also known as outcomes) are described in the following section:

\section{E: Oil recovery}

The oil recovery is one of the ultimate indicators of profitability for any field. The aim of all operations during various stages of the life cycle of the field is to maximize the oil production. During current research, we will use reservoir simulation to estimate the oil production for various 
scenarios considered in the parametric study. Thus, the effect of the controllable factors will be studied on the oil recovery as it is one of the response variables.

\section{F: Development cost}

Economic indicators of the project such as NPV, IRR decide if the project is economically viable. These indicators are dependent on two factors: costs as well as the revenue. The revenue is generated by selling the hydrocarbons. If the costs are higher than the revenue generated, the project in economically unsuccessful. For the purpose of well pattern optimization, the focus would be on the comparative attractiveness of the different development scenarios rather than the net economic value of the project. As the oil price will be the same in all scenarios, only the corresponding costs are compared in the current work. Development costs were estimated for all simulation cases by using standard cost estimates specialized for Alaska North Slope operations and used as the second response variable in optimization stage.

\subsubsection{Range of Controllable Input Parameters}

Range of input parameters was decided based on the practical constraints associated with the wagon-wheel well pattern. Different factors such as effective reservoir size, pay zone distribution were considered in the process. Below section summarizes parameters and range for each parameter in the screening and optimization study.

\section{Parameter Range for Screening Analysis}

Well length: This is chiefly decided by the reservoir dimensions and the feasibility of drilling. Based on the current records of Extended Reach Drilling (ERD) in Alaska, combined length of upto 47,828 feet for a single well and two laterals is achievable (Sullivan, 2019). The low level is $1500 \mathrm{ft}$, which was adapted from earlier Umiat field simulation work (Kohshour, 2013). For high level, the well length was tripled. We observed that the well length of $4500 \mathrm{ft}$ decreases the number of required pads to three.

Number of injectors per pad: The current simulation model consists of two sands ULGS and LLGS separated by a shale barrier. Due to this reason, the number of injectors in a sand can take a minimum value of one and thus, the minimum number of injectors per pad is two (low level). For high level, two injectors in each sand, leading to a total four injectors per pad are considered. 
Producer to Injector ratio: Low level can be described as having equal number of producers and injectors leading to Producer to Injector ratio of $1: 1$. High level was considered as five producers per one injector corresponding to a ratio of $5: 1$.

Injector pressure: Low and high levels of injection pressures were assumed to be 400 and 600 psi, in absence of fracture pressure data and the data from previous research (Kohshour, 2013). Table 4 provides ranges of all parameters to be used for screening analysis.

Table 4: Controllable Parameters range for Screening Analysis

\begin{tabular}{|c|c|c|c|}
\hline & Parameter & Low level $(-1)$ & High level $(+1)$ \\
\hline a. & Well length, $\mathrm{ft}$ & 1500 & 4500 \\
\hline b. & No of injectors/pad & 2 & 4 \\
\hline c. & Producer/Injector Ratio & $1: 1$ & $5: 1$ \\
\hline d. & Injection Pressure, psia & 400 & 600 \\
\hline
\end{tabular}

\section{Parameter Range for Optimization Analysis}

We ensured that the range of parameters in the optimization was practically feasible and representative of actual conditions as these ranges were later used to suggest optimized values of the parameters. To get better estimate of the response surface, we extended the range of certain parameters for the optimization study (well length and number of injectors/pad). Well length was increased to $7500 \mathrm{ft}$ for high level, in such a way that the number of pads further decrease to two. Number of injectors were increased from four to six for high level. Fracture pressure in the field is unknown, hence during optimization, the injection pressure range was further narrowed down. Also, since the reservoir pressure in ULGS is lower than that in LLGS, lower injection pressure was considered for ULGS than LLGS during optimization runs. Median level was also introduced for optimization, as explained in the methodology. Table 5 summarizes the range of parameters for optimization. 
Table 5: Controllable Parameters range for Optimization Analysis

\begin{tabular}{|c|c|c|c|c|}
\hline & Parameter & Low level (-1) & $\begin{array}{c}\text { Median level } \\
(0)\end{array}$ & High level $(+1)$ \\
\hline a. & Well length, ft & 1500 & 4500 & 7500 \\
\hline b. & No of injectors/pad & 2 & 4 & 6 \\
\hline c. & Producer/Injector Ratio & $1: 1$ & $3: 1$ & $5: 1$ \\
\hline d-1. & $\begin{array}{c}\text { Injection Pressure ULGS, } \\
\text { psia }\end{array}$ & 200 & 250 & 300 \\
\hline d-2. & $\begin{array}{c}\text { Injection Pressure LLGS, } \\
\text { psia }\end{array}$ & 300 & 350 & 400 \\
\hline
\end{tabular}

\subsubsection{Design Space Limitations}

Following design space limitations were observed during parameter selection.

- If well length exceeds $7500 \mathrm{ft}$, it will reduce the number of pads to one because of reservoir dimensions. This might not be effective in draining maximum volume of oil from the reservoir.

- Low reservoir pressure and shallow depth also restricts the upper value the injection pressure can take. Subsequently, it limits the range of parameters due to reservoir dimensions and reservoir properties.

- Also, producer to injector ratio can only take a narrow range of values as it directly affects the total number of the wells from a single pad and there is a limit on number of wells/pad due to the nature of the well pattern.

It is therefore important to be watchful of the above points while applying the analysis results for optimization of the well pattern.

\subsection{SOFTWARE TOOLS}

For reservoir simulation, a black oil reservoir simulation software provided by Computer Modeling Group (CMG) was used. We used commercially available statistical analysis software tools such as Minitab and Design-Expert by Stat-Ease for performing analysis on output obtained from simulation runs post application of DoE techniques. 


\subsection{PROCEDURE}

In the first stage of analysis, we selected relevant parameters as per previous section. After parameter selection, we applied $2^{\mathrm{k}}$ full factorial design in designing the screening simulation runs. $2^{\mathrm{k}}$ factorial designs are factorial designs where the factor levels are restricted to two (high and low represented by +1 and -1 respectively.). Full factorial design was chosen to know the interaction effects in addition to main effects. Once the important parameters were identified from factorial study, next step was to optimize the parameters. Box Behnken method was used to design runs for optimization, which requires runs to be carried out at three levels, high $(+1)$, median $(0)$ and low $(-1)$. This three-level design is required to model the curvature in response. Table 6 and Table 7indicate the coded levels for simulation runs in $2^{\mathrm{k}}$ factorial design and Box Behnken design respectively. Details on generating Box Behnken design can be found in Appendix A.

Table 6: Design matrix for $2 \mathrm{k}$ factorial analysis showing coded levels of parameters.

\begin{tabular}{|c|c|c|c|c|}
\hline Run\# & Well Length & $\begin{array}{c}\text { No of } \\
\text { injectors/pad }\end{array}$ & $\begin{array}{c}\text { Producer/Injector } \\
\text { Ratio }\end{array}$ & $\begin{array}{c}\text { Injection } \\
\text { Pressure }\end{array}$ \\
\hline Run_1 & -1 & -1 & -1 & -1 \\
\hline Run_2 & -1 & -1 & -1 & +1 \\
\hline Run_3 & -1 & -1 & +1 & -1 \\
\hline Run_4 & -1 & -1 & +1 & +1 \\
\hline Run_5 & -1 & +1 & -1 & -1 \\
\hline Run_6 & -1 & +1 & -1 & +1 \\
\hline Run_7 & -1 & +1 & +1 & -1 \\
\hline Run_8 & -1 & +1 & +1 & +1 \\
\hline Run_9 & +1 & -1 & -1 & -1 \\
\hline Run_10 & +1 & -1 & -1 & +1 \\
\hline Run_11 & +1 & -1 & +1 & -1 \\
\hline Run_12 & +1 & -1 & +1 & +1 \\
\hline Run_13 & +1 & +1 & -1 & -1 \\
\hline Run_14 & +1 & +1 & -1 & +1 \\
\hline Run_15 & +1 & +1 & +1 & -1 \\
\hline Run_16 & +1 & +1 & +1 & +1 \\
\hline
\end{tabular}


Table 7: Design matrix for Box Behnken analysis showing coded levels of parameters

\begin{tabular}{|c|c|c|c|c|}
\hline Run \# & well length & $\begin{array}{c}\text { No of } \\
\text { injectors/pad }\end{array}$ & $\begin{array}{c}\text { Producer/Injector } \\
\text { Ratio }\end{array}$ & $\begin{array}{l}\text { Injection } \\
\text { Pressure }\end{array}$ \\
\hline Run_1 & 0 & 0 & -1 & +1 \\
\hline Run_2 & 0 & -1 & 0 & +1 \\
\hline Run_3 & 0 & 1 & 0 & +1 \\
\hline Run_4 & +1 & -1 & 0 & 0 \\
\hline Run_5 & -1 & -1 & 0 & 0 \\
\hline Run_6 & +1 & +1 & 0 & 0 \\
\hline Run_7 & +1 & 0 & 0 & -1 \\
\hline Run_8 & -1 & +1 & 0 & 0 \\
\hline Run_9 & 0 & +1 & -1 & 0 \\
\hline Run_10 & 0 & 0 & +1 & -1 \\
\hline Run_11 & 0 & +1 & +1 & 0 \\
\hline Run_12 & 0 & 0 & -1 & -1 \\
\hline Run_13 & -1 & 0 & 0 & +1 \\
\hline Run_14 & 0 & -1 & 1 & 0 \\
\hline Run_15 & -1 & 0 & -1 & 0 \\
\hline Run_16 & +1 & 0 & +1 & 0 \\
\hline Run_17 & 0 & 0 & 0 & 0 \\
\hline Run_18 & +1 & 0 & -1 & 0 \\
\hline Run_19 & 0 & 0 & +1 & +1 \\
\hline Run_20 & -1 & 0 & 0 & -1 \\
\hline Run_21 & +1 & 0 & 0 & +1 \\
\hline Run_22 & 0 & -1 & -1 & 0 \\
\hline Run_23 & 0 & +1 & 0 & -1 \\
\hline Run_24 & -1 & 0 & +1 & 0 \\
\hline Run_25 & 0 & -1 & 0 & -1 \\
\hline
\end{tabular}

\subsection{SIMULATION RUNS}

After the simulation runs were designed, the next step was to build simulation file for each run. As it can be seen from the tables 6 and 7, we conducted 16 runs during screening stage and total number of simulation runs carried out during optimization stage were 25 including one centerpoint run.

Prepared simulation files were run while maintaining minimum BHP constraint of $80 \mathrm{psia}$ in producers whereas, maximum BHP constraint for injectors was changed as per the injection pressure parameter value in each simulation. The field was produced for 50 years' period. 
Each simulation run considered in the current study is a representation of a development scenario. Hence, in the context of our study, a development scenario denotes a simulation run.

\subsection{STUDY BASIS}

Results of any study need to be examined with respect to the study basis. Study basis defines the assumptions and the constraints of the analysis. Any changes in the assumptions or constraints lead to different output. Nevertheless, no analysis can be performed without setting boundaries in terms of assumptions. According to the authors, the study basis is rational based on presently available information in public domain.

The assumptions and constraints considered here just represent one of the possibilities, and therefore the analysis is not presented as the definitive solution, but rather a tool which would improve the understanding of the Umiat reservoir and development cost. With advent of technology, changing market scenario and availability of new data, it may be necessary to revise the study basis. Results and conclusions might change as a result of this.

Following are some of the crucial aspects of the study basis:

- Wagon-wheel pattern of wells has been considered for the well pattern optimization.

- It is assumed that only LGS is developed during Umiat field development.

- It is assumed during the study that the responses are continuous functions of input parameters. By continuous, we mean that the nature of the factors is such that they can take any value inside the specified range. In reality, number of wells can only take an integer value. The same applies to the producer/injector ratio.

- It is assumed that the gas will be available from nearby gas fields such as East Umiat field or Gubik field (Herriott et al., 2018). Figure 20 indicates the relative proximity of the gas fields from Umiat field. In the below Figure, number 23 indicates Umiat field whereas number 3 indicates East Umiat and number 5 indicates Gubik field (all locations circled in red). This can make injection gas availability logistically easy and at lower transportation cost. The composition of injected gas is assumed to be pure methane in the current study. 


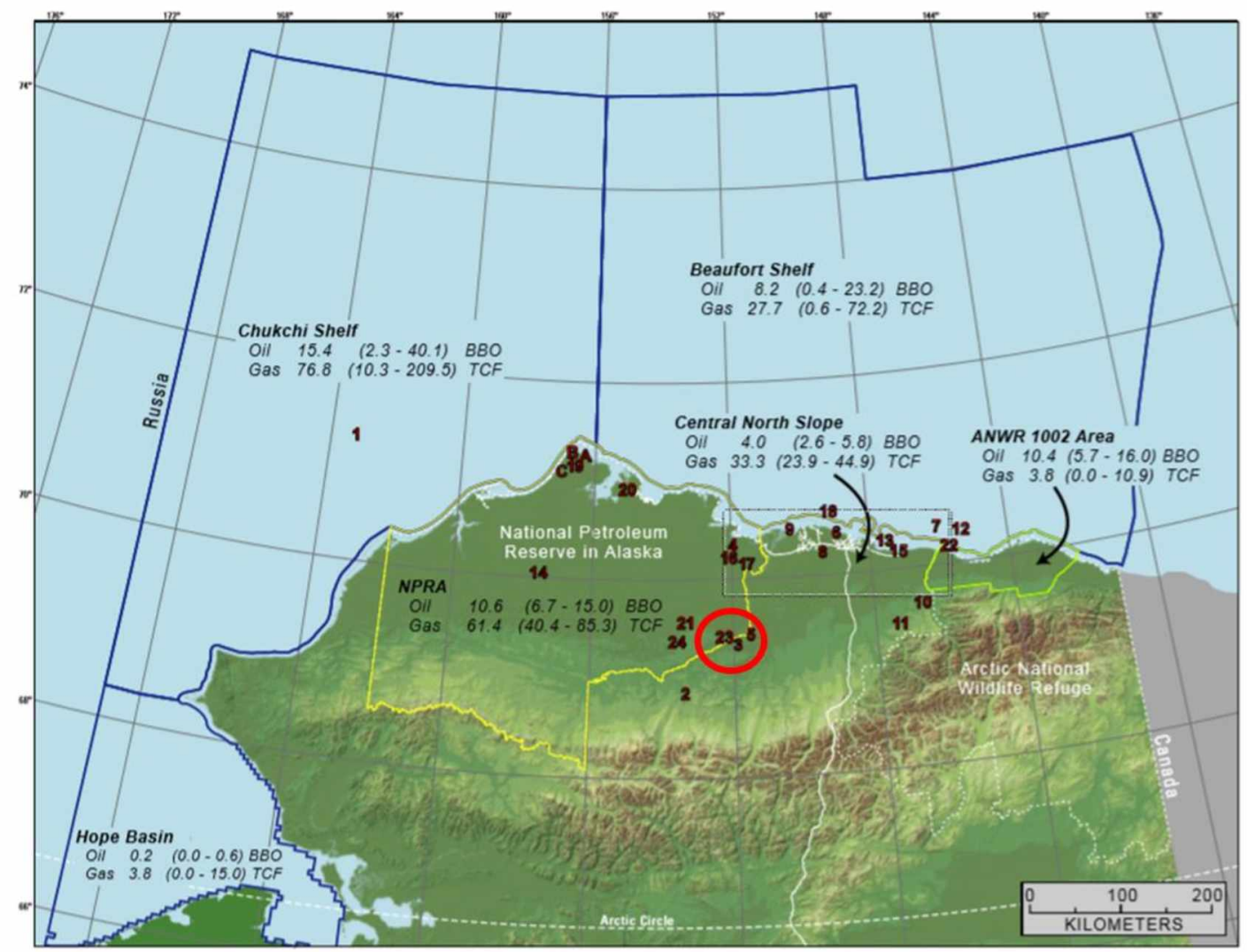

Figure 20: Location of Umiat, East Umiat and Gubik (Modified from Houseknecht and Bird, 2006)

- The analysis is performed as a comparative study of development costs. Development cost estimates are limited to the cost of construction of well pads, drilling wells as well as completion cost. Other capital expenses and operating expenses are not part of the current study. Transportation costs are also excluded.

- All cost estimates are performed with constant dollars and time value of money is not considered.

- Study boundaries are set by the design space which is bounded by the parameter ranges.

- The study assessment stops once the oil reaches the wellbore i.e. the study does not incorporate vertical flow performance and surface network performance. 


\section{Chapter 4: Result and Discussion}

Chapter 4 presents the results, associated analysis methods and the discussion. Section 4.1 gives an overview of how the methodology discussed previously is applied to obtain dependent variables viz. oil recovery and cost. Section 4.2 and 4.3 deal with analysis of simulation output obtained by applying screening and optimization designs. Section 4.4 presents the results and discussion.

\subsection{ESTIMATION OF DEPENDENT VARIABLES}

\subsubsection{Simulation Output}

As discussed in previous section, simulation runs were carried as per DoE designs. Factorial design was used during screening stage and table 6 was used to design simulation runs as per the suggested parameter levels. Table 8 provides the run-wise statistics of actual values of parameters corresponding to coded levels as well as simulation output used for analysis of screening runs. 
Table 8: Simulation results for analysis of screening runs

\begin{tabular}{|c|c|c|c|c|c|c|c|c|c|c|c|}
\hline Run\# & $\begin{array}{c}\text { Well length } \\
\text { (ft) }\end{array}$ & $\begin{array}{c}\text { No of } \\
\text { injectors/ } \\
\text { pad }\end{array}$ & $\begin{array}{l}\text { Ratio of } \\
\text { producers } \\
\text { to injectors }\end{array}$ & $\begin{array}{c}\text { Injection } \\
\text { Pressure } \\
\text { (Psia) }\end{array}$ & $\begin{array}{c}\text { No of } \\
\text { Producers/ } \\
\text { pad }\end{array}$ & $\begin{array}{c}\text { Wells/ } \\
\text { pad }\end{array}$ & $\begin{array}{l}\text { No of } \\
\text { pads }\end{array}$ & $\begin{array}{l}\text { Total } \\
\text { wells }\end{array}$ & $\begin{array}{l}\text { cumoil, } \\
\text { MMSTB }\end{array}$ & $\begin{array}{c}\% \\
\text { Recovery }\end{array}$ & $\begin{array}{c}\text { Development } \\
\text { Cost, MM } \\
\text { USD }\end{array}$ \\
\hline Run_1 & 1500 & 2 & 1 & 400 & 2 & 4 & 5 & 20 & 53 & 3.6 & $1.39 \mathrm{E}+03$ \\
\hline Run_2 & 1500 & 2 & 1 & 600 & 2 & 4 & 5 & 20 & 74 & 5.0 & $1.39 \mathrm{E}+03$ \\
\hline Run_3 & 1500 & 2 & 5 & 400 & 10 & 12 & 5 & 60 & 124 & 8.6 & $1.87 \mathrm{E}+03$ \\
\hline Run_4 & 1500 & 2 & 5 & 600 & 10 & 12 & 5 & 60 & 154 & 11.0 & $1.87 \mathrm{E}+03$ \\
\hline Run_5 & 1500 & 4 & 1 & 400 & 4 & 8 & 5 & 40 & 68 & 4.6 & $1.63 \mathrm{E}+03$ \\
\hline Run_6 & 1500 & 4 & 1 & 600 & 4 & 8 & 5 & 40 & 94 & 6.4 & $1.63 \mathrm{E}+03$ \\
\hline Run_7 & 1500 & 4 & 5 & 400 & 20 & 24 & 5 & 120 & 146 & 10.4 & $2.59 E+03$ \\
\hline Run_8 & 1500 & 4 & 5 & 600 & 20 & 24 & 5 & 120 & 183 & 13.4 & $2.59 \mathrm{E}+03$ \\
\hline Run_9 & 4500 & 2 & 1 & 400 & 2 & 4 & 3 & 12 & 58 & 3.9 & $1.02 \mathrm{E}+03$ \\
\hline Run_10 & 4500 & 2 & 1 & 600 & 2 & 4 & 3 & 12 & 81 & 5.5 & $1.02 \mathrm{E}+03$ \\
\hline$\overline{R u n \_11}$ & 4500 & 2 & 5 & 400 & 10 & 12 & 3 & 36 & 154 & 11.0 & $1.35 \mathrm{E}+03$ \\
\hline Run_12 & 4500 & 2 & 5 & 600 & 10 & 12 & 3 & 36 & 191 & 14.0 & $1.35 \mathrm{E}+03$ \\
\hline Run_13 & 4500 & 4 & 1 & 400 & 4 & 8 & 3 & 24 & 80 & 5.5 & $1.19 \mathrm{E}+03$ \\
\hline Run_14 & 4500 & 4 & 1 & 600 & 4 & 8 & 3 & 24 & 116 & 8.1 & $1.19 \mathrm{E}+03$ \\
\hline Run_15 & 4500 & 4 & 5 & 400 & 20 & 24 & 3 & 72 & 210 & 15.7 & $1.86 \mathrm{E}+03$ \\
\hline Run_16 & 4500 & 4 & 5 & 600 & 20 & 24 & 3 & 72 & 256 & 19.7 & $1.86 \mathrm{E}+03$ \\
\hline
\end{tabular}


Figure 21 presents histogram for ultimate oil recovery from all screening runs.

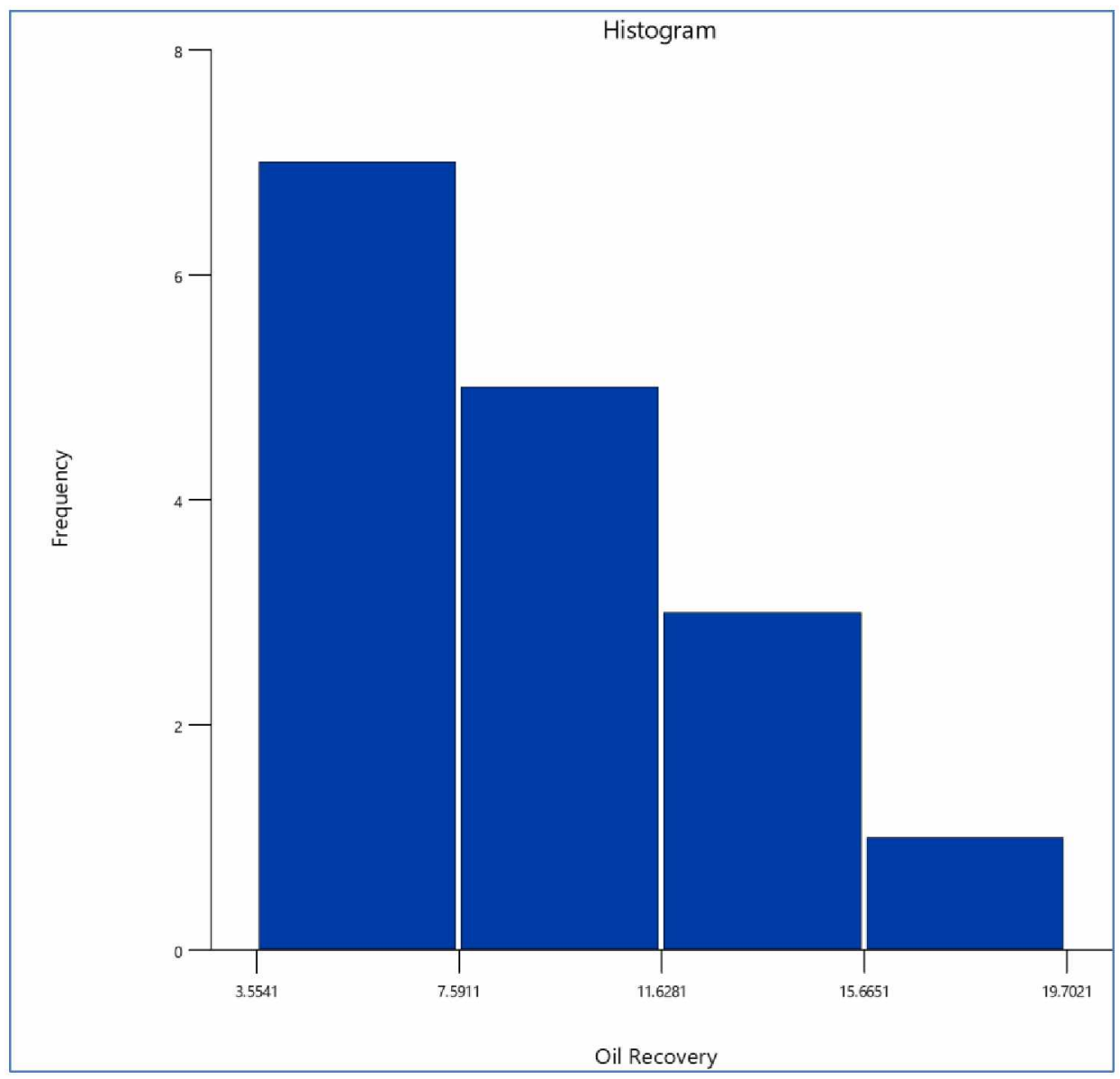

Figure 21: Screening runs histogram- oil recovery $(\%)$

Box Behnken design was used during optimization stage and table 7 was used to design simulation runs as per the suggested parameter levels. Table 9 provides the runwise statistics of actual values of parameters corresponding to coded levels as well as simulation output used for analysis of optimization runs. 
Table 9: Simulation results for analysis of optimization runs

\begin{tabular}{|l|c|c|c|c|c|c|c|c|c|c|}
\hline Run \# & $\begin{array}{c}\text { Well } \\
\text { length } \\
\text { (ft) }\end{array}$ & $\begin{array}{c}\text { No of } \\
\text { injectors/pad }\end{array}$ & $\begin{array}{c}\text { Ratio of } \\
\text { producers } \\
\text { to injectors }\end{array}$ & $\begin{array}{c}\text { Injection } \\
\text { Pressure } \\
\text { (Psia) }\end{array}$ & $\begin{array}{c}\text { No of } \\
\text { Producers/pad }\end{array}$ & Wells/pad & $\begin{array}{c}\text { No of } \\
\text { pads }\end{array}$ & $\begin{array}{c}\text { Total } \\
\text { wells }\end{array}$ & $\begin{array}{c}\text { \% } \\
\text { recovery }\end{array}$ & $\begin{array}{c}\text { Development } \\
\text { Cost, MM } \\
\text { USD }\end{array}$ \\
\hline Run 1 & 4500 & 4 & 1 & 400 & 4 & 8 & 3 & 24 & 4.7 & $1.09 \mathrm{E}+03$ \\
\hline Run 2 & 4500 & 2 & 3 & 400 & 6 & 8 & 3 & 24 & 6.8 & $1.09 \mathrm{E}+03$ \\
\hline Run 3 & 4500 & 6 & 3 & 400 & 18 & 24 & 3 & 72 & 11.7 & $1.76 \mathrm{E}+03$ \\
\hline Run 4 & 7500 & 2 & 3 & 350 & 6 & 8 & 2 & 16 & 7.2 & $8.56 \mathrm{E}+02$ \\
\hline Run 5 & 1500 & 2 & 3 & 350 & 6 & 8 & 5 & 40 & 5.1 & $1.53 \mathrm{E}+03$ \\
\hline Run 6 & 7500 & 6 & 3 & 350 & 18 & 24 & 2 & 48 & 13.1 & $1.37 \mathrm{E}+03$ \\
\hline Run 7 & 7500 & 4 & 3 & 300 & 12 & 16 & 2 & 32 & 10.4 & $1.11 \mathrm{E}+03$ \\
\hline Run 8 & 1500 & 6 & 3 & 350 & 18 & 24 & 5 & 120 & 8.1 & $2.49 \mathrm{E}+03$ \\
\hline Run 9 & 4500 & 6 & 1 & 350 & 6 & 12 & 3 & 36 & 6.5 & $1.25 \mathrm{E}+03$ \\
\hline Run 10 & 4500 & 4 & 5 & 300 & 20 & 24 & 3 & 72 & 10.9 & $1.76 \mathrm{E}+03$ \\
\hline Run 11 & 4500 & 6 & 5 & 350 & 30 & 36 & 3 & 108 & 14.9 & $2.56 \mathrm{E}+03$ \\
\hline Run 12 & 4500 & 4 & 1 & 300 & 4 & 8 & 3 & 24 & 3.8 & $1.09 \mathrm{E}+03$ \\
\hline Run 13 & 1500 & 4 & 3 & 400 & 12 & 16 & 5 & 80 & 9.7 & $2.01 \mathrm{E}+03$ \\
\hline Run 14 & 4500 & 2 & 5 & 350 & 10 & 12 & 3 & 36 & 8.7 & $1.25 \mathrm{E}+03$ \\
\hline Run 15 & 1500 & 4 & 1 & 350 & 4 & 8 & 5 & 40 & 3.6 & $1.53 \mathrm{E}+03$ \\
\hline Run 16 & 7500 & 4 & 5 & 350 & 20 & 24 & 2 & 48 & 14.2 & $1.37 \mathrm{E}+03$ \\
\hline Run 17 & 4500 & 4 & 3 & 350 & 12 & 16 & 3 & 48 & 12.6 & $1.42 \mathrm{E}+03$ \\
\hline Run 18 & 7500 & 4 & 1 & 350 & 4 & 8 & 2 & 16 & 5.9 & $8.56 \mathrm{E}+02$ \\
\hline Run 19 & 4500 & 4 & 5 & 400 & 20 & 24 & 3 & 72 & 12.6 & $1.76 \mathrm{E}+03$ \\
\hline Run 20 & 1500 & 4 & 3 & 300 & 12 & 16 & 5 & 80 & 8.6 & $2.01 \mathrm{E}+03$ \\
\hline Run 21 & 7500 & 4 & 3 & 400 & 12 & 16 & 2 & 32 & 11.7 & $1.11 \mathrm{E}+03$ \\
\hline Run 22 & 4500 & 2 & 1 & 350 & 2 & 4 & 3 & 12 & 3.0 & $9.18 \mathrm{E}+02$ \\
\hline Run 23 & 4500 & 6 & 3 & 300 & 18 & 24 & 3 & 72 & 10.3 & $1.76 \mathrm{E}+03$ \\
\hline Run 24 & 1500 & 4 & 5 & 350 & 20 & 24 & 5 & 120 & 8.4 & $2.49 \mathrm{E}+03$ \\
\hline Run 25 & 4500 & 2 & 3 & 300 & 6 & 8 & 3 & 24 & 5.7 & $1.09 \mathrm{E}+03$ \\
\hline
\end{tabular}


Figure 22 and Figure 23 present histogram for ultimate oil recovery and development cost respectively, from all optimization runs.

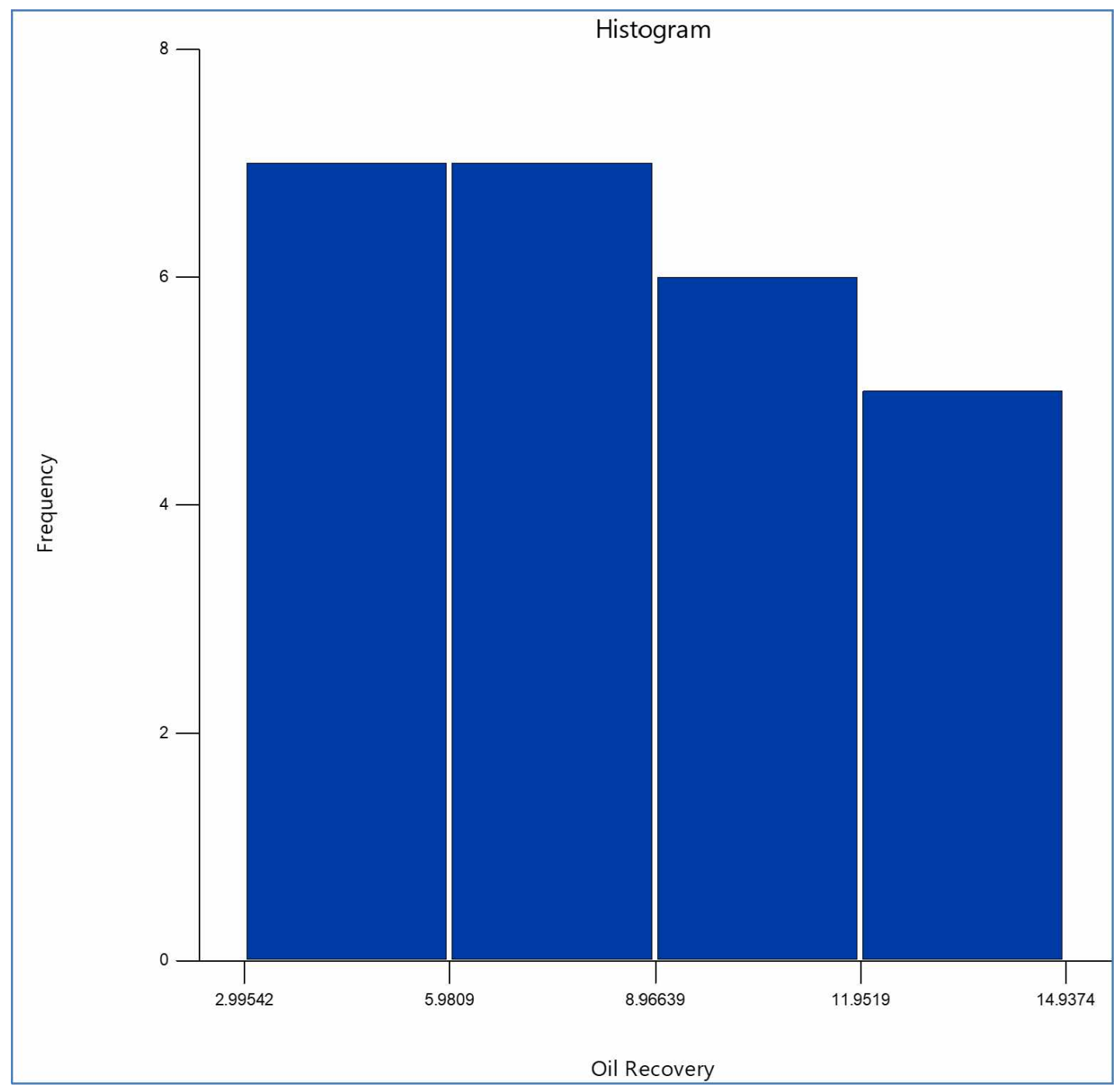

Figure 22: Optimization runs histogram- oil recovery $(\%)$ 


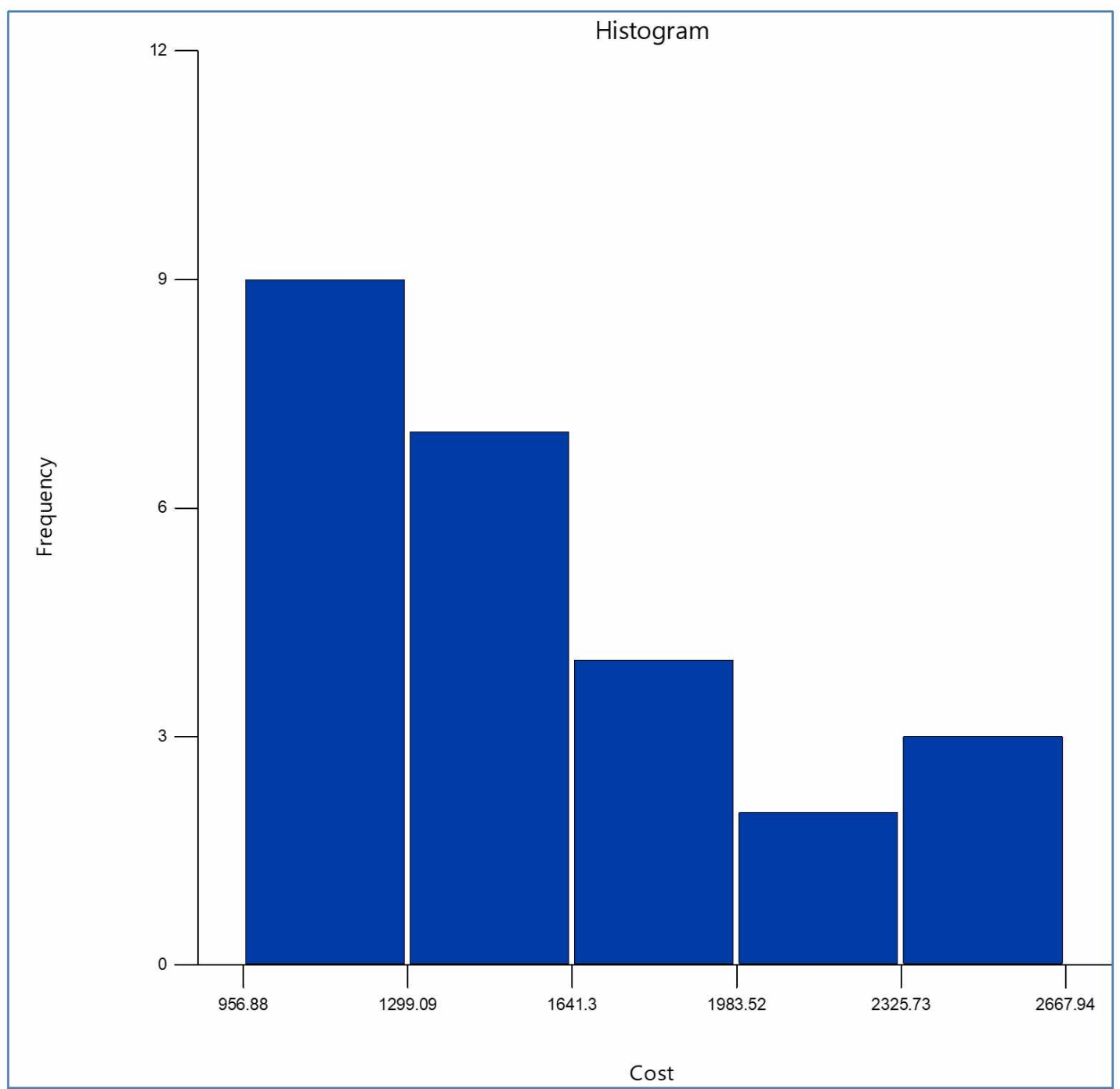

Figure 23: Optimization runs histogram- development cost (MM USD)

In screening analysis, the oil recovery ranged from 3.4 to $19.7 \%$ (table 8), while in optimization analysis, this range narrowed down to 3 to $14.9 \%$ (table 9 ). This difference can be attributed to higher injection pressure range and the single injection pressure value being used for both sands in the screening analysis. At the same time, development cost varied between $1 * 10^{3}$ to $2.6^{*} 10^{3}$ MM USD during screening analysis (table 8). During optimization study, this range increased slightly with $0.9^{*} 10^{3}$ to $2.7^{*} 10^{3}$ MM USD (table 9). Although, well length increases from screening analysis to optimization analysis, well cost is significantly low in comparison with well pad cost. Thus, we can see that increasing well length does not affect the total cost greatly. 
The change in input parameters range from screening analysis to optimization analysis, shows a change from theoretical to practical constraints making it more realistic and hence achievable in the field.

\subsubsection{Economic Consideration}

Economic models are a representation of real economic scenarios and provide approximate relationship between different components in the economic system. General direction can be obtained through the modeling; however, any kind of quantification is highly uncertain due to high uncertainty in input parameters such as oil price. An economic analysis is performed to evaluate the commerciality of the project. In oil and gas industry, this means to assess whether a particular field can be developed with satisfactory return on investment.

Remoteness of accumulations from the TAPS, harsh weather of the Arctic and the lack of infrastructure generally results in higher exploration and development costs in Alaska than rest of the USA locations. It is assumed that with wagon-wheel pattern of wells using pad drilling, the development cost in Umiat is considerably lowered.

Since this analysis involves comparing different development scenarios (represented by different simulation runs), comparative cost analysis is performed to assess the economic impact of different scenarios on the total cost. Only the development cost is considered as almost all other costs such as exploration and operating costs will remain fairly constant through different scenarios. Development cost consists of costs of drilling wells, construction of surface facilities and transport infrastructure. Transport infrastructure cost remains almost the same for all scenarios, hence, the deciding factors in cost estimates in current analysis are well cost and drilling pad cost. During optimization analysis, one of the objectives would be to minimize the costs. Understandably, scenarios with the lowest cost will be favored if only the objective function of cost has to be considered for optimization.

Table 10 summarizes well cost estimates using suitable assumptions (Oil Search Limited, October 2018). These costs include drilling and completion costs. 
Table 10: Well drilling cost estimates

\begin{tabular}{|c|c|}
\hline Well length, ft & $\begin{array}{r}\text { Drilling and completion } \\
\text { cost, Millions USD }\end{array}$ \\
\hline $1500 \mathrm{ft}$ & 12 \\
\hline $4500 \mathrm{ft}$ & 14 \\
\hline $7500 \mathrm{ft}$ & 16 \\
\hline
\end{tabular}

In absence of any substantial data on pad construction cost in public domain, an educated guess was made after having a detailed discussion with industry professionals working in Alaska. Table 11 provides estimates of pad construction cost. This shows that, as the well length changes, total cost of pads associated with it also changes and in turn affects development cost.

Table 11: Pad construction cost estimates

\begin{tabular}{|c|c|}
\hline Pad size & Pad construction cost, Millions USD \\
\hline Small ( $<25$ wells $)$ & 150 \\
\hline Large $(>25$ wells $)$ & 250 \\
\hline
\end{tabular}

Cold gas injection is considered in the current study for pressure maintenance and injection pressure is one of the parameters whose effect on the oil recovery is assessed. However, gas injection facility does not change significantly from case to case, hence, gas injection cost is assumed to be constant for all simulation runs. Thus, it is excluded from the comparative cost analysis.

As per the United States Geological Survey (USGS) report, very little information on facilities cost is available in public domain (Attanasi and Freeman, 2009). Consequently, appropriate approximations were made while estimating the development costs.

Construction cost of pads for facilitating drilling and providing support for production facilities can be estimated for individual development scenarios. The total number of pads is a function of well length. As the well length increases, it increases the reservoir contact and reduces 
the number of pads. Once the number of pads is determined for each development scenario (i.e. optimization simulation runs), cost of pad construction per pad is used to determine the total pad construction cost.

For estimating well drilling and completion cost, the number of wells for each simulation run needs to be determined first. Number of wells is the total of producers and injectors. The number of producers is calculated by using the number of injectors/pad and the producer/injector ratio. Depending upon the number of wells and the well length, the drilling cost will be different for different development scenarios.

The break-up of the development investment considered in Umiat field is as follows:

Table 12: Development cost components

\begin{tabular}{|l|l|}
\hline Type of expense & Expense, MM USD \\
\hline Construction of well pads & $\begin{array}{l}\text { Changes as per the development } \\
\text { scenario }\end{array}$ \\
\hline $\begin{array}{l}\text { Company cost (Project management, } \\
\text { supervision, studies, preliminary } \\
\text { work and insurance) }\end{array}$ & 180 (Bret-Rouzaut and Favennec, 2011) \\
\hline Provisions & 120 (Bret-Rouzaut and Favennec, 2011) \\
\hline Wells Drilling and Completion & $\begin{array}{l}\text { Changes as per the development } \\
\text { scenario }\end{array}$ \\
\hline
\end{tabular}


Figure 24 shows break-up of development cost for run-4 of Optimization analysis. The development scenario considers well length of $7500 \mathrm{ft}$ which leads to the requirement of two well pads.

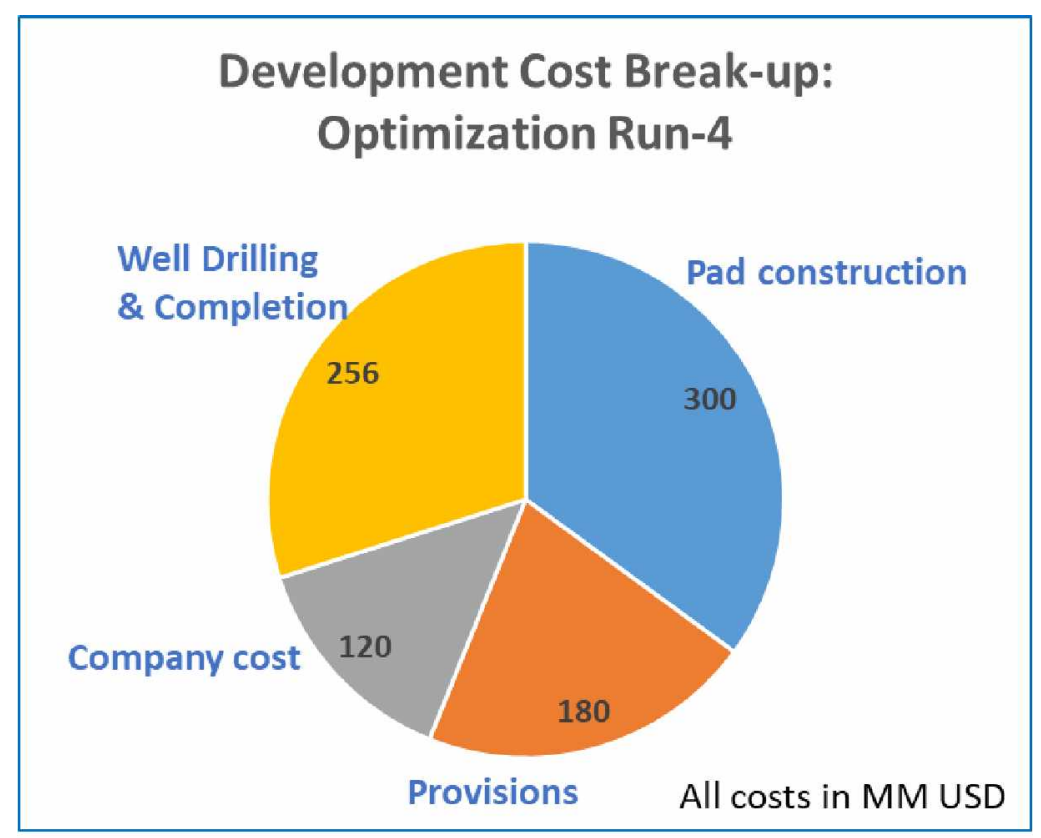

Figure 24: Development cost break-up: Optimization run-4 
Figure 25 shows break-up of development cost for run-5 of Optimization analysis. The development scenario considers well length of $1500 \mathrm{ft}$ which leads to the requirement of five well pads. All other parameters except well length remain the same for run- 4 andrun-5.

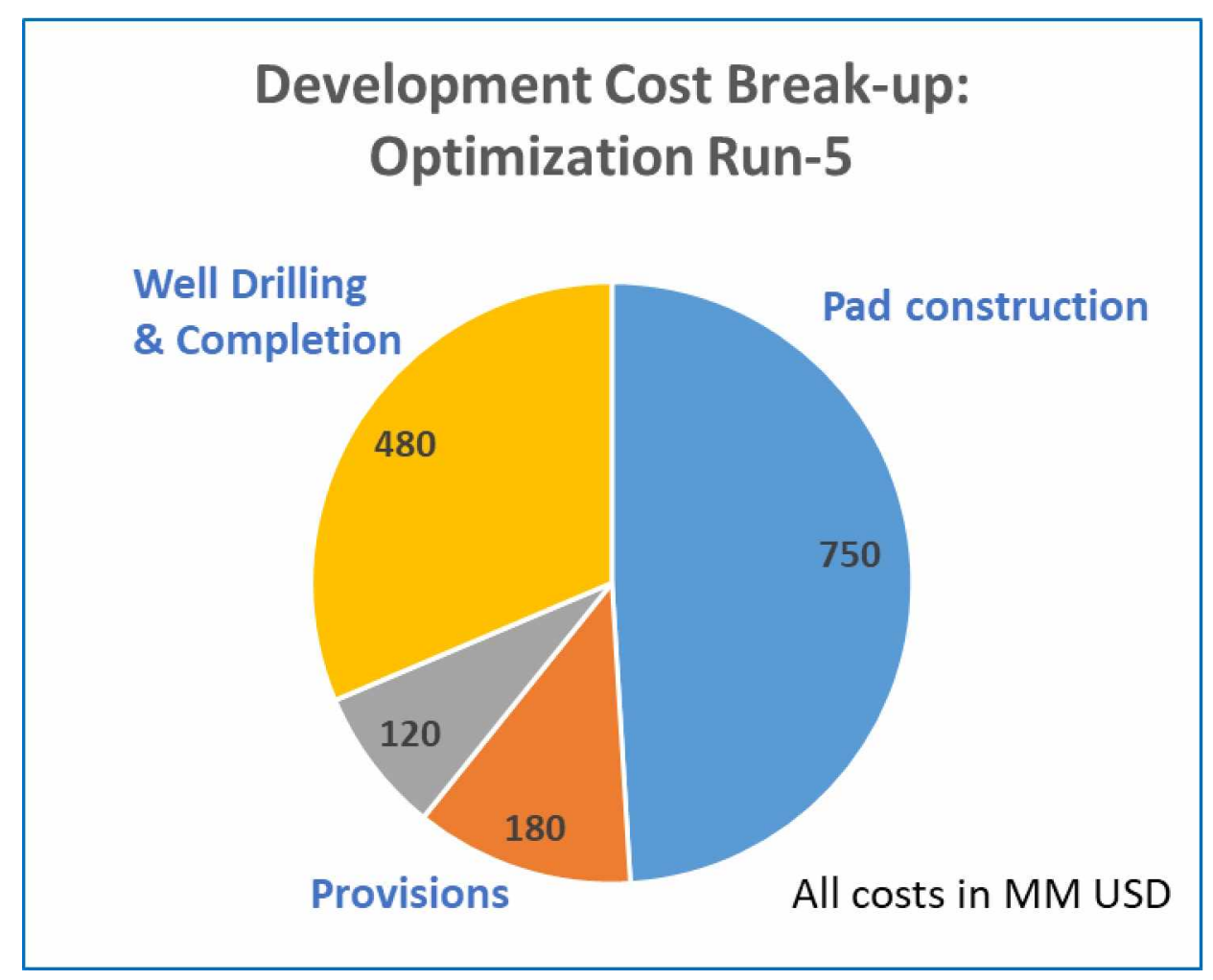

Figure 25: Development cost break-up: Optimization run-5

The total development cost of run-4 is 857 MM USD (well length $7500 \mathrm{ft}$ and two pads) and that of run-5 is 1530 MM USD (well length $1500 \mathrm{ft}$ and five pads). It is clear from the two scenarios that the major component of the development cost is well pad cost. Hence, any reduction in the drilling pads will hugely reduce the development cost. The next biggest reduction in development cost can be achieved by reducing the well drilling cost. 


\subsection{ANALYSIS OF SCREENING RUNS}

To analyse the screening runs, we performed an Analysis of Variance (ANOVA) on the simulation results obtained by applying factorial design on the parameters with predefined range. This analysis was performed to inspect the significance of different parameters on the oil recovery.

The ANOVA is performed to divide the total variance in the data into variance due to random error and variance due to changes in the values of independent variables.

The sum of squares is the summation of the squares of the differences from the mean. The total sum of squares (SS) is the summation of treatment sum of squares (SST) and the residual error sum of squares (SSE).

The total sum of squares $=$ treatment sum of squares $(\mathrm{SST})+$ sum of squares of the residual error (SSE)

When the sum of squares is divided by the degree of freedom, we get mean squares which indicates how significant a factor is. The larger the mean square, the bigger the effect of the treatment.

One of the ways to represent ANOVA model mathematically is as follows:

$$
Y_{i j k}=\mu+\alpha_{i}+\beta_{i}+E_{i j k}
$$

Where,

Subscript i- level of factor 1

Subscript $\mathrm{j}$ - factor 2

Subscript k- kth observation in the $(\mathrm{i}, \mathrm{j})$ th cell

The predicted values and residuals of the model are given by following equations,

$$
\begin{gathered}
\hat{Y}_{i j k}=\hat{\mu}+\hat{\alpha}_{i}+\hat{\beta}_{j} \ldots \ldots \ldots \ldots \ldots \\
R_{i j k}=Y_{i j k}-\hat{\mu}-\hat{\alpha}_{i}-\hat{\beta}_{j}
\end{gathered}
$$

Where, $\alpha^{\wedge} i$ - effect of ith level of factor 1

$\beta^{\wedge} j$ - effect of $j$ th level of factor 2 
F test is used in ANOVA to achieve the factor effects, which is named after its test statistic, F. The F statistic is simply a ratio of two variances. Variance is used to indicate the scatter in the data with respect to the mean. F statistic can be determined by dividing the mean square for the factor by the residual mean square. This statistic follows a probability distribution with (k-1) and (N-k) degrees of freedom where $\mathrm{k}$ is the number of levels for any factor.

Table 13 shows $F$ test results of the DoE runs. The model $F$ value is 55.09 indicating that the model is significant. There is only $0.01 \%$ chance that this high value of $\mathrm{F}$ could be due to noise.

Table 13: Analysis of Variance (ANOVA): Screening

\begin{tabular}{|l|c|c|c|c|c|c|}
\hline \multicolumn{1}{|c|}{ Source } & $\begin{array}{c}\text { Sum of } \\
\text { Squares }\end{array}$ & df & $\begin{array}{c}\text { Mean } \\
\text { Square }\end{array}$ & Fvalue & p-value & \\
\hline Model & 324.09 & 5 & 64.82 & 55.09 & $<0.0001$ & significant \\
\hline A-Well Length & 26.00 & 1 & 26.00 & 22.10 & 0.0008 & \\
\hline $\begin{array}{l}\text { B-No of } \\
\text { Injectors/pad }\end{array}$ & 27.76 & 1 & 27.76 & 23.59 & 0.0007 & \\
\hline $\begin{array}{l}\text { C- } \\
\text { Producer/Injector } \\
\text { Ratio }\end{array}$ & 234.25 & 1 & 234.25 & 199.07 & $<0.0001$ & \\
\hline $\begin{array}{l}\text { D-Injection } \\
\text { Pressure }\end{array}$ & 24.74 & 1 & 24.74 & 21.02 & 0.0010 & \\
\hline AC & 11.35 & 1 & 11.35 & 9.64 & 0.0112 & \\
\hline Residual & 11.77 & 10 & 1.18 & & & \\
\hline Cor Total & 335.86 & 15 & & & & \\
\hline
\end{tabular}

All four factors, namely well length (A), number of injectors/pad (B), producer/injector ratio (C) and injection pressure (D) and interaction of well length and number of injectors/pad (AC) are significant at $5 \%$ confidence interval, considering their p-value is less than 0.05 .

We need to validate the model further and following plots are used for examination. 
1. A normal probability plot of residuals (Figure 26) is approximately linear, indicating that errors are normally distributed with one outlier.

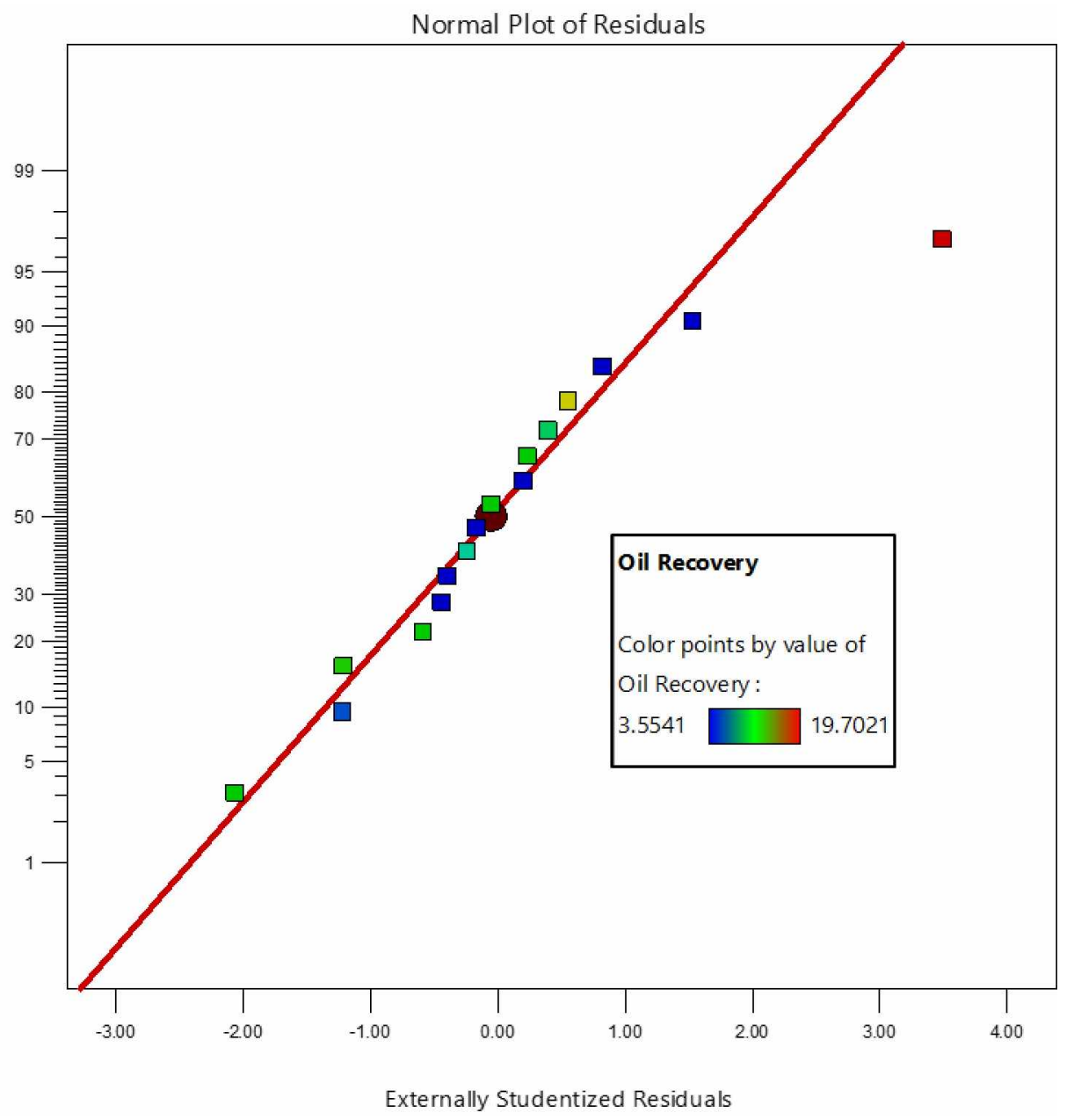

Figure 26: Normal probability plot of residuals- Oil recovery (Screening) 
2. A scatter plot of the predicted values against the residuals (Figure 27) shows a random pattern, indicating a good fit.

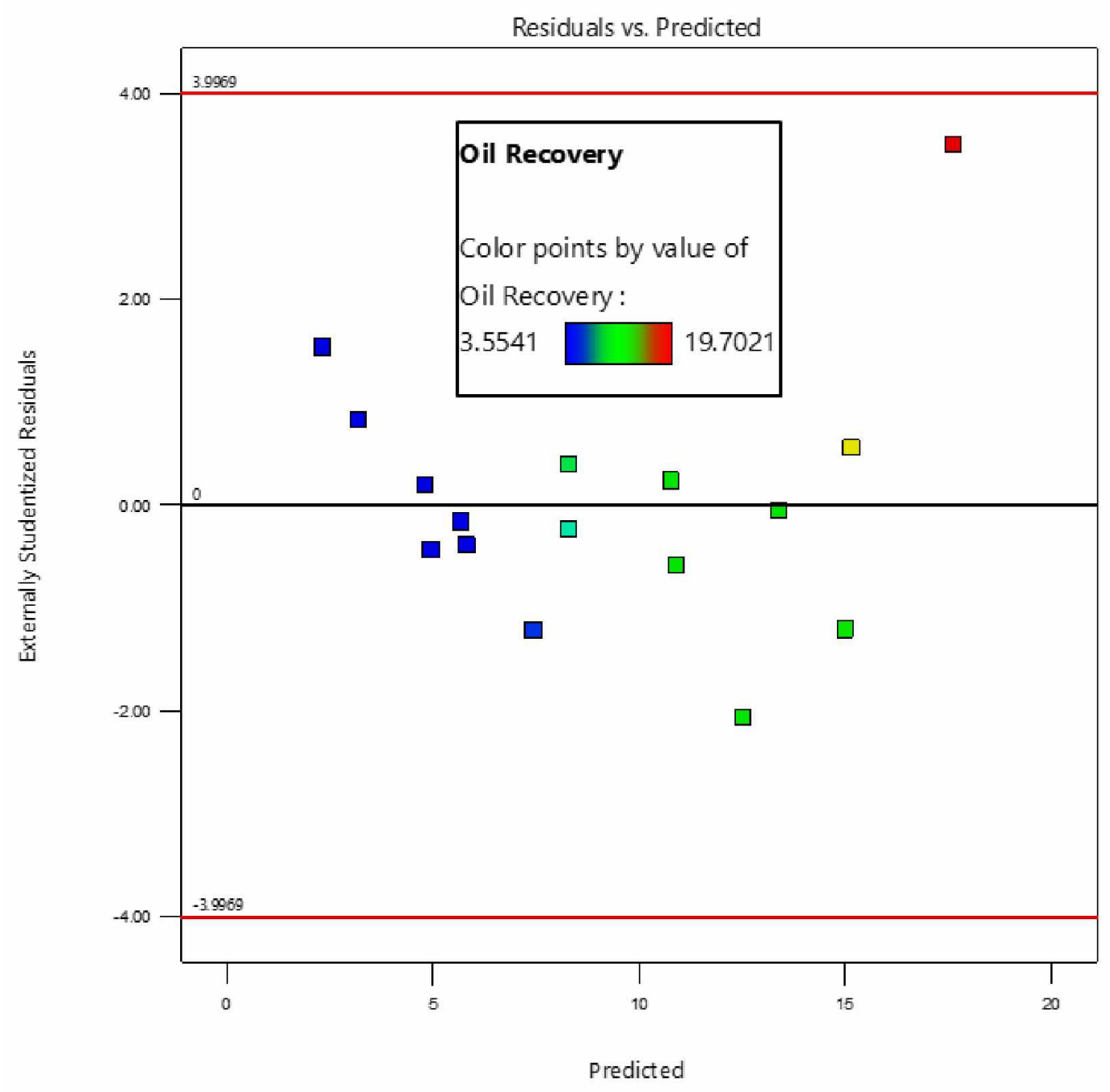

Figure 27: Residuals vs predicted- Oil recovery (Screening) 
3. Figure 28 exhibits predicted versus actual oil recovery for screening runs. The plot shows a good match between actual and simulated values. Simulated values are obtained from 16 simulation runs in screening analysis.

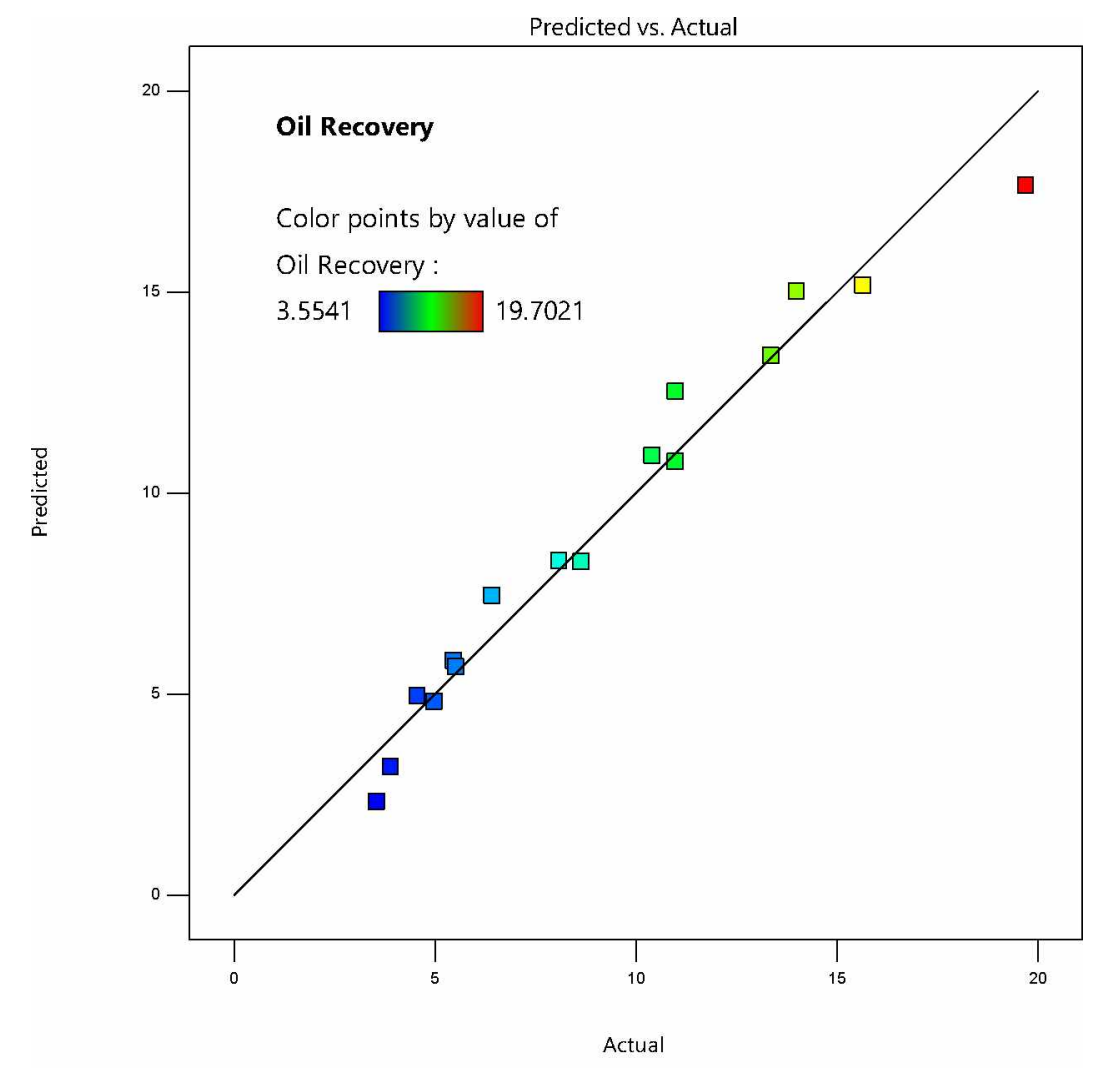

Figure 28: Predicted vs Simulated- Oil recovery (Screening)

\section{Main effects plot for oil recovery (Figure 29)}

The main effect is when different levels of a factor affect the response differently. The plot indicating the response mean at different levels of a factor is called a main effect plot. The response means at different levels of a factor are connected by a line. As the angle of the line from horizontal increases, the magnitude of the main effect increases. Also, if the response mean increases with increase in factor level, the effect is called a positive effect. Similarly, inverse relationship between the response mean and the factor indicates a negative effect.

The main effects chart for oil recovery shows dependency of oil recovery on all parameters due to presence of slanted lines and absence of horizontal lines (Figure 29). No negative effects can be observed. It also indicates that producer/injector ratio is the most significant parameter. 
Factors such as well length, number of injectors/pad and injection pressure have almost similar main effect, which is smaller than that of producer/injector ratio.

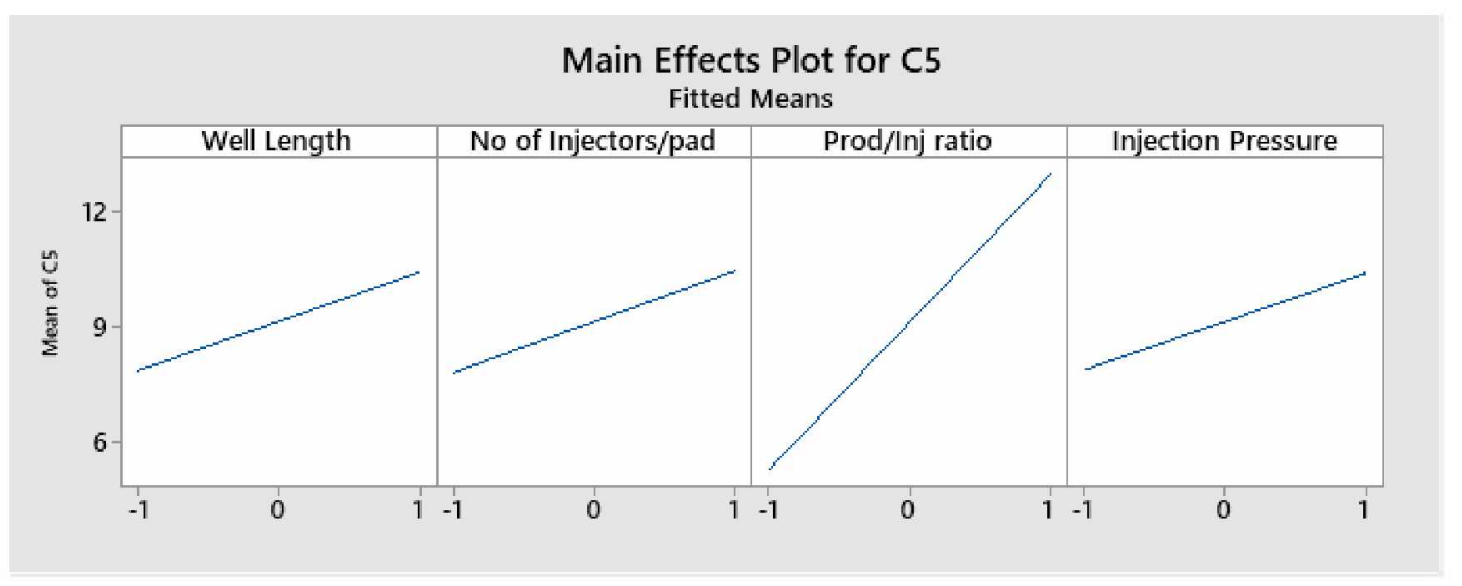

Figure 29: Main Effects Plot for Oil Recovery

\section{Pareto chart for standardized effects (Figure 30)}

The Pareto chart displays the absolute values of the standardized effects from the largest effect to the smallest effect. We can determine magnitude and importance of the effects from this plot. The reference line for statistical significance is determined by the significance level.

All main effects cross the reference line in Figure 30; hence all main effects are significant The dotted reference line of 2.2 corresponds to the critical t-value at confidence interval of $95 \%$. Any parameter having effect greater than 2.2 is considered significant. Magnitudes of standardized effects from the chart in the decreasing order are as follows:

Producer/Injector ratio- 10.54

Number of injectors/pad- 3.7

Well length- 3.5

Injection pressure- 3.4 


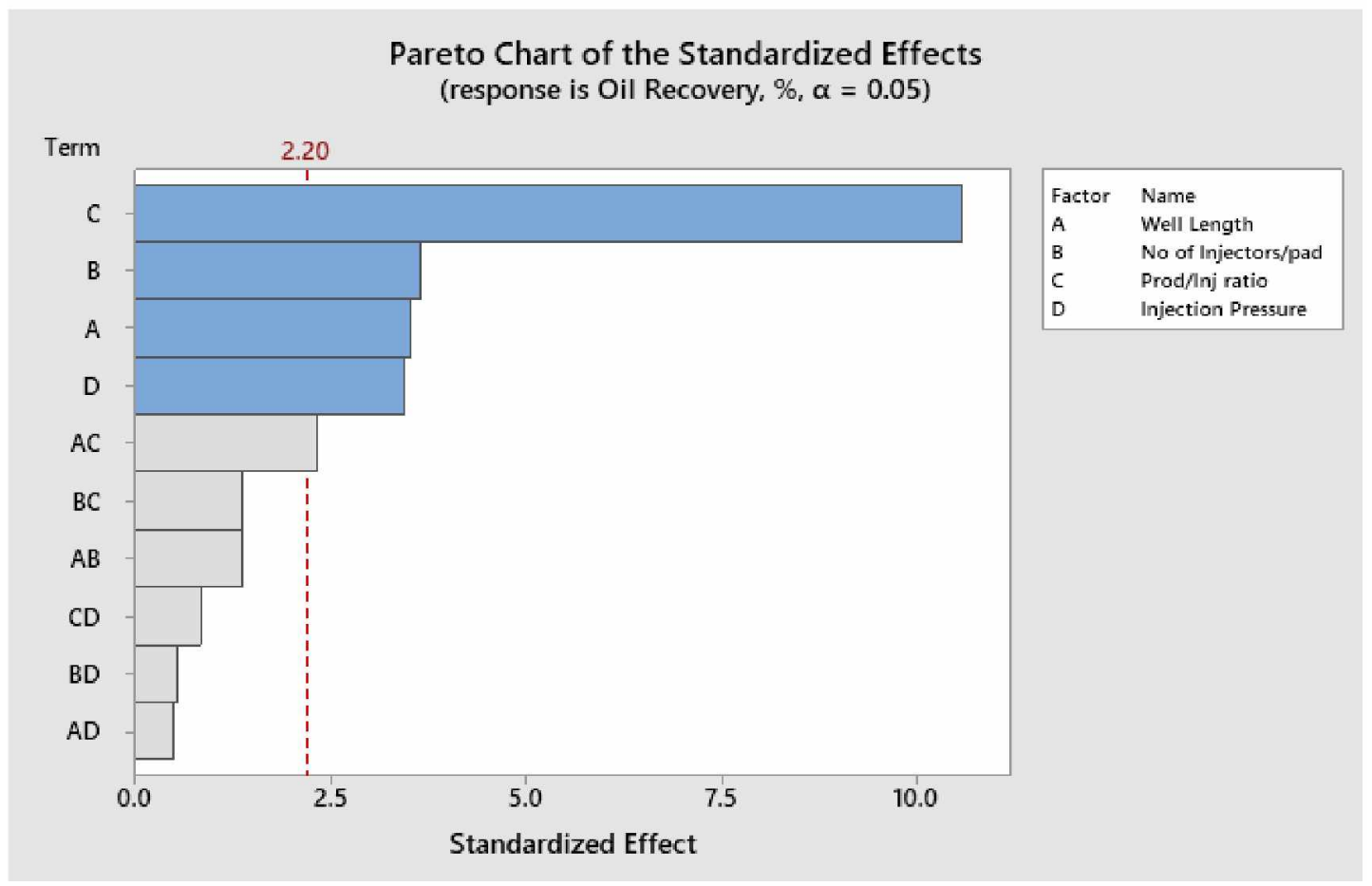

Figure 30: Pareto chart of the standardized effects

\section{Interaction plot}

Interaction plot is nothing but a visual representation of the interaction between two factors. If the lines in the plot are parallel, no interaction exists. If the lines are non-parallel, interaction is present. The more non-parallel lines become, greater the interaction.

Interaction plot for oil recovery (Figure 31) indicates that factor $\mathrm{C}$ (producer/injector ratio) shows the biggest interaction with factor A (well length) and factor B (No. of injectors/pad). Also, interaction between well length and injection pressure is negligible. 


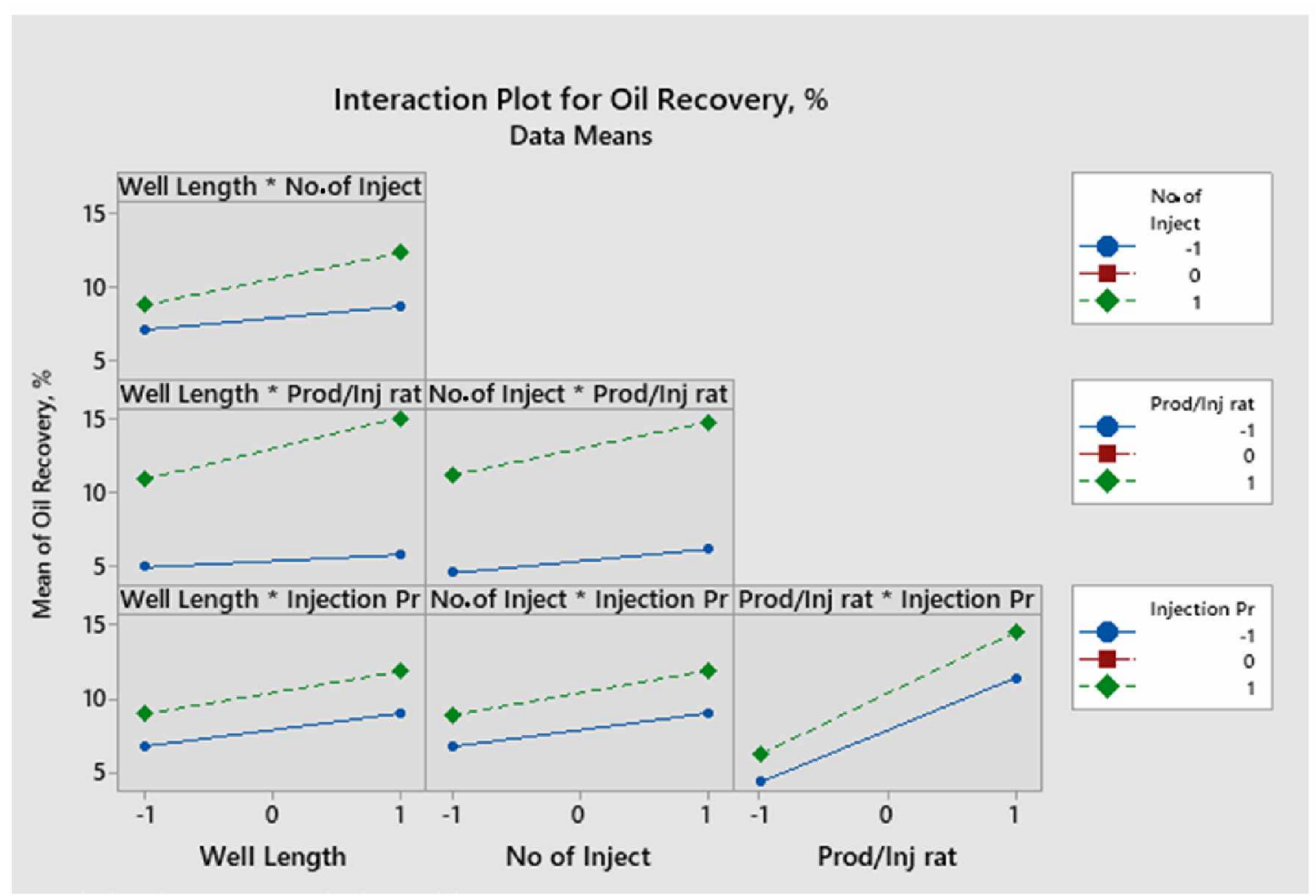

Figure 31: Interaction plot for oil recovery

\section{Normal plot of standardized effects}

The normal probability plot displays the standardized effects relative to a distribution fit line when all the effects are 0 . The effects away from zero standardized effect line are significant.

It can be observed in Figure 32 that all main effects are statistically significant at 0.05 level of $\alpha$ (confidence interval of $95 \%$ ) and have a positive effect. 


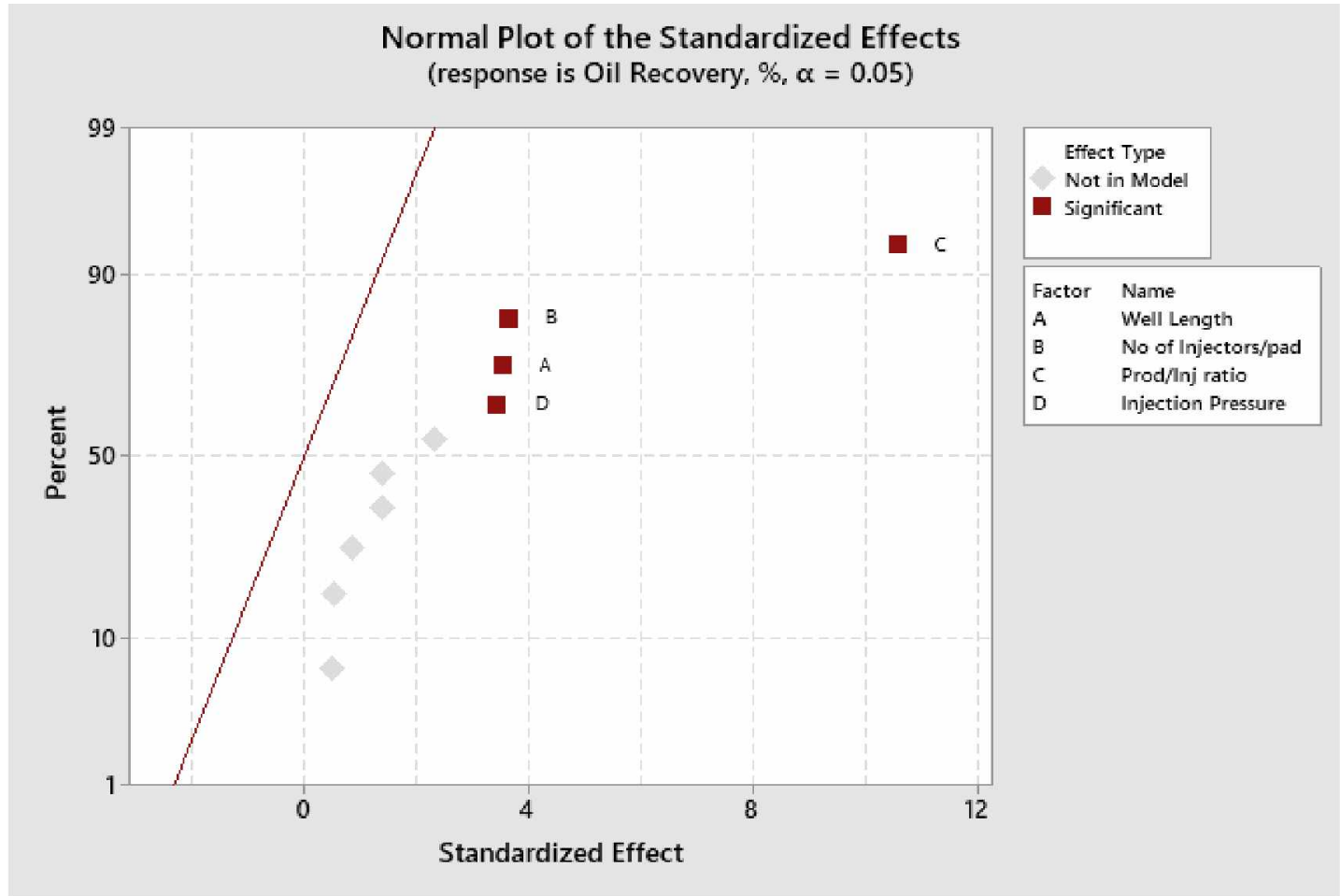

Figure 32: Normal plot of standardized effects

As we can see that all factors are significant, no factor was eliminated while designing optimization runs.

\subsection{ANALYSIS OF OPTIMIZATION RUNS}

\subsubsection{Regression Model}

Regression analysis is a statistical approach to estimate change in the response variable corresponding to changes in the input variables or input parameters and generates a mathematical equation. It was applied on the oil recovery (simulation output) and corresponding development cost separately.

The regression models obtained from the analysis are shown below (Equation 6 and 7 for oil recovery and development cost respectively)-

$$
\begin{aligned}
& \text { Oil Recovery, } \%=12.580+1.582 \mathrm{~A}+2.351 \mathrm{~B}+3.513 \mathrm{C}+0.618 \mathrm{D}-1.609 \mathrm{~A} * \mathrm{~A}- \\
& 2.230 \mathrm{~B} * \mathrm{~B}-2.700 \mathrm{C} * \mathrm{C}-1.509 \mathrm{D} * \mathrm{D}+0.749 \mathrm{~A} * \mathrm{~B}+0.865 \mathrm{~A} * \mathrm{C}+0.045 \mathrm{~A} * \\
& \mathrm{D}+0.693 \mathrm{~B} * \mathrm{C}+0.077 \mathrm{~B} * \mathrm{D}+0.174 \mathrm{C} * \mathrm{D}
\end{aligned}
$$




$$
\begin{aligned}
& \text { Development Cost, Millions USD } \\
& \qquad \begin{aligned}
& 1524.6-450.3 \mathrm{~A}+373.1 \mathrm{~B}+373.1 \mathrm{C}-0.0 \mathrm{D}+126.9 \mathrm{~A} * \mathrm{~A} \\
& +25.0 \mathrm{~B} * \mathrm{~B}+25.0 \mathrm{C} * \mathrm{C}-12.5 \mathrm{D} * \mathrm{D}-112.7 \mathrm{~A} * \mathrm{~B}-112.7 \mathrm{~A} * \mathrm{C} \\
& -0.0 \mathrm{~A} * \mathrm{D}+243.7 \mathrm{~B} * \mathrm{C}+0.0 \mathrm{~B} * \mathrm{D}+0.0 \mathrm{C} * \mathrm{D}
\end{aligned}
\end{aligned}
$$

Note that above equations are applicable to coded levels of factors.

Below table 14 and table 15 show fit summary of oil recovery function and cost function, respectively. For both functions, quadratic model was selected over linear model as it is desirable to select a higher order polynomial to be able to model the response surface adequately. Also, the cubic model was aliased, so it is not advisable to use this model. As seen in the below tables, for both oil recovery and cost quadratic model has an adjusted $\mathrm{R}^{2}$ of greater than 0.9 , which is very high and indicates that the model fits well in both cases. (It is recommended to use adjusted $\mathrm{R}^{2}$ in case of multivariate regression as it takes only significant terms into account and hence more reliable indicator of model's health).

Table 14: Fit summary (Oil Recovery)

\begin{tabular}{|c|c|c|c|c|}
\hline Model Type & $\begin{array}{c}\text { Sequential } \\
\mathrm{p} \text {-value }\end{array}$ & Adjusted $\mathrm{R}^{2}$ & Predicted $\mathrm{R}^{2}$ & \\
\hline Linear & $<0.0001$ & 0.8411 & 0.8158 & \\
\hline Quadratic & $\mathbf{0 . 0 0 4 6}$ & $\mathbf{0 . 9 7 3 3}$ & & Selected \\
\hline Cubic & 0.9787 & 0.8020 & & Aliased \\
\hline
\end{tabular}

Table 15: Fit summary (Development Cost)

\begin{tabular}{|c|c|c|c|c|}
\hline Model Type & $\begin{array}{c}\text { Sequential p- } \\
\text { value }\end{array}$ & Adjusted $\mathrm{R}^{2}$ & ${\text { Predicted } \mathrm{R}^{2}}$ & \\
\hline Linear & $<0.0001$ & 0.9111 & 0.8828 & \\
\hline Quadratic & $\mathbf{0 . 0 0 2 0}$ & $\mathbf{0 . 9 8 8 4}$ & $\mathbf{0 . 9 3 5 6}$ & Selected \\
\hline Cubic & 0.6815 & 0.9856 & & Aliased \\
\hline
\end{tabular}


Regression model statistics is given in the below table for both oil recovery and cost.

Table 16: Regression model statistics

\begin{tabular}{|l|l|c|}
\hline & Oil Recovery, \% & $\begin{array}{c}\text { Development } \\
\text { Cost, Million USD }\end{array}$ \\
\hline Std Deviation & 0.8753 & 54.91 \\
\hline Mean & 8.72 & 1603.57 \\
\hline $\mathbf{R}^{\mathbf{2}}$ & 0.9733 & 0.9952 \\
\hline Adj $\mathbf{R}^{\mathbf{2}}$ & 0.9359 & 0.9884 \\
\hline
\end{tabular}

A normal probability plot of residuals for oil recovery (Figure 33) is approximately linear, indicating that errors are normally distributed apart from a few outliers.

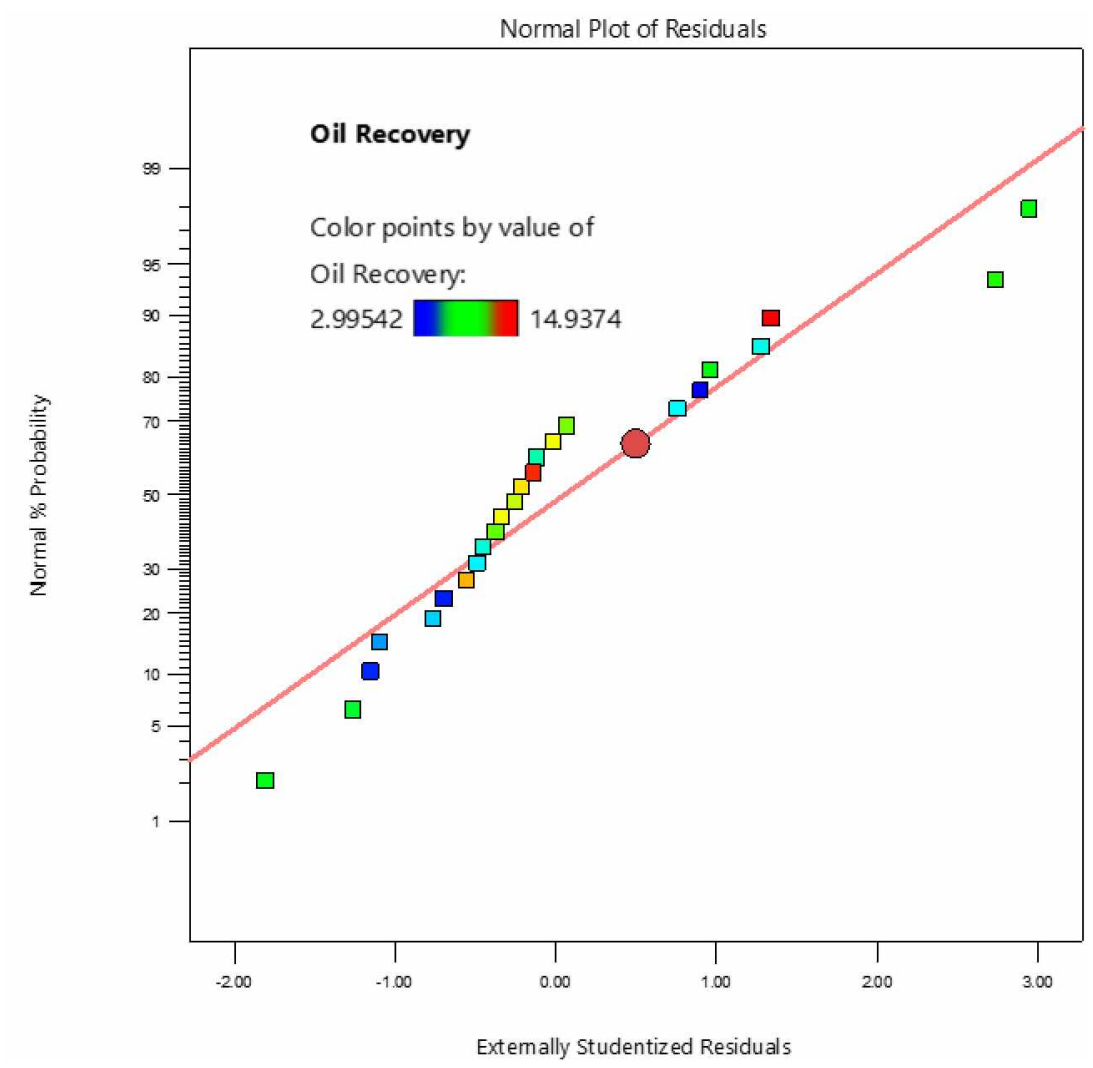

Figure 33: Normal probability plot of residuals- Oil recovery (Optimization) 
A scatter plot of the residuals against the predicted values of oil recovery (Figure 34) shows a random pattern, thus displaying a good fit.

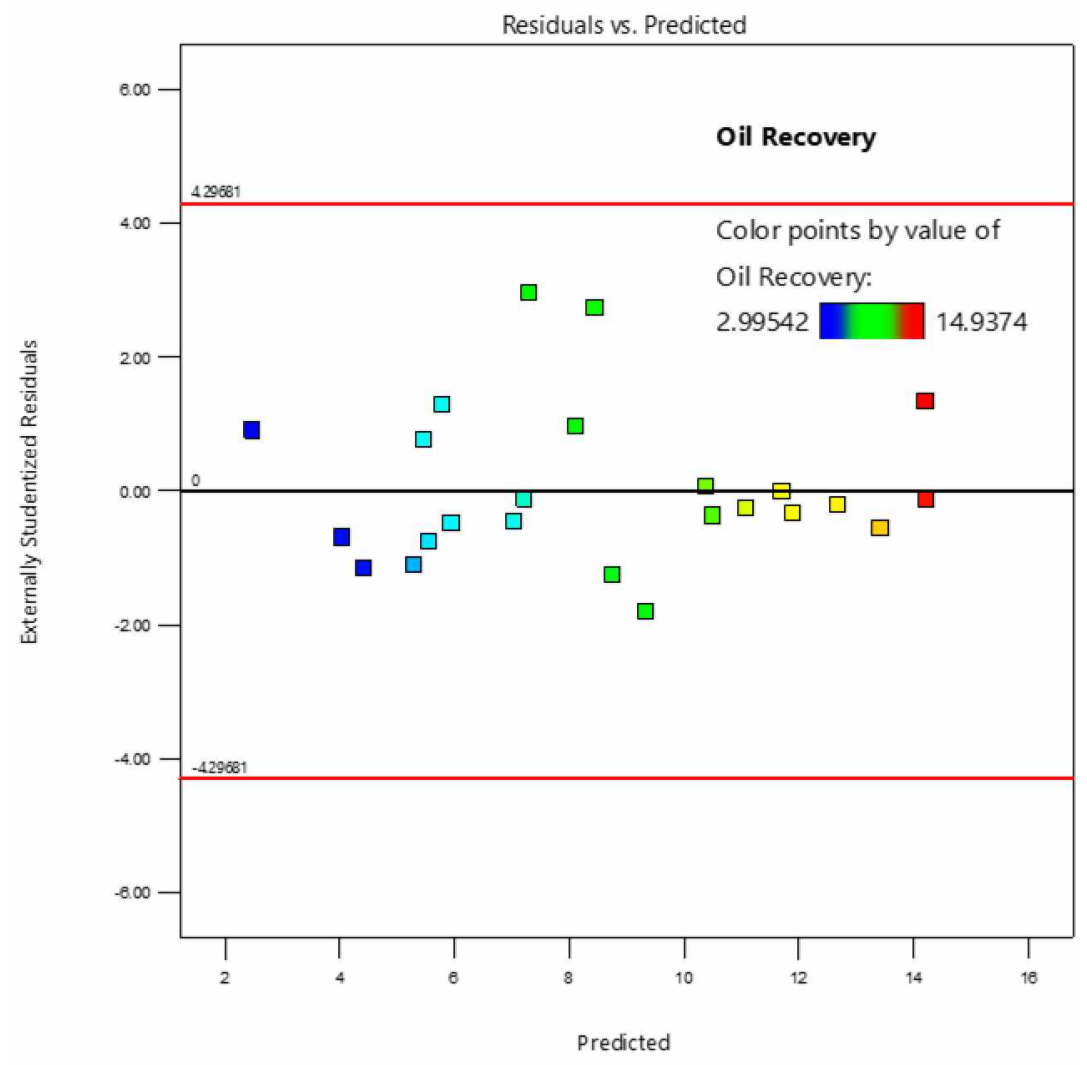

Figure 34: Residuals vs predicted- Oil recovery (Optimization) 
A plot below (Figure 35) shows predicted versus simulated oil recovery for optimization and a good match is observed. Simulated values are obtained from 25 simulation runs in optimization analysis.

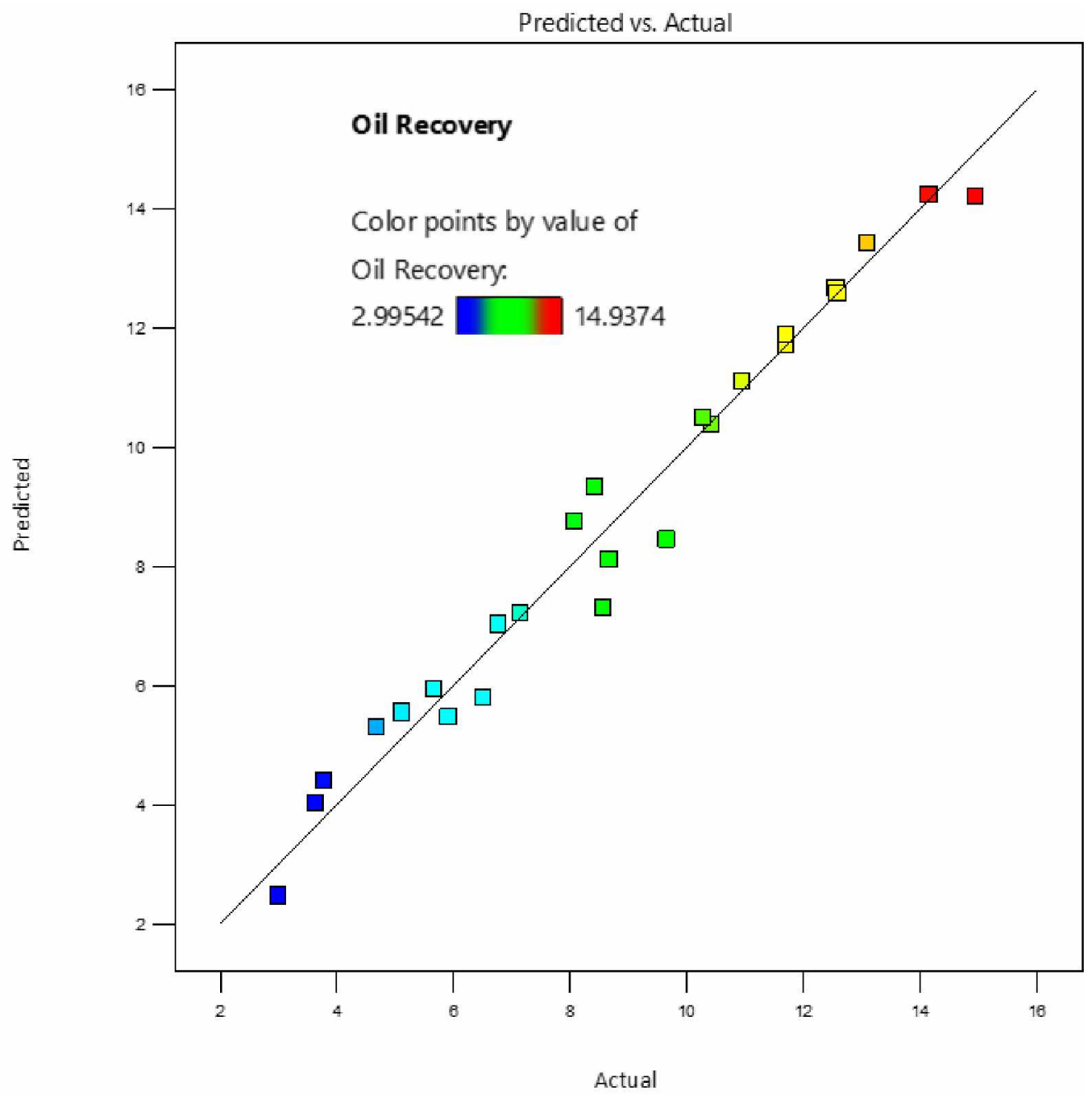

Figure 35: Predicted vs Simulated- Oil recovery (Optimization) 
A normal probability plot of residuals for development cost (Figure 36) follows a linear pattern, indicating it follows a normal distribution except an outlier.

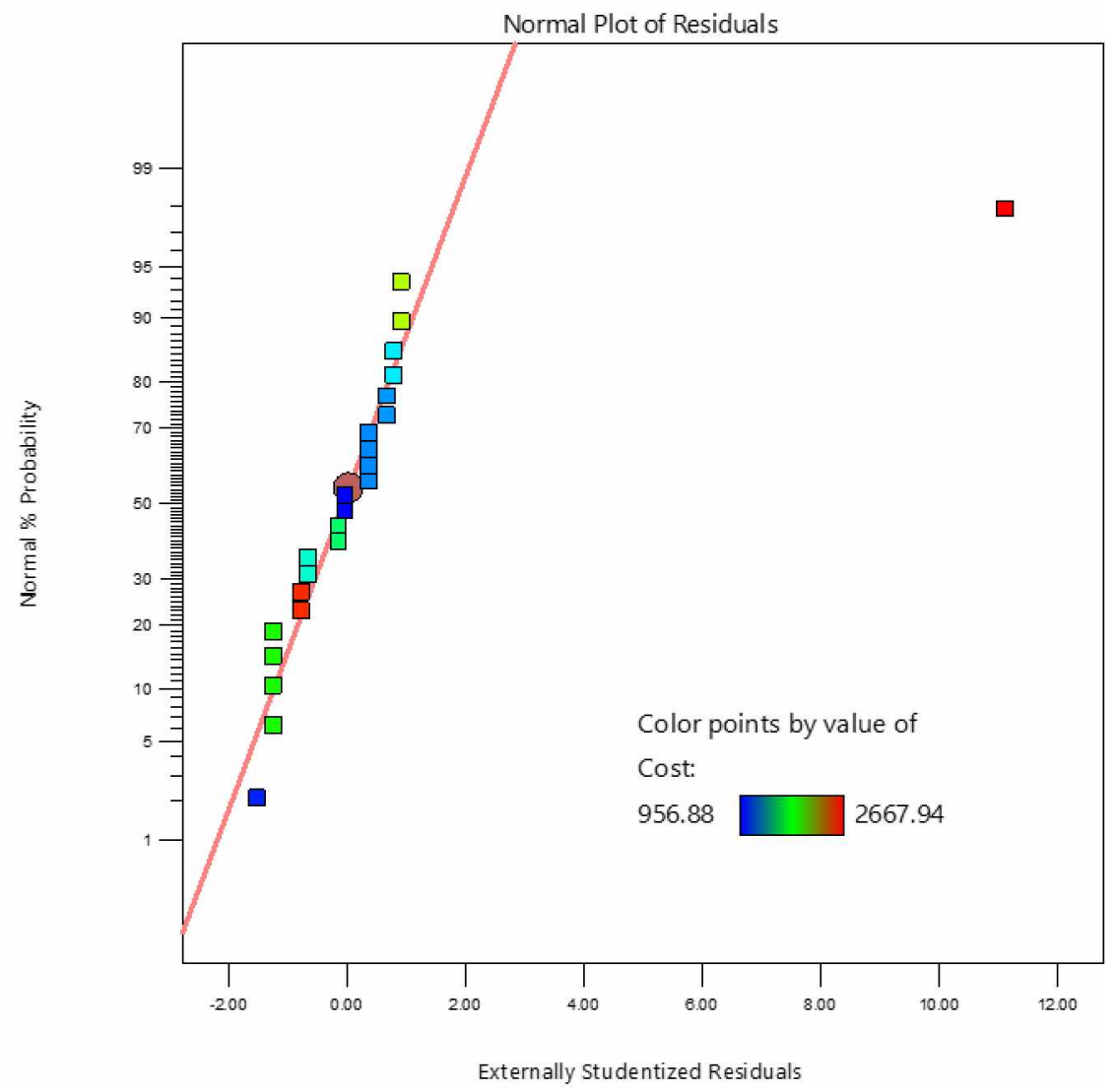

Figure 36: Normal probability plot of residuals- Development cost (Optimization) 
A scatter plot of the residuals against the predicted values of development cost (Figure 37) shows a random pattern, thus displaying a good fit.

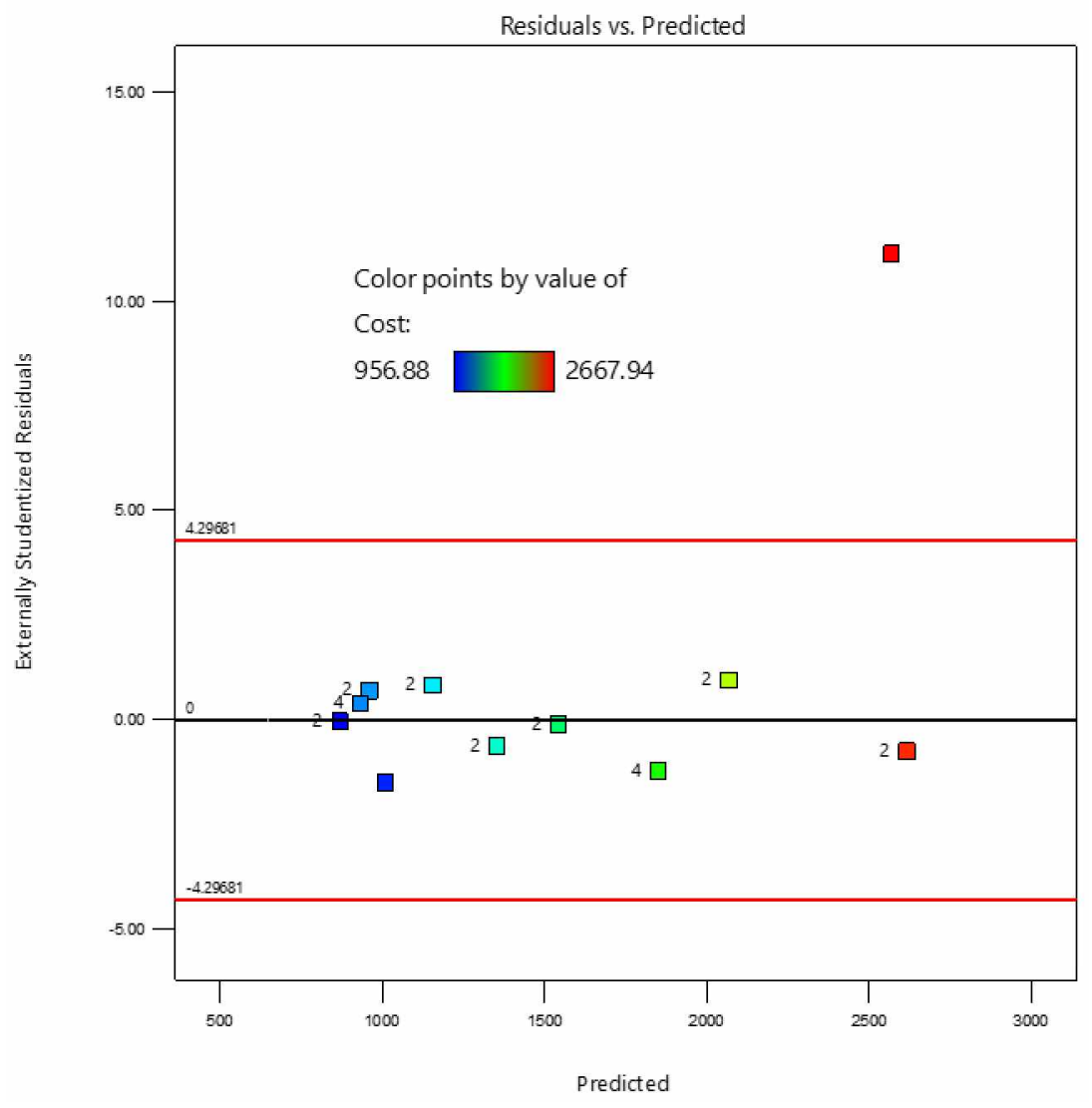

Figure 37: Residuals vs predicted- Development cost (Optimization) 
A plot below (Figure 38) demonstrates predicted versus actual cost for optimization and a good match is seen.

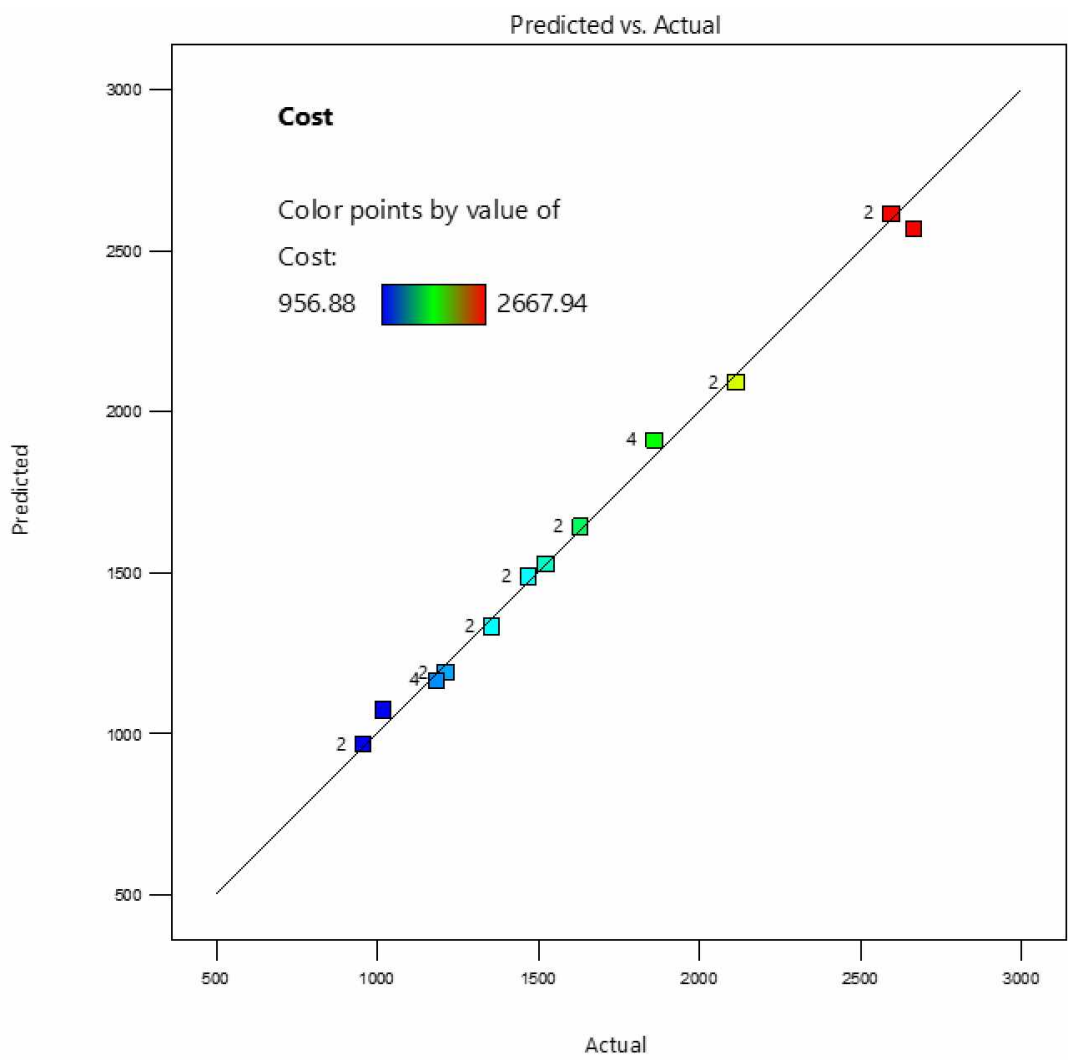

Figure 38: Predicted vs actual- Development Cost (Optimization) 


\subsubsection{Output Sensitivity to Parameters}

Figure 39 and Figure 40 show sensitivity of oil recovery and development cost to all parameters. For any factor, the response is plotted for all levels of a factor while keeping levels of rest of the factors fixed. All parameters show similar trend with respect to oil recovery (Figure 39). It also shows that as the parameters increase from level -1 to +1 , initially oil recovery increases with increase in the parameter value. Once a peak arrives, oil recovery starts decreasing with increase in the parameter. In case of the development cost (Figure 40), it has an inverse relationship with well length i.e. well drilling cost decreases with the increase in well length. Also, injection pressure has no effect on the development cost, in line with the cost estimation assumptions.

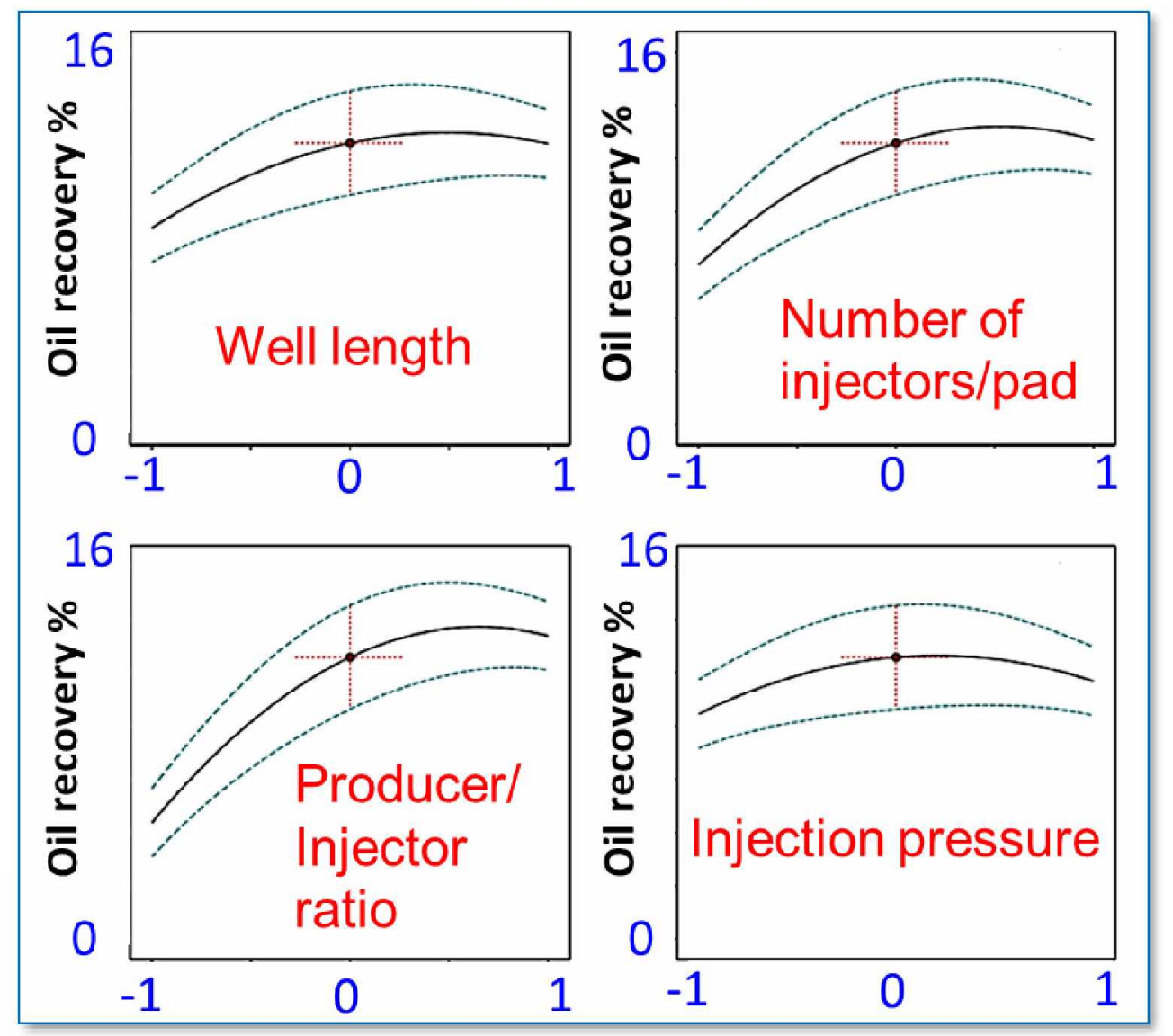

Figure 39: Oil recovery sensitivity to all parameters. 


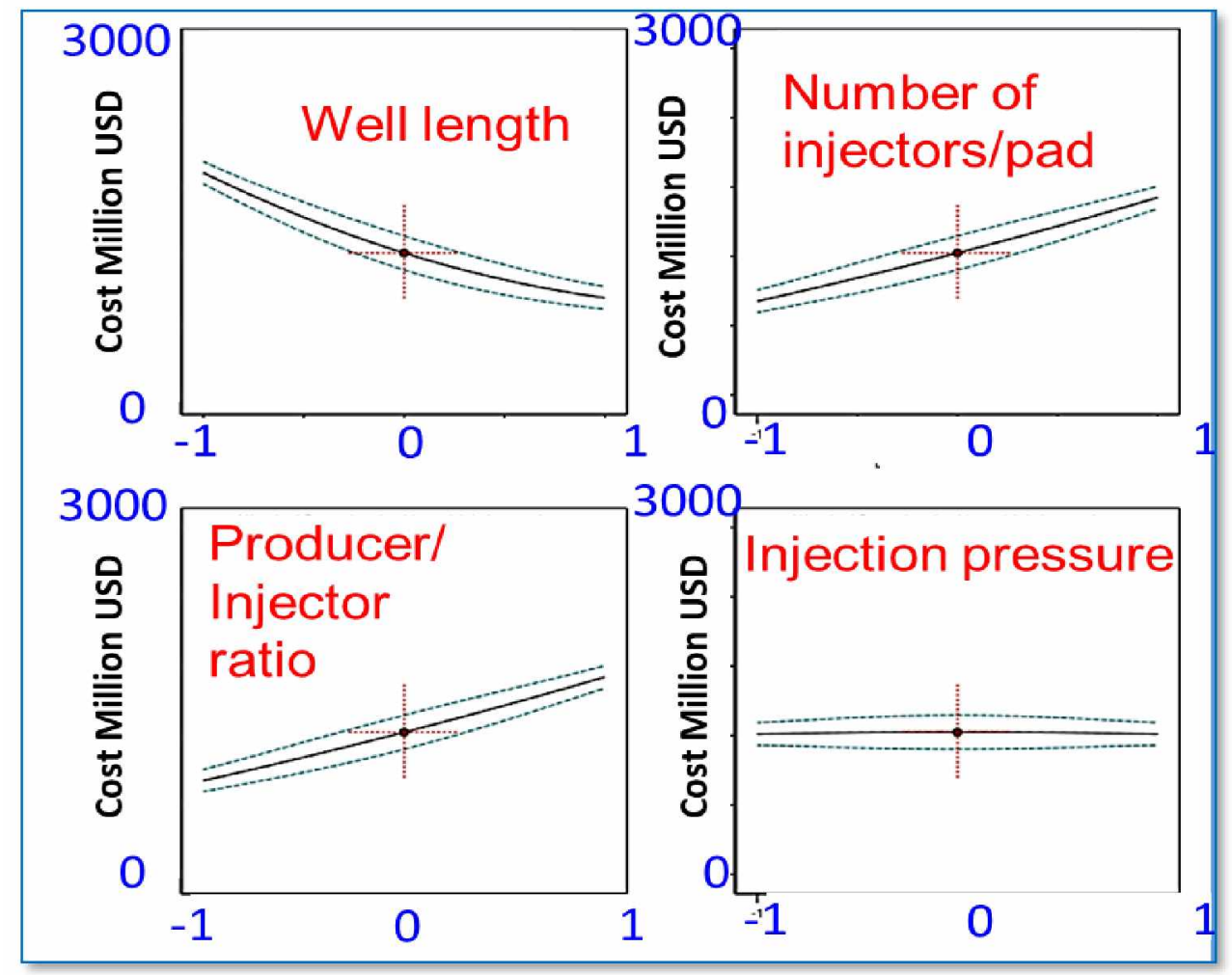

Figure 40: Development cost sensitivity to all parameters.

We can notice from Figure 39 and Figure 40 that, irrefutably well length must be more than $1500 \mathrm{ft}$ for production optimization since it increases the cost (Figure 40) and is also associated with lowest recovery among three levels of well length (Figure 39). For number of injectors/pad and producer/injector ratio, optimization is tricky as they have an opposite relationship with recovery and cost.

\subsection{DISCUSSION}

The aim of the current research was to identify, and screen important factors associated with oil recovery and development cost in Umiat field. It was also aimed at examining the design space carefully and understanding the nature of the relationship between the controllable factors and the objective functions. In the screening analysis, the objective was to find the statistically significant factors. For screening, factorial design was applied on reservoir simulation. Linear relationship was assumed between the factors and the objective functions by using only two levels of factors. The factorial design was successfully able to determine significant factors. Optimization analysis was focused on determining any curvature in the response surface and maximizing or minimizing 
the objective functions as per the requirement. This required introducing median level in addition to low and high levels for factors in the analysis. The analysis was performed by applying Box Behnken design on reservoir model. The investigation of the resulting data showed that the factors and the objective functions follow a quadratic relationship. Thus, Box Behnken design was successfully applied to determine the curvature in the response surface.

During factors selection, representative factors were chosen in such a way that they represent many other important factors and can be controlled during field development phase.

Recovery optimization is a difficult problem as it involves multiple objective functions, which have maxima or minima at different levels of the factors. Different factors affect different responses in a varying proportion. As a result, the optimal range of parameters for maximizing oil recovery and that for minimizing development cost is different. This indicates that the sensitivity analysis can become a challenging task.

Any regression model has its own limitations. The functional relationship between input variables and the outcome is assumed on some data. There is a very high probability that if more data or more input variables are considered, the relationship would change. Also, we have only considered controllable factors in the current analysis. Any uncertainties in the uncontrollable parameters can also significantly affect the outcome e.g. if fault modeling is taken into consideration, it can change the response function substantially. Also, any changes in the geological model due to data obtained from newly drilled wells can add more information and can affect the oil production. As per previous work done by Kohshour (2013), oil in- place volume is the most affected by uncertainty in oil-water contact. Hence, any change in oil-water contact can greatly affect in-place volumes and in turn affect the estimated oil recovery. Moreover, maintaining low DLS can be challenging in the shallowest parts of the reservoir. Furthermore, changing the location of wells / well pads could change the ultimate recovery due to reservoir heterogeneity. Hence, it is suggested to run extra simulations to check the reliability of the RSM model and update the model from time-to-time, to honor the latest available information.

To select the optimized parameters during field development, simulation runs need to be carried out using the updated reservoir simulation model to verify the recovery factors. Although, development cost has been considered as one of the criteria to propose optimization scenarios; 
actual parameters will be determined by NPV from different scenarios. In addition, it will also depend on drilling feasibility and fracture pressure.

High production costs are expected in Umiat field due to high costs of transportation being away from the TAPS. Capital costs are higher as a result of higher drilling costs of onshore Alaska. Harsh Arctic weather also demands higher operational costs. Gaining insight into expected production cost per barrel of oil produced for Umiat field is a challenging task due to several reasons. Fluctuations in oil price create a huge uncertainty in the analysis. Also, using published data on production costs has severe limitations since the very limited data is available and it is a proprietary information only available through subscriptions (Aguilera, 2014). Often, the expenditure is not released by the corporations on individual project basis because of the competitive nature of the industry. However, Aguilera (2014) has provided supply cost curves for crude oil and natural gas for different operating conditions. According to Figure 41, cost of production per barrel of oil equivalent for Arctic region comes out to be roughly 30-50 USD. The inflation adjusted costs for 2020 would be 33.3-55.5 USD, assuming inflation rate of 1.11 USD from 2013 to 2020. Similarly, average cost of oil production per barrel before tax in Alaska was quoted to be 52 USD by Alaska Oil and Gas Association in 2016 (CNBC, 2016). Considering the above mentioned estimates, Umiat would still need to wait for the oil prices to reach at least 50 USD. One of the ways, this field could be economically more attractive, is by cluster development. Deeper oil field in the vicinity of Umiat field from Entek Energy Ltd.'s leases could prove to be the necessary boost for reigniting the interest in Umiat field (Oil and Gas Journal, 2018). 


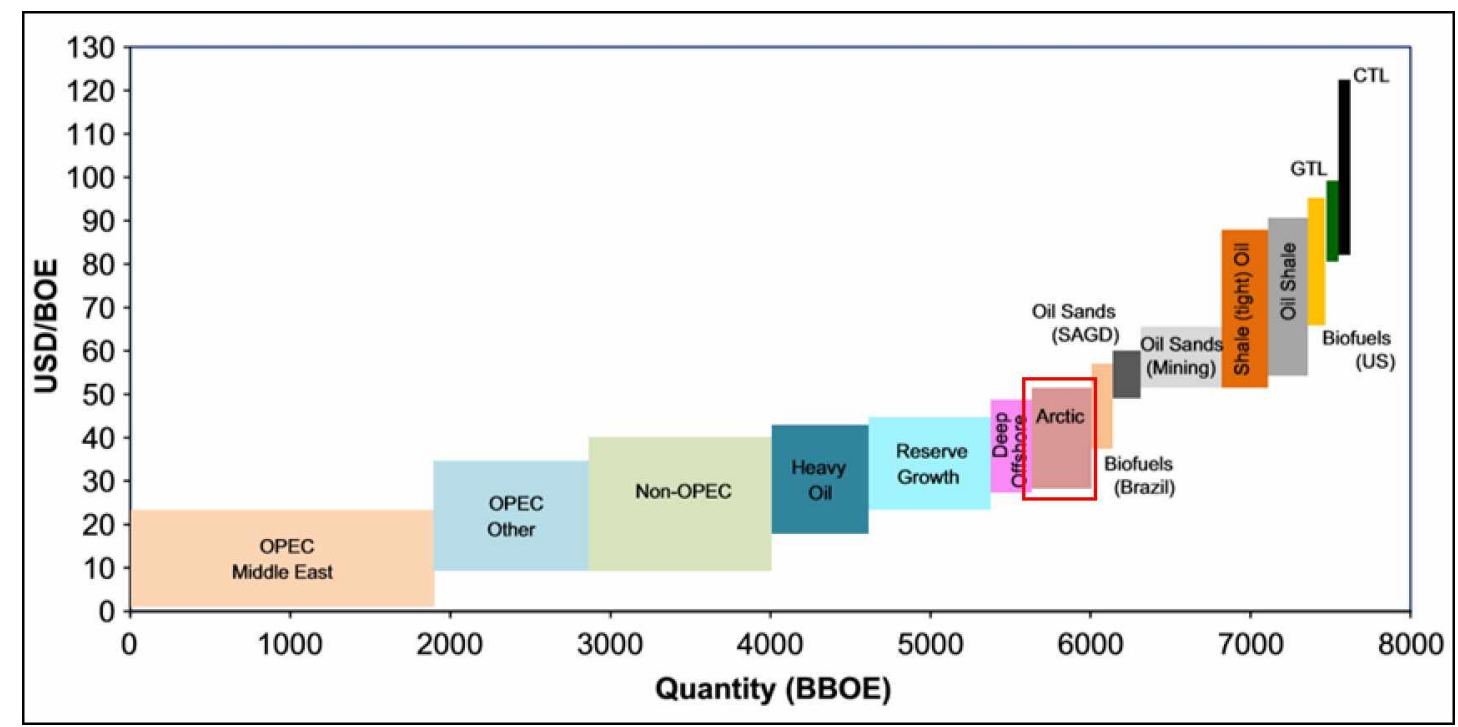

Figure 41: Liquid supply cost curve showing production costs versus recoverable quantities

(Modified from Aguilera, 2014)

\subsection{SUMMARY}

\section{Screening}

Based on screening analysis, all four factors were found to be significant. Factors in the decreasing order of significance are as follows:
a. Producer to injector ratio
b. Number of injectors/pad
c. Well length
d. Injection pressure

\section{Optimization}

For optimization, both graphical and analytical methods were used. First, graphical method was used to visualize the potential areas of response surface that can produce optimum solution. Figure 42 shows the desirability contour for well length and Prod/Inj ratio while injection pressure is fixed at level 1 and number of injectors/pad fixed at level 0 . We can observe from the desirability plot, that the desirability increases as well length and producer/Injector ratio increase; while injection pressure and number of injectors/pad are maintained at level 1 and 0 respectively. 


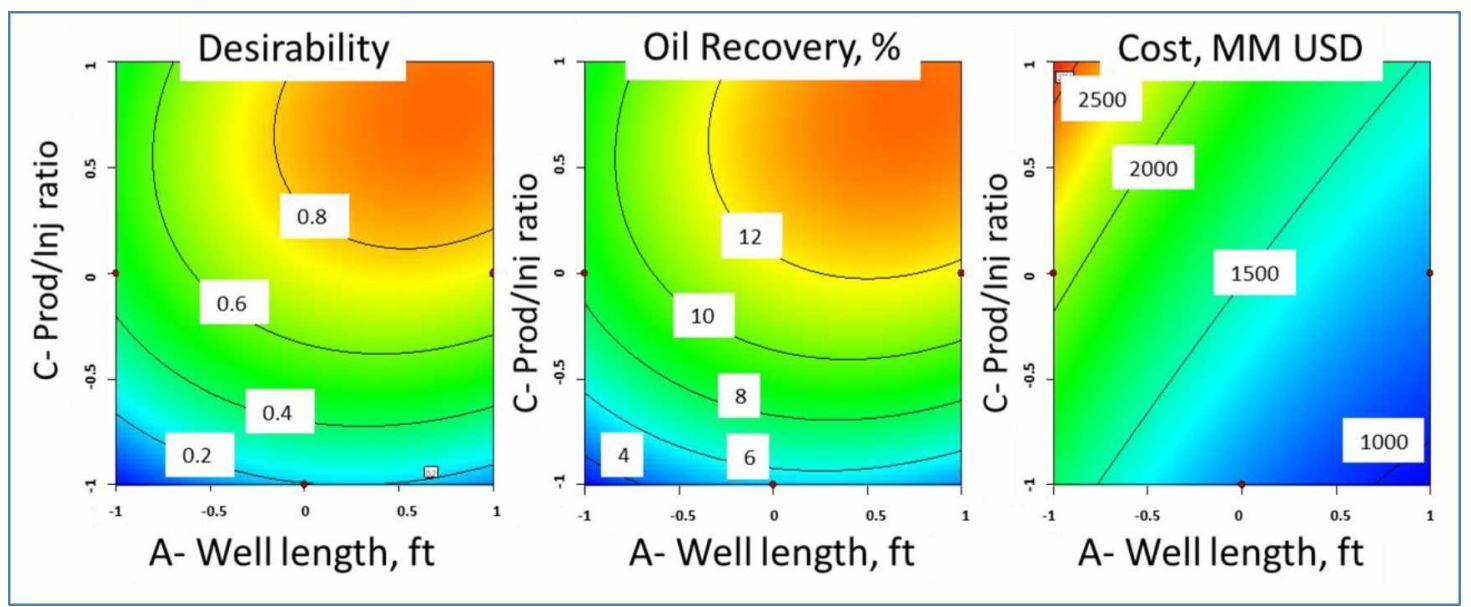

Figure 42: Desirability contour for well length and Prod/Inj ratio with injection pressure at level1 and number of injectors/pad at level 0

Using the above observations from the graphical method as well as the equations from the regression model, following examples of optimization are demonstrated (table 17). Run_13 of optimization runs is considered as the base case for estimating the incremental recovery and incremental cost saving. The incremental recovery and incremental cost saving indicate the additional recovery and cost saving when compared to base case i.e. run_13 of optimization run. 
Table 177: Values of optimized parameters

\begin{tabular}{|c|c|c|c|c|c|c|c|c|}
\hline $\begin{array}{c}\text { Optimized } \\
\text { case }\end{array}$ & $\begin{array}{c}\text { Well } \\
\text { length, } \\
\text { (ft) }\end{array}$ & $\begin{array}{c}\text { No of } \\
\text { Injectors } \\
\text { /pad }\end{array}$ & $\begin{array}{c}\text { Producer/ } \\
\text { Injector ratio }\end{array}$ & $\begin{array}{c}\text { Total } \\
\text { Wells }\end{array}$ & $\begin{array}{c}\text { Injection } \\
\text { pressure (UGGS, } \\
\text { LLGS), psia }\end{array}$ & $\begin{array}{c}\text { Total } \\
\text { Pads }\end{array}$ & $\begin{array}{c}\text { Incremental } \\
\text { development cost saving } \\
\text { w.r.t. base case*, MM USD }\end{array}$ & $\begin{array}{c}\text { Incremental oil } \\
\text { recovery w.r.t. base } \\
\text { case*, MM BBL }\end{array}$ \\
\hline $\mathbf{1}$ & 4500 & 4 & 4 & 60 & $(260,360)$ & 3 & $260(87 \%)$ & $90.9(50 \%)$ \\
\hline $\mathbf{2}$ & 7000 & 4 & 3 & 32 & $(275,375)$ & 2 & $825(60 \%)$ & $65.2(70 \%)$ \\
\hline
\end{tabular}

*Run 13 of optimization design was considered as an arbitrary base case to estimate the incremental values. 


\section{Chapter 5: Conclusion and Recommendation}

Chapter 5 presents summary of the research. Section 5.1 discusses how the research methodology was successfully applied to determine answer to research questions. Section 5.2 provides recommendations for applying current research in Umiat field case study.

\subsection{CONCLUSION}

The application of DoE in well pattern optimization is comparatively new. The case study presented in this thesis gives an illustration of a successful application of DoE in reservoir simulation for well pattern optimization. DoE and RSM work together in the optimization of the Wagon-Wheel pattern of Umiat field. DoE is effectively used in optimizing the number of simulation runs involved in the screening study. ANOVA is used to analyse the oil recovery data generated by running reservoir simulation runs as per DoE. ANOVA quantifies the statistical effects of various factors on oil recovery. It also determines the interaction effects between various factors. RSM works as an effective tool in designing simulation runs for well pattern optimization. Regression analysis plays an instrumental role in analyzing the oil recovery values generated from the RSM simulation runs as well as development costs associated with these scenarios. The study of well pattern optimization lays a solid foundation for production system optimization in Umiat field.

The following conclusions can be drawn from application of DoE to a real-life case study of Umiat field simulation model:

1. Recovery optimization in Umiat is a challenging task due to various local as well as field specific issues such as economic constraint due to high operation cost in Alaska, the need to minimize surface footprint in a socio-economically sensitive area of NPRA, uncertainty in fracture pressure, and low reservoir energy.

2. The most important parameter affecting oil recovery in current wagon-wheel well pattern in Umiat field is the producer to injector ratio.

3. All four parameters studied have a significant impact on oil recovery. The parameters in the order of decreasing statistical significance are as follows: 

a. Producer to injector ratio
b. Number of injectors/pad
c. Well length
d. Injection pressure

4. For optimization of the entire production system, modeling needs to integrate reservoir with wells, flow network and surface facilities. Also, cash flow analysis with economic indicators such as NPV, IRR considering actual costs instead of estimated development cost is required to be performed for comparing scenarios.

5. Well pattern optimization in Umiat observes upto $70 \%$ improvement in oil recovery and development cost (as compared to the assumed base case) despite highly constrained design space. 


\subsection{RECOMMENDATIONS}

The following recommendations are made assuming that development in Umiat is focused on only LGS unit.

It was found during the study that with decreasing reservoir pressure, the quantity of required injection gas increases with time. Hence, it is recommended to re-inject the produced gas into the formation to reduce the requirement of additional gas with time to a certain extent.

Umiat field is a shallow reservoir, causing reservoir pressure to be unusually low. Hence, the fracture pressure of the formation is also low. Care needs to be taken so that injection gas pressure does not exceed fracture pressure of the formation.

Low pressure in Umiat can create flow assurance issues during fluid flow from reservoir to surface facilities. To ensure sustained flow of fluids throughout the life of the field, artificial lift needs to be installed in the wellbore as well compressors and pumps need to be installed in the flowline and at the separator. It would be interesting to check whether additional oil can be recovered by lowering the FBHP further.

Another potential flow assurance issue in Umiat is hydrate formation in the wellbore and flowlines when there is associated water production with produced gas. To mitigate this, hydrate inhibitor injection should be practiced as per the need on a continuous or intermittent basis. The injection location should be determined in advance such as downhole or at tree. This will aid in effective well completion designing. Also, hydrate inhibitor reclamation unit needs to be designed during surface facility designing.

While drilling wells in Umiat field, it would be difficult to maintain the DLS below maximum DLS constraint due to shallow depths. It can create challenges during drilling in passing the drill-string through the curved sections of the wellbore. If the DLS is severe, installation of artificial lift becomes a challenge too. Thus, special care needs to be taken while drilling wells along the anticline axis.

It is recommended to focus on the LGS for development due to certain crucial reasons. Firstly, drilling horizontal wells in Upper Grandstand (UGS) would prove to be difficult due to even higher DLS than that possible in LGS. In case vertical wells are drilled, much higher number of wells would be required as compared to thatof horizontal wells to achieve similar production. This will cause much higher surface footprint. 
The optimization exercise performed here focuses on the recovery optimization from the reservoir. Pressure loss occurs during the fluid flow through the entire production system starting from the reservoir to the production facilities. Pressure loss in the reservoir can be expressed in terms of the drawdown. Although reservoir can produce this volume of fluid, the fluid may not have sufficient energy to flow to the surface facilities through wellbore and flowlines. The recovery factors obtained here might not be representative of true recovery factors. This calls for entire production system optimization, which covers optimization of various factors such as type of pump, pump specifications, tubing ID, flowlines ID and length and facility capacities. This will ensure detecting and de-bottlenecking the potential constraints in the flow system.

The current research provides a strong groundwork to optimize recovery in Umiat field within economic constraints. The recommended combinations of well pattern parameters are suggested based on oil recovery and development cost. For realistic optimization parameters, cash flow analysis is recommended to be used as one of the criteria as opposed to development cost. 


\section{References}

Abdul-Latif, B. L., Fathi Elsharkawi, A. M., and Daniel Edem, T. (2017). Uncertainty Analysis and Design Optimization of Gas-Condensate Fields. In SPE Kurwait Oil and Gas Show and Conference (p. 20). Society of Petroleum Engineers. https://doi.org/10.2118/187639-MS

Aguilera, R. F. (2014). Production costs of global conventional and unconventional petroleum. Energy Policy, 64, 134-140.

Ahmadi, M., Hanks, C., and Kohshour, I. O. (2013). Uncertainty Assessment in Geologic Modeling and Sensitivity Analysis of Static and Dynamic Models in Umiat: A Frozen Shallow Oil Accumulation in National Petroleum Reserve of Alaska. In SPE Western Regional and AAPG Pacific Section Meeting 2013 Joint Technical Conference (p. 37).

Society of Petroleum Engineers. https://doi.org/10.2118/165341-MS

Attanasi, E. D., and Freeman, P. A. (2009). Economics of undiscovered oil and gas in the North Slope of Alaska: Economic update and synthesis. US Geological Survey.

Ayokunle, A. T., and Hashem, M. H. (2016). Design Optimization of Multilateral Wells in Heterogeneous Reservoirs. In SPE Kingdom of Saudi Arabia Annual Technical Symposium and Exhibition. Society of Petroleum Engineers. https://doi.org/10.2118/182764-MS

Bailey, A. (2009). Ready at Umiat: Renaissance says field development will depend on sustained oil price. Petroleum News, v. 14, no. 37. Petroleum News.

http://www.petroleumnews.com/pntruncate/496392442.shtml

Baptist, O. C. (1960). Oil recovery and formation damage in permafrost, Umiat field, Alaska: US Department of Interior, Federal Bureau of Mines. Report of Investigations, Report, 5642, 22.

Bevillon, D., and Mohagerani, S. (2015). A Miscible EOR Project in a Mature, Offshore, Carbonate Middle East Reservoir - Uncertainty Analysis With Proxy Models Based on Experimental Design of Reservoir Simulations. In SPE Reservoir Characterisation and Simulation Conference and Exhibition (p. 24). Society of Petroleum Engineers. https://doi.org/10.2118/175642-MS 
Bird, K J. (1985). The framework geology of the North Slope of Alaska as related to oil-source rock correlations. In Alaska North Slope Oil/Source Correlation Study.

Bird, K J. (1999). Geographic and Geologic Setting in the Oil and Gas Resource Potential of the 1002 Area, Arctic National Wildlife Refuge, Alaska, by ANWR Assessment Team, 51 pp. US Geol. Surv. Open File Rep, 34-98.

Bird, Kenneth J, and Molenaar, C. M. (1992). The North Slope foreland basin, Alaska, in Macqueen,R.W., and Leckie, D.A., eds., Foreland basins and fold belts: American Association of Petroleum Geologists Memoir 55.

Bret-Rouzaut, N., and Favennec, J.-P. (2011). Oil and gas exploration and production: Reserves, costs, contracts. Editions Technip.

Burns, W. M., Hayba, D. O., Houseknecht, D. W., and Rowan, E. L. (2002). Timing of hydrocarbon generation in the National Petroleum Reserve-Alaska (NPRA) from burial and thermal history modeling. AAPG Bulletin, 86(6), 1139.

Cheap oil creates a new frontier in Alaska - making ends meet. (2016). CNBC. https://www.cnbc.com/2016/04/21/cheap-oil-creates-a-new-frontier-in-alaska-making-endsmeet.html

Cheong, Y. P., and Gupta, R. (2005). Experimental Design and Analysis Methods for Assessing Volumetric Uncertainties. SPE Journal, 10(03), 324-335. https://doi.org/10.2118/80537-PA

Coakley, B. J., and Watts, A. B. (1991). Tectonic controls on the development of unconformities: the North Slope, Alaska. Tectonics, 10(1), 101-130.

Collins, F. R., Bergquist, H. R., Brewer, M. C., and Gates, G. L. (1958). Test Wells, Umiat area, Alaska: U.S .Geological Survey Professional Paper 305-B.

Cyril, O., and Peacock, A. (2010). Using Experimental Design Table with Reservoir Simulation to Manage Sub-surface Uncertainties - A Niger Delta Case Study. In Nigeria Annual International Conference and Exhibition (p. 10). Society of Petroleum Engineers. https://doi.org/10.2118/140613-MS

Denney, D. (2007). Validating the Use of Experimental-Design Techniques in Exploratory Evaluations. Journal of Petroleum Technology, 59(12), 60-62. https://doi.org/10.2118/1207-0060-JPT

Drive mechanisms and recovery - AAPG Wiki. (n.d.). AAPG Wiki. Retrieved April 15, 2020, from https://wiki.aapg.org/Drive_mechanisms_and_recovery 
Entek negotiates option for Alaskan leases | Oil and Gas Journal. (2018). Oil and Gas Journal. https://www.ogj.com/general-interest/companies/article/17296862/entek-negotiates-optionfor-alaskan-leases

Estimating horizontal well productivity - PetroWiki. (2015). PetroWiki.

https://petrowiki.org/Estimating_horizontal_well_productivity

Explorers 2014: Linc sees a 'clear path' for Umiat oil development - July 20, 2014 - Petroleum

News. (2014). Petroleum News.

http://www.petroleumnews.com/pntruncate/371859094.shtm1

Faidi, S. A., Ponting, D. K., and Eagling, T. L. (1996). Experimental design in interactive reservoir simulation. Petroleum Computer Conference.

Friedmann, F., Chawathe, A., and Larue, D. K. (2003). Assessing Uncertainty in Channelized Reservoirs Using Experimental Designs. SPE Reservoir Evaluation and Engineering, 6(04), 264-274. https://doi.org/10.2118/85117-PA

Gates, G. L., Caraway, W. H., Seaton, F. A., and Ankeny, M. J. (1960). Well Productivity Related to Drilling Muds: Umiat Field, Naval Petroleum Reserve No. 4, Alaska. Report of Investigations 5706 United States Department of the Interior.

Ghaderi, S. M., Clarkson, C. R., and Chen, Y. (2012). Optimization of WAG Process for Coupled $\mathrm{CO}_{2}$ EOR-Storage in Tight Oil Formations: An Experimental Design Approach. In SPE Canadian Unconventional Resources Conference (p. 17). Society of Petroleum Engineers. https://doi.org/10.2118/161884-MS

Godabrelidze, V. (2010). Characterization and fluid flow properties of frozen rock systems of Umiat oil field, Alaska. M.S. thesis, University of Alaska Fairbanks.

Gubaidullin, M. G., and Makarsky, N. A. (2013). Study of the temperature of near-surface permafrost layers to providing their stability during the operation of oilfields. SPE Arctic and Extreme Environments Conference [AEE] (Moscow, Russia, 10/15-17/2013) Proceedings. https://doi.org/10.2118/166938-ru

Hanks, C. L., Shimer, G., Kohshour, I. O., Ahmadi, M., McCarthy, P. J., Dandekar, A., Mongrain, J., and Wentz, R. (2014). Integrated reservoir charactenzation and simulation of a shallow, light-oil, low-temperature reservoir: Umiat field, National Petroleum Reserve, Alaska. In AAPG Bulletin (Vol. 98, Issue 3, pp. 563-585). American Association of Petroleum Geologists. https://doi.org/10.1306/08201313011 
Hanks, C., Shimer, G., Ahmadi, M., Kohshour, I. O., McCarthy, P., Dandekar, A. Y., Mongrain, J., Wentz, R., and Davis, J. (2012). Can A Shallow Frozen Reservoir Be Successfully Exploited? A Predevelopment Case Study Of The Umiat Oil Field, Northern Alaska. In SPE Annual Technical Conference and Exhibition (p. 15). Society of Petroleum Engineers. https://doi.org/10.2118/159249-MS

Herlugson, C. J., McKendrick, J. D., and Parnell, J. A. (1996). Gravel Pad Restoration on Alaska's North Slope. In SPE Health, Safety and Environment in Oil and Gas Exploration and Production Conference (p. 7). Society of Petroleum Engineers.

https://doi.org/10.2118/35883-MS

Herriott, T. M., Wartes, M. A., Decker, P. L., Gillis, R. J., Shellenbaum, D. P., Willingham, A. L., and Mauel, D. J. (2018). Geologic map of the Umiat-Gubik area, central North Slope, Alaska: Alaska Division of Geological and Geophysical Surveys Report of Investigation 2018-6, 55 p., 1 sheet, scale 1:63,360.

Houseknecht, D., and Bird, K. (2006). Oil and Gas Resources of the Arctic Alaska Petroleum Province. U.S. Geological Survey Professional Paper.

Houseknecht, D. W., Bird, K. J., and Schenk, C. J. (2009). Seismic analysis of clinoform depositional sequences and shelf-margin trajectories in Lower Cretaceous (Albian) strata, Alaska North Slope. Basin Research, 21(5), 644-654.

Houseknecht, D. W., and Schenk, C. J. (2005). Sedimentology and sequence stratigraphy of the Cretaceous Nanushuk, Seabee, and Tuluvak Formations exposed on Umiat Mountain, north-central Alaska. US Geological Survey.

Huckabay, A., and Hanks, C. (2009). The Petroleum Geology of Umiat Oil Field, North Slope, Alaska. 2009 AAPG 3P Arctic Conference, Moscow, Russia.

Kalla, S., and White, C. D. (2007). Efficient Design of Reservoir Simulation Studies for Development and Optimization. SPE Reservoir Evaluation and Engineering, 10(06), 629637. https://doi.org/10.2118/95456-PA

Kloosterman, H. J., Herring, T. R., Tull, S., and van der Lee, J.-W. (2007). From Test-tube to Value-generator: Effective Use of Experimental Design for Uncertainty Analysis and Development Concept Optimisation. In EUROPEC/EAGE Conference and Exhibition (p. 8). Society of Petroleum Engineers. https://doi.org/10.2118/106893-MS 
Kohshour, I. O. (2013). Geological modeling and reservoir simulation of Umiat: a large shallow oil accumulation. M.S. thesis, University of Alaska Fairbanks.

Kumar, N., Bird, K. J., Nelson, P. H., Grow, J. A., and Evans, K. R. (2002). A digital atlas of hydrocarbon accumulations within and adjacent to the National Petroleum Reserve - Alaska (NPRA). In Open-File Report. https://doi.org/10.3133/OFR0271

Lawal, K. A. (2009). Modelling Subsurface Uncertainties with Experimental Design: Some Arguments of Non-Conformists. In Nigeria Anmual International Conference and Exhibition (p. 11). Society of Petroleum Engineers. https://doi.org/10.2118/128350-MS

Levi-Johnson, O. I. (2010). Petrophysical property modeling of Umiat field, a frozen oil reservoir. M.S. thesis, University of Alaska Fairbanks.

Lidji, E. (2016). Market challenges two Linc Energy projects: The Explorers, Petroleum News, v. 21, no. 21. Petroleum News. $\mathrm{http}: / / \mathrm{www}$.petroleumnews.com/pntruncate/124855179.shtm1

Linc drills first Umiat exploration well since '79 - Alaska Journal. (2013). Alaska Journal. https://www.alaskajournal.com/business-and-finance/2013-03-21/linc-drills-first-umiatexploration-well-79

Linc Energy acquires controlling interest in Alaskan oil field - NS Energy. (2011). NS Energy. https://www.nsenergybusiness.com/news/newslinc-energy-acquires-controlling-interest-inalaskan-oil-field-170611/

Linc Energy files for bankruptcy | Australasian Mine Safety Journal. (2016). Australasian Mine Safety Journal. https://www.amsj. com.au/linc-energy-files-bankruptcy/

Linc Energy to develop Alaska Umiat oil field | Oil and Gas Journal. (2011). Oil and Gas Journal. https://www.ogj.com/home/article/17265608/linc-energy-to-develop-alaska-umiatoil-field

Magoon, L. B., Lillis, P. G., Bird, K. J., Lampe, C., and Peters, K. E. (2003). Alaskan North Slope petroleum systems.

Malamute Energy - Alaska Oil Exploration. (n.d.). Malamute Energy. Retrieved April 15, 2020, from http://malamuteenergy .com/

Marushack, J. (2017). ConocoPhillips Alaska: Investing in Alaska in Changing Times. ConocoPhillips Alaska. www.conocophillips.com/nongaap. 
Minton, Jeremy. (2014). A Comparison of Common Methods for Optimal Well Placement. SIAM Undergraduate Research Online. 7. 10.1137/13S012510.

Moore, T. E., Wallace, W. K., Bird, K. J., Karl, S. M., Mull, C. G., and Dillon, J. T. (1994). Geology of northern Alaska. Geological Society of America.

Mull, C. G., Houseknecht, D., and Bird, K. (2003). Revised Cretaceous and Tertiary Stratigraphic Nomenclature in the Colville Basin, Northern Alaska. U.S. Geological Survey Professional Paper 1673, 1673, 1-51.

Narahara, G. M., Spokes, J. J., Brennan, D. D., Maxwell, G., and Bast, M. S. (2005).

Incorporating Uncertainties in Well-Count Optimization With Experimental Design for the Deepwater Agbami Field. SPE Reservoir Evaluation and Engineering, 8(06), 548-560. https://doi.org/10.2118/91012-PA

NPR-A leaseholder lays the groundwork for development-Anchorage Daily News. (2009). Anchorage Daily News. https://www.adn.com/economy/article/npr-leaseholder-laysgroundwork-development/2009/09/20/

Onwunalu, J. E., and Durlofsky, L. J. (2011). A new well-pattern-optimization procedure for large-scale field development. SPE Journal, 16(3), 594-607. https://doi.org/10.2118/124364-PA

Peake, W. T., Abadah, M., and Skander, L. (2005). Uncertainty Assessment using Experimental Design: Minagish Oolite Reservoir. In SPE Reservoir Simulation Symposium (p. 8). Society of Petroleum Engineers. https://doi.org/10.2118/91820-MS

Potter, C. J., and Moore, T. E. (2003). Brookian structural plays in the National Petroleum Reserve, Alaska. US Department of the Interior, US Geological Survey.

Productivity index (J) - PetroWiki. (2016). PetroWiki.

https://petrowiki.org/Productivity_index_(J)

Renaissance Alaska Shot Survey In Umiat Field | Hart Energy. (2008). Hart Energy. https://www.hartenergy.com/news/renaissance-alaska-shot-survey-umiat-field-33399

Renewal of the Federal Grant for the Trans-Alaska Pipeline System, Draft Environmental Impact Statement: Renewal of the Federal Grant for the Trans-Alaska Pipeline System Right-ofway, Volume 3. (2002). U. S. Department of Interior, Bureau of Land Management. 
Romanovsky, V., Burgess, M., Smith, S., Yoshikawa, K., and Brown, J. (2002). Permafrost temperature records: Indicators of climate change. EOS, Transactions American Geophysical Union, 83(50), 589-594.

Sayers, Z., Sallee, A., Burton, J., and Francis, M. (2015). Unlocking a Frozen Resource: Horizontal Milestone in Permafrost Drilled at $-80^{\circ}$ Fahrenheit. SPE Western Regional Meeting.

Shimer, G. T., McCarthy, P. J., and Hanks, C. L. (2014). Sedimentology, stratigraphy, and reservoir properties of an unconventional, shallow, frozen petroleum reservoir in the Cretaceous Nanushuk Formation at Umiat field, North Slope, Alaska. AAPG Bulletin, 98(4), 631-661.

Shukla, C. (2011). Fluid characterization and phase behavior studies of oil from the frozen reservoir of Umiat oil field, Alaska. University of Alaska Fairbanks. M.S. thesis, University of Alaska Fairbanks.

Sullivan, P. (2019). Longest rotary well in Alaska for the 17th time | spiritnow stories. ConocoPhillips. http://www.conocophillips.com/spiritnow/story/longest-rotary-well-inalaska-for-the-17th-time/

Trabelsi, R., Boukadi, F., Lee, J., Boukadi, B., Seibi, A., and Trabelsi, H. (2017). Type Curves Relating Well Spacing and Heterogeneity to Oil Recovery in a Water Flooded ReservoirA Case Study. Natural Resources, 8(10), 632-645.

Vanegas, J. W., Cunha, J. C. S., and Cunha, L. B. (2005). Uncertainty Assessment Using Experimental Design and Risk Analysis Techniques, Applied to Offshore Heavy Oil Recovery. In SPE International Thermal Operations and Heavy Oil Symposium (p. 9). Society of Petroleum Engineers. https://doi.org/10.2118/97917-MS

Venepalli, K. K. (2011). Implications of pore-scale distribution of frozen water for the production of hydrocarbon reservoirs located in permafrost.University of Alaska Fairbanks.

Vicente, M. G., Mustieles, F. J., Limeres, A. C., Izaguirre Ozamiz, E., and Rieu, R. (2010). Uncertainty Evaluation in Emerging Gas Projects in North Africa Using Geological Modeling, Reservoir Simulation and Experimental Design. In North Africa Technical Conference and Exhibition (p. 23). Society of Petroleum Engineers.

https://doi.org/10.2118/127853-MS 
Wentz, R. (2014). Fracture characteristics and distribution in cretaceous rocks near the Umiat anticline, North Slope of Alaska. University of Alaska Fairbanks. 


\section{Appendices}

\section{Appendix A \\ DOE DESIGN GENERATION USING DESIGN-EXPERT SOFTWARE}

\section{Design-Expert Software by Stat-Ease}

- Open Design-Expert software from Start menu in Windows.

- Go to Files and select 'New Design'.

- Select the type of design.

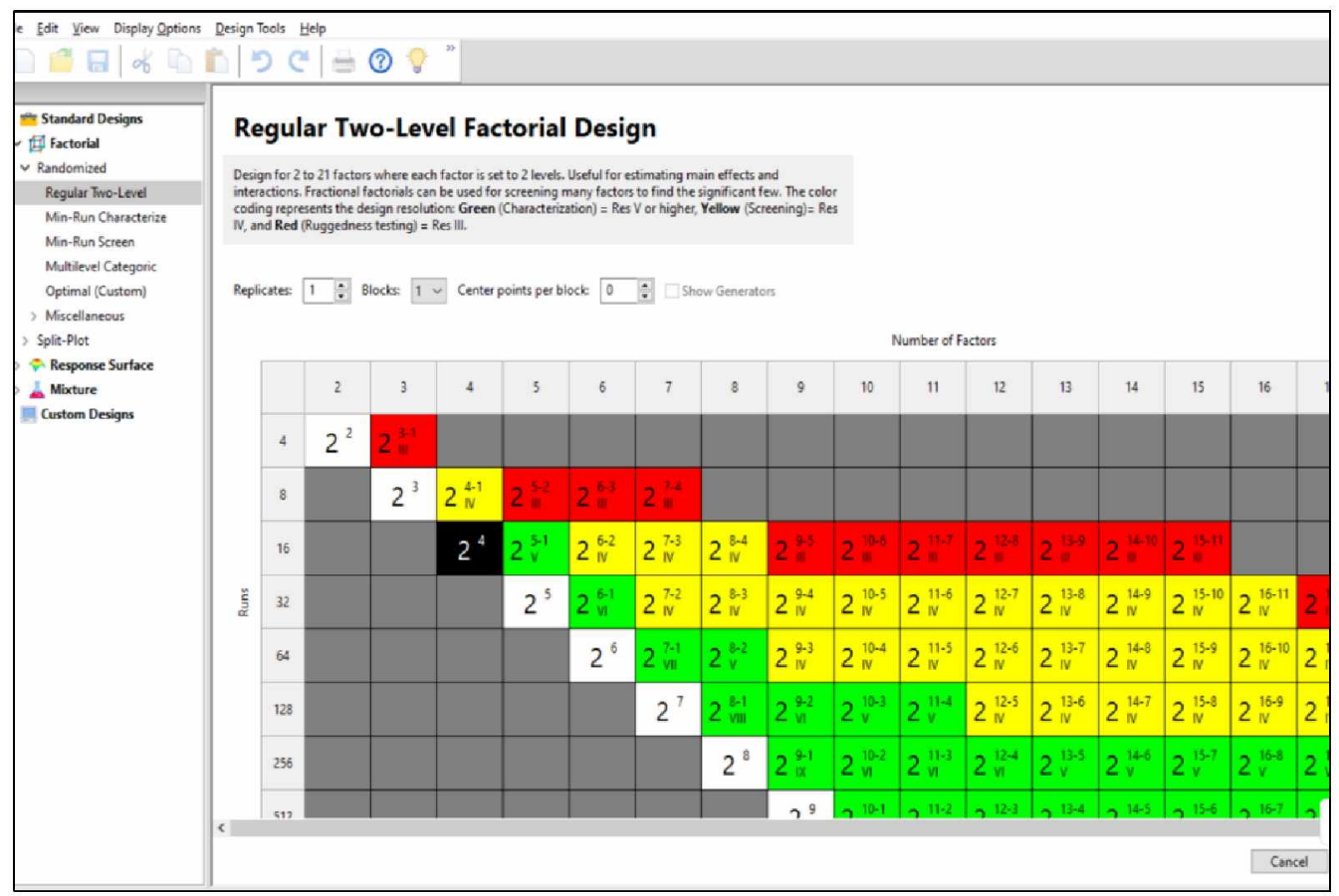

- Select the number of factors, the number of responses, the number of center points.

- Enter factor names and select the factor levels. Enter the units for all factors.

- The software will create a design matrix showing the number of runs and associated combination of parameter levels. 


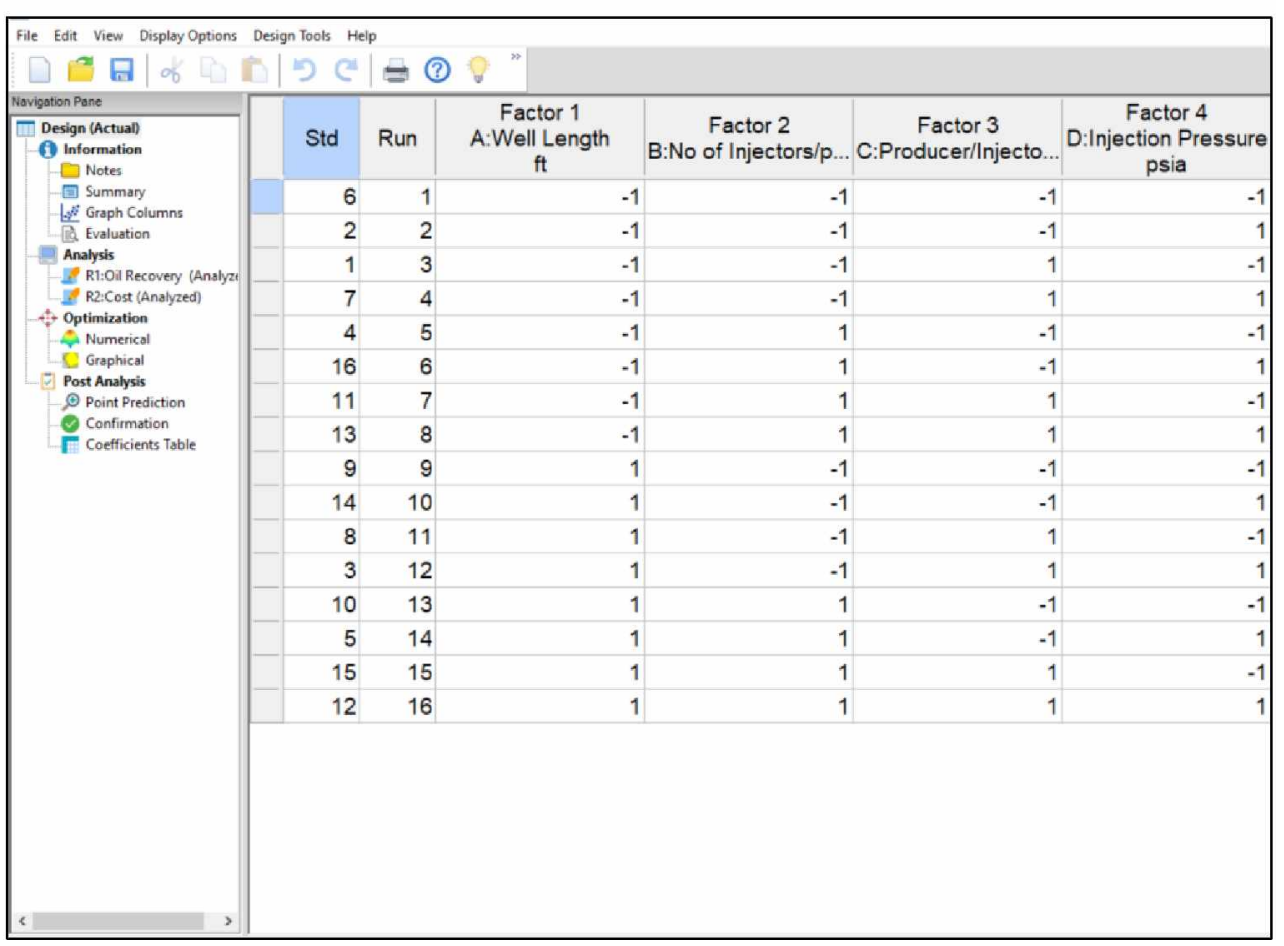

- Once the response values are obtained, go to analysis to analyse the response.

- After the analysis is performed, the results can be extracted into an excelsheet or word document as needed. 


\section{Appendix B}

\section{WELL PAD LOCATIONS FOR DIFFERENT WELL LENGTHS}

As the well length increases, number of pads reduce as per the experimental design requirement. Following tables (Table B1, Table B2, Table B3) provide well pad locations. Figures B1, B2 and B3 show schematics of wagon-wheel pattern of wells and corresponding well locations

Table B1: Well pad locations for well length $1500 \mathrm{ft}$

\begin{tabular}{|l|c|l|}
\hline \multicolumn{3}{|c|}{ scenario 1: No. of pads- 5, } \\
Well length- 1500 ft wells \\
\hline & X (ft) & Y (ft) \\
\hline Pad1 & 237498.8 & 5629336 \\
\hline Pad2 & 231743.7 & 5628774 \\
\hline Pad3 & 225988.5 & 5629548 \\
\hline Pad4 & 220233.3 & 5629004 \\
\hline Pad5 & 214478.2 & 5630178 \\
\hline
\end{tabular}

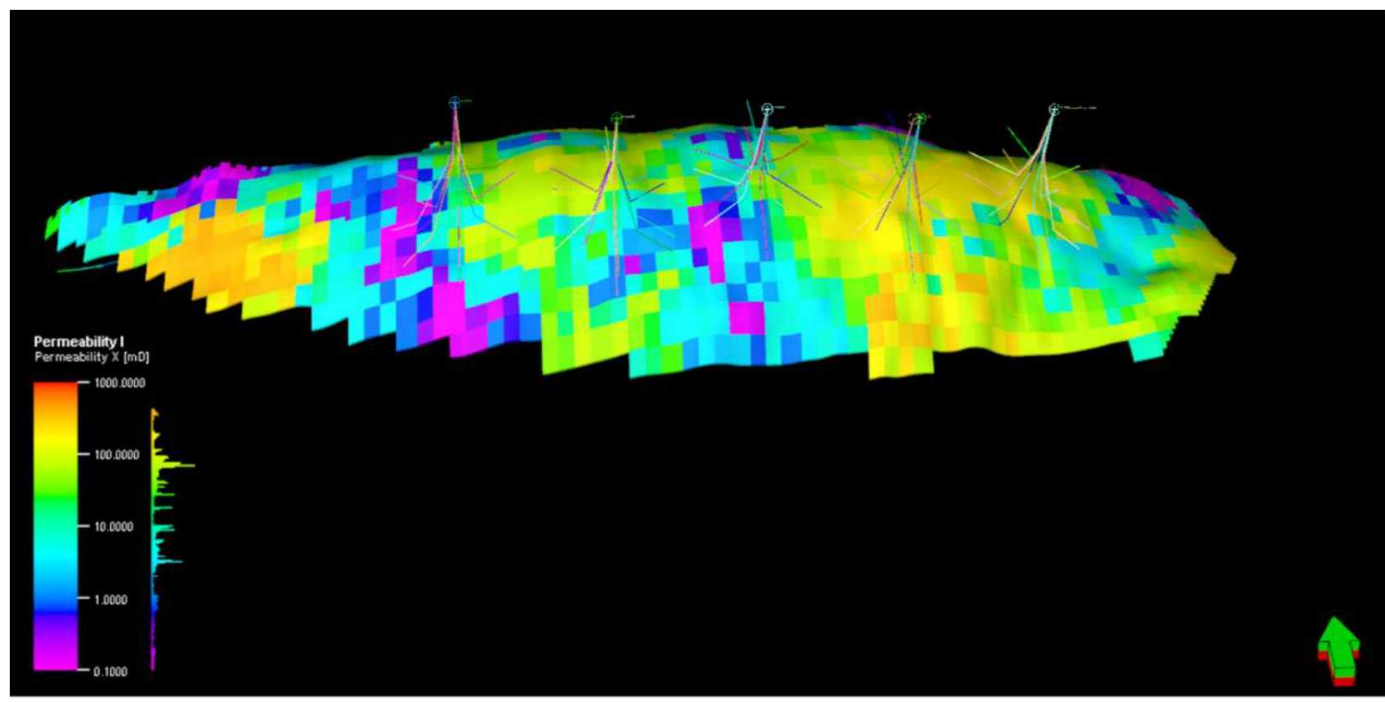

Figure B1: Schematic showing well pad locations and wells for well length $1500 \mathrm{ft}$ against permeability of layer 32 
Table B2: Well pad locations for well length $4500 \mathrm{ft}$ scenario 2: No. of pads- 3, Well length- $4500 \mathrm{ft}$ wells

\begin{tabular}{|l|l|l|}
\hline & X (ft) & Y (ft) \\
\hline pad1 & 237498.8 & 5629336 \\
\hline pad3 & 225988.5 & 5629548 \\
\hline pad5 & 214478.2 & 5630178 \\
\hline
\end{tabular}

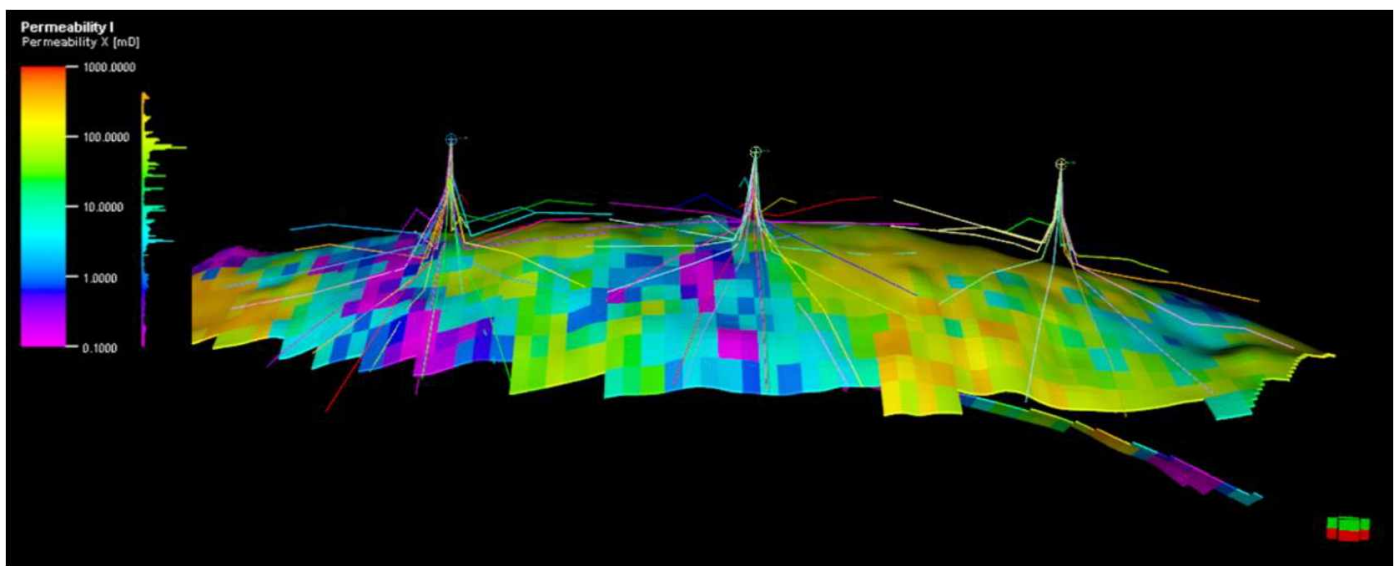

Figure B2: Schematic showing well pad locations and wells for well length $4500 \mathrm{ft}$ against permeability of layer 32

Table B3: Well pad locations for well length $7500 \mathrm{ft}$

\begin{tabular}{|c|c|c|}
\hline \multicolumn{3}{|c|}{$\begin{array}{c}\text { scenario 2: No. of pads- 3, } \\
\text { Well length- } 4500 \mathrm{ft} \text { wells }\end{array}$} \\
\hline & X (ft) & Y (ft) \\
\hline pad1a & 233945 & 5629133 \\
\hline pad5a & 213062 & 5630304 \\
\hline
\end{tabular}




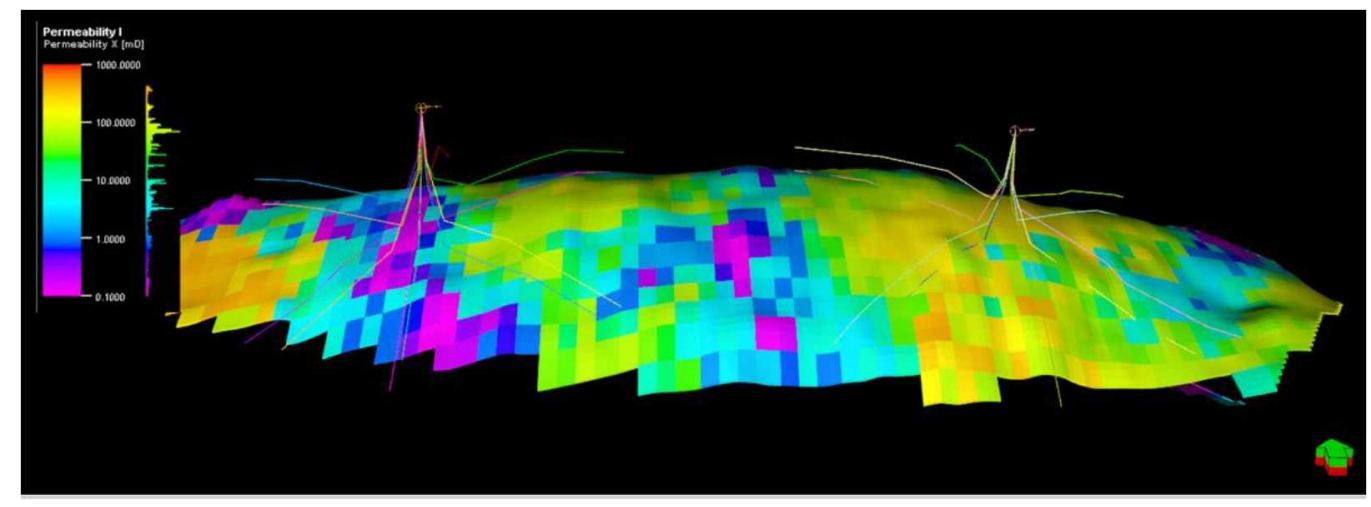

Figure B3: Schematic showing well pad locations and wells for well length $7500 \mathrm{ft}$ against permeability of layer 32 